\title{
EVALUATING PERCEPTION TOWARDS ELECTRIC VEHICLES IN THE GREATER TORONTO AND HAMILTON AREA
}

by

Joshua Goodfield, Bachelor of Arts (Honours), Queen's University, April 2015

\begin{abstract}
A thesis presented to Ryerson University
in partial fulfillment of the requirements for the degree of Master of Applied Science in the program of Environmental Applied Science and Management
\end{abstract}

Toronto, Ontario, Canada, 2017

(C) Joshua Goodfield, 2017 


\section{Author's Declaration}

I hereby declare that I am the sole author of this thesis. This is a true copy of the thesis, including any required final revisions, as accepted by my examiners.

I authorize Ryerson University to lend this thesis or dissertation to other institutions or individuals for the purpose of scholarly research.

I further authorize Ryerson University to reproduce this thesis or dissertation by photocopying or by other means, in total or in part, at the request of other institutions or individuals for the purpose of scholarly research.

I understand that my thesis may be made electronically available to the public. 
Evaluating Perception Towards Electric Vehicles in the Greater Toronto and Hamilton Area MASc 2017 Joshua Goodfield

Environmental Applied Science and Management

Ryerson University

\section{Abstract}

The vast majority of the world's transportation options heavily rely on fossil fuel outputs, which has been a major contributing factor in the acceleration of global climate change. Given Ontario's relatively ‘clean' supply mix of electricity, recent public policy outputs reflect a shifting interest in better utilizing electricity to reform the transportation sector to meet greenhouse gas (GHG) emissions reduction targets. The minimal proportion of electric vehicle ownership despite the province's incentive programs suggests research into the barriers to adoption in the Greater Toronto and Hamilton Area must be identified to inform future decisionmaking. A survey was completed amongst current electric vehicle owners as well as gasolineand diesel-vehicle owners to understand attitudes towards the technology and sustainable transportation reform more broadly. The results aim to better predict future tactics for a more successful diffusion of alternative mobility options to acquire greater consumer and public acceptance. 


\section{Acknowledgements}

This thesis is a result of the unwavering support I have received from my colleagues, family, and friends. I would foremost like to express my gratitude to my supervisor, Dr. Philip Walsh for welcoming me into his research group and providing assistance at every point. Phil's continuous support, patience, enthusiasm, and knowledge inspired my academic ambitions and direction. Further gratitude is extended to Dr. Sara Edge, Dr. Seung Hwan (Mark) Lee, and Dr. Darko Joksimovic for their participation and expert insight as members of my thesis committee.

My parents Carolyn and Rob, and sister Kayla have all been extremely supportive throughout my studies. This encouragement extends to my family in Ontario and Manitoba who have cared deeply about my work and wellbeing.

The privilege of being mentored by Dr. Josipa Petrunic as well as Cara Clairman and the Plug'n Drive team shaped me into a more pragmatic individual. The individuals supporting my research were instrumental to the completion of this project through graciously sharing their knowledge, resources, and passion for this sector with me throughout my time at the Centre for Urban Energy.

Lastly, I would also like to acknowledge the Environmental Applied Science and Management Program as well as the Yeates School of Graduate Studies and Mitacs for the financial and administrative support that enabled my success throughout my time in graduate studies. 


\section{Dedication}

This thesis is dedicated to my grandfather, Alexander Berkowits. You insisted that I accomplish what makes me happy, and I was always listening. 


\section{Table of Contents}

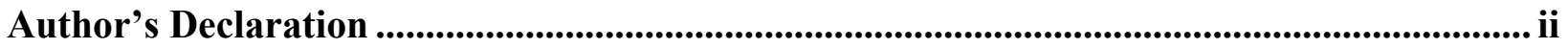

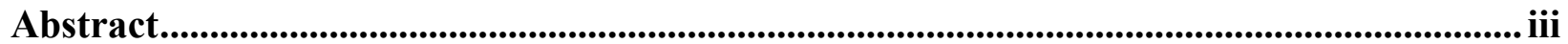

Acknowledgements ................................................................................................................. iv

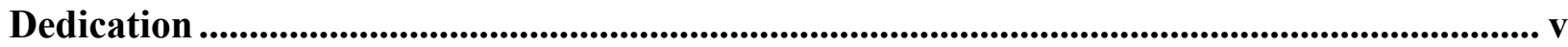

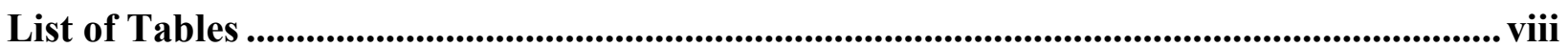

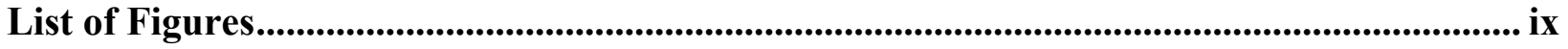

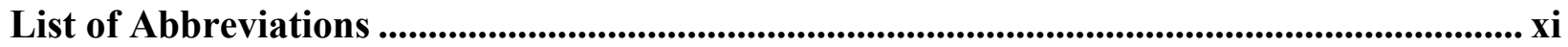

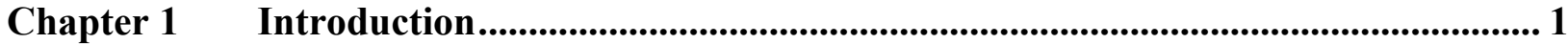

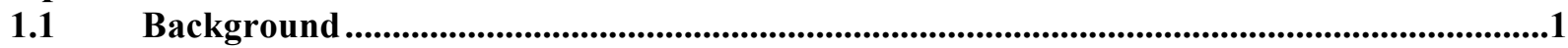

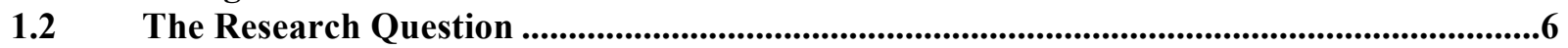

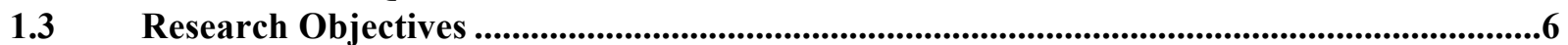

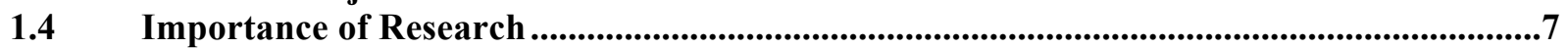

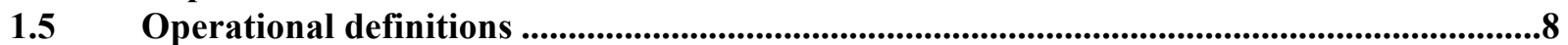

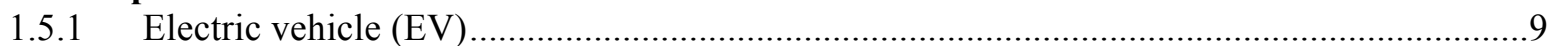

1.5.2 Internal combustion engine (ICE) vehicle .................................................................. 10

Chapter 2 Literature Review ...................................................................................... 12

2.1 History of the contemporary electric vehicle .................................................................................12

$2.2 \quad$ Environmental sustainability .........................................................................................................14

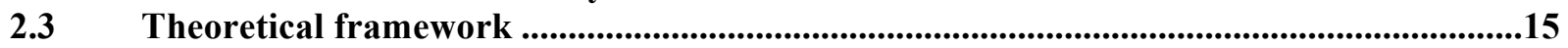

2.4 Strategic management of competitive advantage and innovation ......................................20

2.5 Sustainable transportation reform in the GTHA .......................................................................23

2.6 Climate change action targets in Ontario ...................................................................................25

2.7 Consumer preferences for electric vehicles.............................................................................29

2.8 Electric vehicle innovation and adoption in Canada ............................................................35

2.9 Conclusion ...................................................................................................................................40

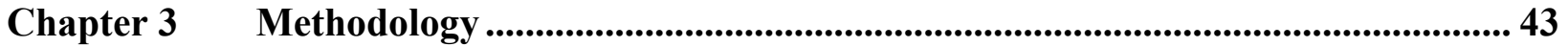

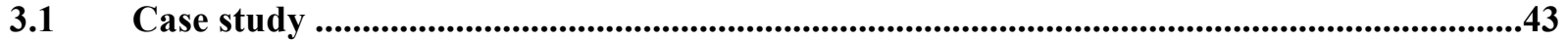

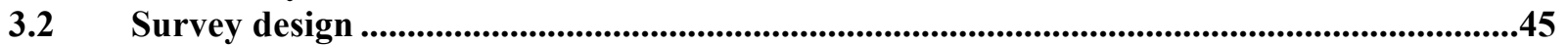

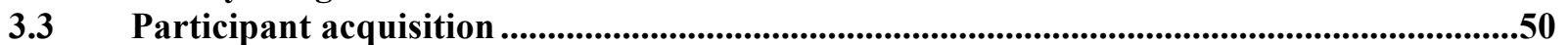

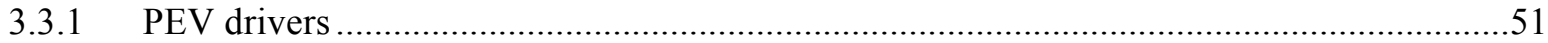

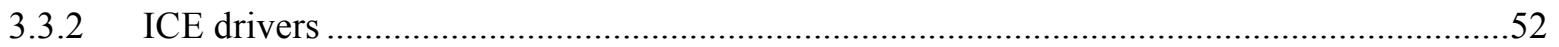

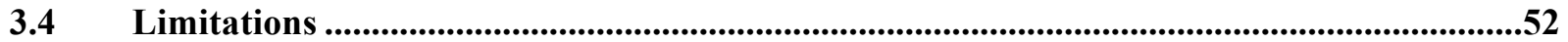

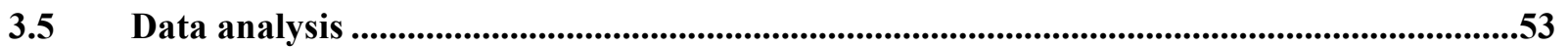

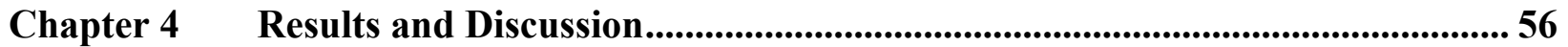

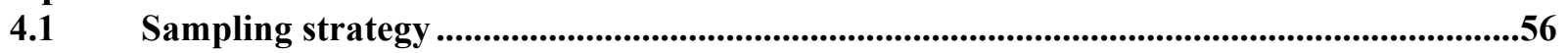

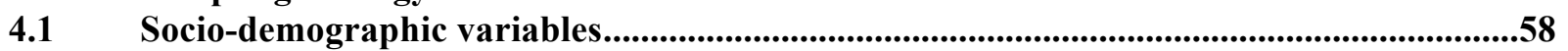

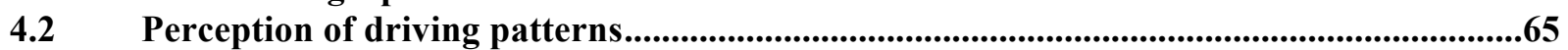

4.3 Loyalty and upfront commitment in the automotive sector ..............................................66

4.4 Predictive modelling of the likelihood to purchase an EV as a next vehicle ......................69

4.4.1 Perceived relative advantages (operating costs) as an indicator of purchase......................77

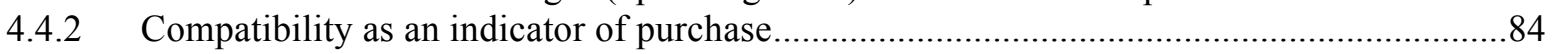

4.4.3 Complexity (ease of use) as an indicator of purchase ........................................................89 
4.4.4 Trialability as an indicator of purchase

4.4.5 Observability as an indicator of purchase

4.4.6 Social norm .

Chapter 5 Conclusions .................................................................................................................... 100

Appendix ................................................................................................................................ 104

Bibliography ................................................................................................................................. 109 


\section{List of Tables}

TABLE 1: RELEVANT COMPONENTS OF ONTARIO'S CLIMATE CHANGE ACTION PLAN TO ELECTRIC

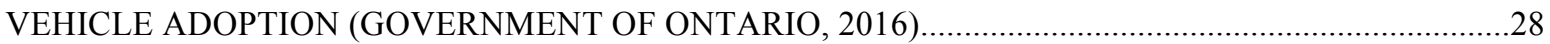

TABLE 2: FINANCIAL INFORMATION OF AVAILABLE ELECTRIC VEHICLES IN CANADA, AS OF

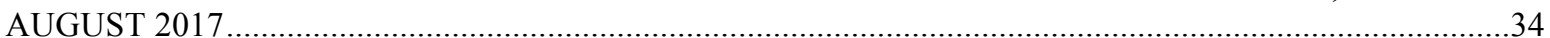

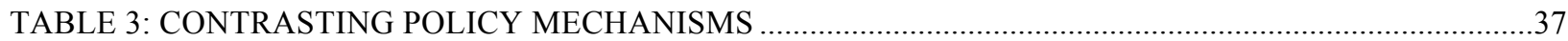

TABLE 4: RELEVANT OUTPUTS FROM A LITERATURE REVIEW OF NORTH AMERICAN SOURCES BASED ON THE PETERS AND DÜTSCHKE, 2014 MODEL ...............................................................41

TABLE 5: SURVEY QUESTIONS TO PROVIDE INSIGHT TO MODEL ………….......................................49

TABLE 6: SOCIO-DEMOGRAPHIC INFORMATION OF SURVEY PARTICIPANTS ……................................58

TABLE 7: STATISTICALLY SIGNIFICANT RELATIONSHIPS AMONGST SOCIO-DEMOGRAPHIC VARIABLES AMONGST ICE DRIVERS

TABLE 8: STATISTICALLY SIGNIFICANT RELATIONSHIPS AMONGST SOCIO-DEMOGRAPHIC

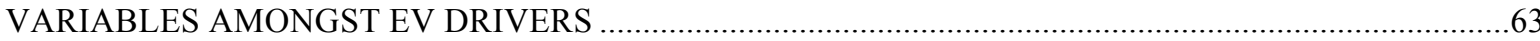

TABLE 9: CASE PROCESSING SUMMARY OF ICE DRIVER DATA ..........................................................70

TABLE 10: PARAMETER ESTIMATES OF ICE DRIVER DATA ……………….......................................... 70

TABLE 11: CASE PROCESSING SUMMARY OF EV DRIVER DATA ……................................................

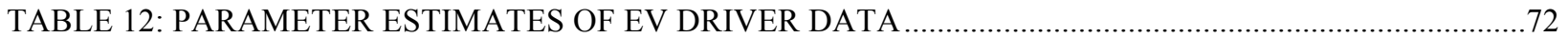

TABLE 13: STATISTICALLY SIGNIFICANT RELATIONSHIPS AMONGST PURCHASE DECISIONMAKING FACTORS BASED ON SOCIO-DEMOGRAPHIC FACTORS AMONGST ICE DRIVERS........73

TABLE 14: STATISTICALLY SIGNIFICANT RELATIONSHIPS AMONGST PURCHASE DECISIONMAKING FACTORS BASED ON SOCIO-DEMOGRAPHIC FACTORS AMONGST EV DRIVERS.........73

TABLE 15: STATISTICALLY SIGNIFICANT RELATIONSHIPS AMONGST FACTORS TO INFLUENCE PURCHASE AMONGST ICE DRIVERS.

TABLE 16: STATISTICALLY SIGNIFICANT RELATIONSHIPS AMONGST FACTORS TO INFLUENCE PURCHASE AMONGST EV DRIVERS .75

TABLE 17: PREDICTIVE MODEL TO DETERMINE THE LIKELIHOOD TO PURCHASE AN EV AMONGST

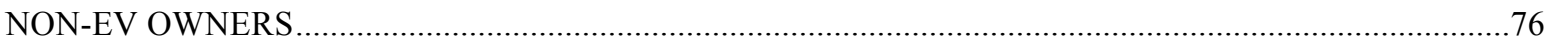

TABLE 18: STATISTICALLY SIGNIFICANT (GREATER THAN 95 PER CENT CONFIDENT LEVEL) CORRELATIONS

TABLE 19: FULL RELATIONSHIP MODELLING AMONGST SOCIO-DEMOGRAPHIC VARIABLES AMONGST ICE DRIVERS (FROM TABLE 6). 104

TABLE 20: FULL RELATIONSHIP MODELLING AMONGST SOCIO-DEMOGRAPHIC VARIABLES AMONGST EV DRIVERS (FROM TABLE 7)

TABLE 21: FULL RELATIONSHIP MODELLING AMONGST PURCHASE DECISION-MAKING FACTORS BASED ON SOCIO-DEMOGRAPHIC FACTORS AMONGST ICE DRIVERS (FROM TABLE 12) ........105

TABLE 22: FULL RELATIONSHIP MODELLING AMONGST PURCHASE DECISION-MAKING FACTORS BASED ON SOCIO-DEMOGRAPHIC FACTORS AMONGST EV DRIVERS (FROM TABLE 13) .........106

TABLE 23: FULL RELATIONSHIP MODELLING AMONGST FACTORS TO INFLUENCE PURCHASE

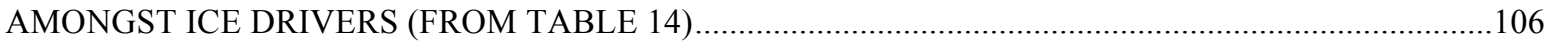

TABLE 24: FULL RELATIONSHIP MODELLING AMONGST FACTORS TO INFLUENCE PURCHASE AMONGST EV DRIVERS (FROM TABLE 15) 


\section{List of Figures}

FIGURE 1: THEORY OF REASONED ACTION (TRA) MODEL (AJZEN \& FISHBEIN, 1975) ..........................16

FIGURE 2: TECHNOLOGY ACCEPTANCE MODEL (TAM) (DAVIS ET AL., 1993)........................................17

FIGURE 3: DIFFUSION OF INNOVATION THEORY (ROGERS, 2003) ...........................................................18

FIGURE 4: INTENTION TO PURCHASE AND USE AN ELECTRIC VEHICLE MODEL (PETERS \& DÜTSCHKE, 2014)

FIGURE 5: GENERATOR OUTPUT BY FUEL TYPE MONTHLY REPORT, Q1: JANUARY - APRIL, 2017

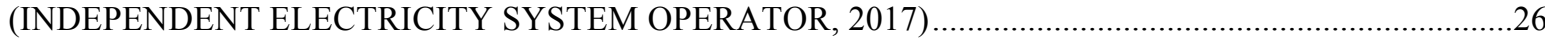

FIGURE 6: TOTAL CANADIAN PLUG-IN ELECTRIC VEHICLE SALES, 2011-2016 .....................................36

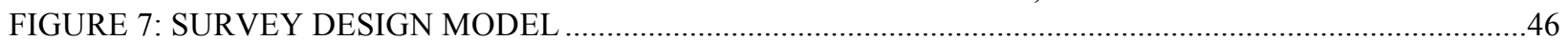

FIGURE 8: INTERPRETATION OF PETERS \& DÜTSCHKE MODEL FOR GTHA-FOCUSED STUDY ............48

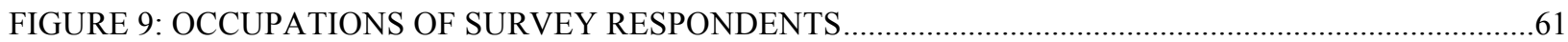

FIGURE 10: NUMBER OF VEHICLES OWNED OR LEASED BY SURVEY PARTICIPANTS .........................62

FIGURE 11: ESTIMATED FREQUENCY OF VEHICLE TRAVEL AMONGST SURVEY RESPONDENTS .....65

FIGURE 12: BRAND LOYALTY COMMITMENT AMONGST SURVEY PARTICIPANTS ..............................67

FIGURE 13: TYPE OF CAR COMMITMENT AMONGST SURVEY PARTICIPANTS …..................................68

FIGURE 14: PERCENTAGE OF SURVEY RESPONDENTS COMMITTED TO A PARTICULAR UPFRONT PRICE RANGE FOR THEIR VEHICLE PURCHASE OR LEASE ……….................................................68

FIGURE 15: THE LIKELIHOOD OF PURCHASING AN EV AS A NEXT VEHICLE AMONG SURVEY RESPONDENTS ...........................................................................................................................69

FIGURE 16: CONSIDERATION OF FUEL ECONOMY PRIOR TO PURCHASING ONE'S VEHICLE AMONG

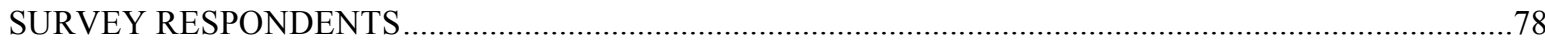

FIGURE 17: PERCEIVED TOTAL AMOUNT OF MONEY ASSUMED TO SPEND FUELLING A VEHICLE

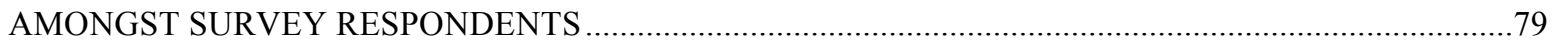

FIGURE 18: BELIEF THAT EVS CAN HELP A HOUSEHOLD SAVE MONEY ON FUEL COSTS COMPARED TO A GASOLINE OR DIESEL CAR AMONG EV DRIVING RESPONDENTS ........................................80

FIGURE 19: BELIEF THAT EVS CAN TRAVEL MORE THAN 150 KM ON A SINGLE BATTERY CHARGE EVEN IF THE AIR CONDITIONING OR HEATING SYSTEM IS TURNED ON AMONG EV DRIVING RESPONDENTS

FIGURE 20: SATISFACTION RATES OF DISTANCE ONE'S EV CAN TRAVEL BASED ON A FULLY CHARGED BATTERY AMONG EV DRIVING RESPONDENTS.

FIGURE 21: CONSIDERATION OF MAINTENANCE COSTS PRIOR TO PURCHASING ONE'S VEHICLE

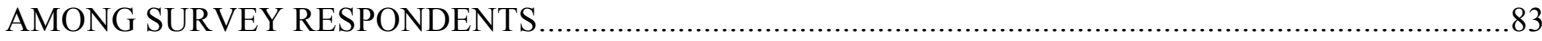

FIGURE 22: PERCEIVED ASSUMED AND ACTUAL COSTS OF MAINTENANCE FOR VEHICLES AMONG

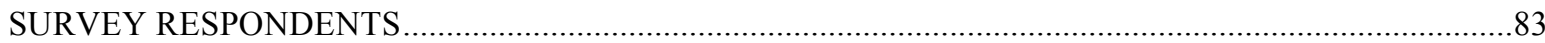

FIGURE 23: BELIEF THAT PRESENT DAY CLIMATE CHANGE IS OCCURRING BECAUSE OF GHG EMISSIONS FROM THE COMBUSTION OF FOSSIL FUELS ASSOCIATED WITH TRANSPORTATION

FIGURE 24: BELIEF THAT THE USE OF AUTOMOBILES HAS A NEGATIVE EFFECT ON THE

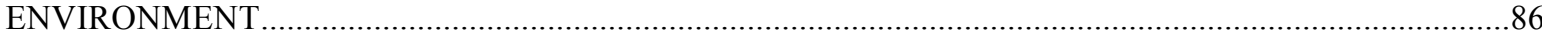

FIGURE 25: BELIEF THAT SWITCHING THE MAJORITY OF THE WORLD'S TRANSPORTATION SYSTEMS TO PEVS WOULD HELP STOP CLIMATE CHANGE AT A GLOBAL LEVEL.......................86

FIGURE 26: BELIEF THAT ONE HAS A PERSONAL ROLE TO PLAY IN STOPPING GLOBAL CLIMATE CHANGE

FIGURE 27: SUPPLY MIX OPTIONS PERCEIVED TO BE CATEGORIZED AS A 'FOSSIL FUEL' AMONG

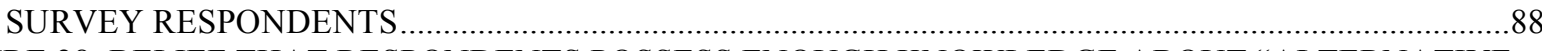

FIGURE 28: BELIEF THAT RESPONDENTS POSSESS ENOUGH KNOWLEDGE ABOUT “ALTERNATIVE VEHICLES” TO MAKE AN INFORMED CHOICE FOR POTENTIAL FUTURE PURCHASE .................89

FIGURE 29: BELIEF THAT SUFFICIENT INFORMATION ABOUT EVS IS AVAILABLE ONLINE AMONG EV DRIVING RESPONDENTS

FIGURE 30: BELIEF THAT THEY WERE MORE KNOWLEDGEABLE THAN THE SALES STAFF AT DEALERSHIPS AMONGST EV DRIVING RESPONDENTS WHO VISITED A DEALERSHIP PRIOR TO MAKING A PURCHASE. 
FIGURE 31: PARTICIPANTS AWARE OF ONTARIO'S PROVINCIAL INCENTIVES FOR PHEV AND BEV PURCHASES

FIGURE 32: PARTICIPANTS AWARE OF ONTARIO'S PROVINCIAL INCENTIVES FOR ELECTRIC VEHICLES SUPPLY EQUIPMENT (EVSE) PURCHASES …............................................................992

FIGURE 33: PARTICIPANTS AWARE OF ONTARIO'S PROVINCIAL INCENTIVES FOR ELECTRIC VEHICLE SUPPLY EQUIPMENT (EVSE) INSTALLATION ....................................................93

FIGURE 34: PARTICIPANTS THAT COMPLETED TEST DRIVES AMONGST POTENTIAL MAKES AND MODELS CONSIDERED FOR PURCHASE ......................................................................................99

FIGURE 35: TYPE OF ELECTRIC VEHICLES TEST DRIVEN BY PARTICIPANTS .......................................95

FIGURE 36: PARTICIPANT PROCESSES FOR REVIEWING POTENTIAL MAKES AND MODELS OF VEHICLES FOR PURCHASE OR LEASE

FIGURE 37: INTRODUCTION OF PHEV OR BEV BY ANYONE IN ONE'S SOCIAL NETWORKS................98

FIGURE 38: PARTICIPANTS WHO SPOKE WITH COLLEAGUES, FAMILY MEMBERS, OR FRIENDS ABOUT CAR OPTIONS PRIOR TO PURCHASE

FIGURE 39: PARTICIPANTS WHO TRIED DRIVING A PHEV OR BEV OWNED BY A FRIEND OR COLLEAGUE 


\section{List of Abbreviations}

BAU - Business-as-usual

BEV - Battery electric vehicle

CAD - Canadian dollar

ENGO - Environmental non-governmental organization

EV - Electric vehicle

EVCO - Electric Vehicle Chargers Ontario

EVSE - Electric Vehicle Supply Equipment

EVIP - Electric Vehicle Incentive Program

FCEV - Fuel cell electric vehicle

GHG - Greenhouse gas

GEA - Green Energy Act

GTHA - Greater Toronto and Hamilton Area

HEV - Hybrid electric vehicle

HOT - High occupancy toll

HOV - High occupancy vehicle

HST - Harmonized sales tax

ICE - Internal combustion engine

$\mathrm{kWh}$ - Kilowatt hour

LDC - Local distribution company

LRT - Light-rail transit

MOECC - Ministry of the Environment and Climate Change

MPV - Multi-purpose vehicle

MSRP - Manufacturer's suggested retail price

MTO - Ministry of Transportation Ontario

NGO - Non-governmental organization

OEM - Original equipment manufacturer

OGIF - Ontario Green Investment Fund

PEOU - Perceived ease of use

PEV - Plug-in electric vehicle

PHEV - Plug-in hybrid electric vehicle

PU - Perceived usefulness

R\&D - Research and development

RBV - Resource based view

RER - Regional express rail

RET - Renewable energy technology

RFP - Request for proposal

ROI - Return on investment

SPSS - Statistical Package for the Social Sciences

STEM - Science, technology, engineering and mathematics

SUV - Sport utility vehicle

TAM - Technology acceptance model

TPAP - Transit Project Assessment Process

TPB - Theory of planned behaviour

TRA - Theory of reasoned action 
UN - United Nations

WTP - Willingness-to-purchase

ZEV - Zero emissions vehicle 


\section{Chapter 1 Introduction}

This chapter describes an overview to the research conducted in the study. The content therefore covers the background pertaining to this project, the research question, the research objectives, the importance of this research, and the operational definitions to inform the subsequent content of this thesis. Thereafter, in Chapter 2, a literature review is conducted to synthesize the key findings from the current state of research regarding public perception towards electric vehicles (EVs) and relevant work to further enlighten the study. In Chapter 3, the methodology that guides the thesis is described. In Chapter 4, the results of the research are presented and discussed. Lastly, in Chapter 5, the conclusion informs pathways of further commercializing the EV based on the results to intending to intervene and guide future decisionmaking processes.

\subsection{Background}

Transportation has extensively been acknowledged as a major contributing sector to global climate change and the key environmental issues that plague the world. Ninety-five per cent of the world's existing transportation systems operate predominately on petroleum-based products that generate harmful emissions into the atmosphere (Intergovernmental Panel on Climate Change, 2007). In recent years, concerted efforts at a variety of scales have been made to better align the transport sector towards a pathway that embodies a futuristic, low-carbon vision, in turn promising long-term savings potential on fuel costs and the mitigation of climate change.

Canada is one the world's largest country in terms of total area, and has a substantial demand amongst its growing population to offer affordable and efficient multimodal transportation solutions (World Bank, n.d.). As a result of such demand, in 2014, transportation 
was Canada's second highest emitting economic sector, accounting for 23 per cent of the total GHG inventory (Environment and Climate Change Canada, 2016). The proportion of Canada's transportation emissions substantially exceed the global average of 14 per cent (Sims et al., 2014). Nonetheless, most developed countries have higher proportions of GHG emissions resulting from their transportation sector than the average (ibid.). Yet, between the years 1990 and 2005, Canada's transportation sector experienced a 31 per cent increase in GHG emissions, and attempts at inciting extensive sustainable reform to the sector amongst key decision-makers have remained largely ephemeral and inconsequential (Transport Canada, 2011). However, in recent years, a large focal point of emissions reduction efforts has been apportioned to the transportation sector, as recognized strategies to achieve shorter-term emissions reductions exist and are gaining public traction.

Communal awareness and concern related to the impacts of climate change amongst Canadians generally exceed those of other international populations (Capstick et al., 2015; Drews \& van den Bergh, 2016; Smith et al., 2017). Heightened public opinion has prompted Canada along with its provincial and municipal governments to become signatories in coalitions and policies to mitigate environmental issues (Lachapelle et al., 2012; Houle et al., 2015; Mills \& Gore, 2016). Nonetheless, climate change regulation to date has predominantly been of a voluntary nature, and is therefore not legally binding (Burch, 2010; Harrison, 2013). When penalties are not issued as a result of failure to comply, the argument can be made that decisionmakers undermine the importance of such legislation (ibid.).

Governments in Canada at various levels have identified the transportation sector as an opportune area to prioritize efforts to curb emissions. Canada set recent targets to reduce GHG emissions 30 per cent below 2005 baseline levels by 2030 (Environment and Climate Change 
Canada, 2015). In a broad sense, there have been considerable yet inconsistent variances of provincial and municipal initiatives to enact more climate-oriented policies to support national targets (Gore, 2010; Brown, 2012; Craft et al., 2013; Stuart et al., 2016). There has also been some evidence within the public sector of interest in developing and supporting practical solutions to decarbonize transportation initiatives, including but not limited to the partial electrification of transit lines and incentive programs to support the adoption of cleaner technology. Nonetheless, there are perceived social and economic barriers amongst decisionmakers and existing governance structures that intrude on the mass transformation in the sector. Certain jurisdictions at various scales within Canada have advanced the development of environmental-oriented action plans to enact more sustainable means to existing operations and networks. Yet, as global populations urbanize at unprecedented rates, persistent challenges are exacerbated as a result of concentrated air pollution, in large part from the increased usage of private internal combustion engine (ICE) vehicles.

Usage of the ICE vehicle comes with known environmental and human health consequences that have immense impacts on land-use beahviour and planning (Abelsohn et al., 2002; Lave \& McLean, 2002; Hatzopoulou et al., 2007; Moussa et al., 2016). For the most part since World War II, North American cities have become increasingly automobile dependent, and as a result have historically privileged the car thereby presenting (perhaps unintentionally) alternatives modes of transportation as inferior (Freund \& Martin, 2007). The relationship between the car and other means of mobility has both highlighted and exacerbated the socioeconomic divisions prevalent in contemporary societies that dictate access to basic goods and services. Modern North American cities have left individuals who are unable to access a car (i.e. because of affordability, physical or cognitive impairment, etc.) often challenged to reach 
essential services and activities (Nolan, 2010). Furthermore, a societal reliance on ICE vehicles indicates that a high proportion of fossil fuels will be emitted, which can impact energy security and conjure apprehensions towards the resource's finite nature (Bang, 2010; Sattler, 2014).

The Greater Toronto and Hamilton Area (GTHA) is currently home to 6.8 million residents, representing 51.7 per cent of Ontario's population (Statistics Canada, 2017). The growth of the GTHA's inhabitants has increased car demand creating problematic traffic congestion and competing ideas as to how to solve key transportation issues (Keil \& Young, 2008; Woudsma et al., 2016). Traffic congestion in Toronto has been estimated to produce annual costs of approximately $\$ 3.3$ billion to commuters and $\$ 2.7$ billion to the economy, and if left unabated those costs are expected to elevate to $\$ 7.8$ and $\$ 7.2$ billion respectively (City of Toronto, 2014). High concentrations of light-duty vehicles (passenger cars and light trucks) have contributed to the increase in transportation-related emissions. The private vehicle, which operates completely at the discretion of the user, will likely remain a popular and feasible choice amongst Torontonians for the foreseeable future. Therefore, the electrification of such applications offers a promising solution to attenuate environmental impacts and avoid the challenges of attempting a drastic reform in which car usage is discouraged (e.g. exclusively engaging in walking, cycling, and/or transit) (Bilgin et al., 2015; Shokrzadeh \& Bibeau, 2016).

Electrification is to be thought of as a spectrum which can be measured in terms of efficiency on a scale from mild-hybridization with integrated gasoline and diesel systems to complete singular propulsion through battery electric or fuel cell technologies (Weiss et al., 2012; Tamor et al., 2013). Emerging private transportation alternatives, such as the electric vehicle (EV), offer users efficient and high-performing options with less carbon outputs relative to traditional carbon vehicle technologies. Electric technologies for transport have historically 
faced challenges in their diffusion into mainstream markets, and this exploratory research aims to progress the limited dialogue to date as to why this has been the case. In terms of the integration of a sustainable narrative into this trend, one must consider the emissions from a well-to-wheel perspective as to what the electricity in said vehicle is comprised of. The EV must then be proven to be as close to zero-emissions in order to demonstrate that this initiative is complimentary to a sustainability-driven agenda. Vehicles are commonly measured in terms of efficiency, and therefore, when the application of electricity into a vehicle is considered, the problem statement remains: if one sends an electron into a system, they should get out a unit of propulsion as efficiently as possible. If efforts to electrify the transportation sector are not dedicated to a high-level of efficiency, the objective will likely not be achieved.

Since the inception of contemporary electrified technologies, the available makes and models have proven to be relatively uncompetitive and unintegrated into mainstream Canadian markets (Melton et al., 2017; Sykes \& Axsen, 2017). The support for the furtherance of diversified transportation networks has been challenged by habitual and often more convenient industrial processes and human behaviour (Relph, 2013; Kamruzzaman et al., 2015). The practice and reinforcement of relying on carbon-emitting technologies have perpetuated market and policy barriers for carbon-reduction alternatives as well as less conventional methods of mobility with a lower modal share. Since the single passenger vehicle embodies such a high proportion of emissions in the GTHA, understanding the attitudes and perception towards emerging technologies that can alleviate harmful emissions amongst residents of the city is essential for future planning. Ultimately, even if the world's most 'sustainable' technologies are at the disposal of the masses, if public interest or knowledge is not evident, the impact of the technology will not be substantial. Therefore, in order to assess the commercialization potential 
of EVs, it is of great significance to understand the likelihood of adoption amongst current drivers of ICE vehicles and the satisfaction rates amongst early adopters of EVs to help guide policy making and better target public outreach efforts.

\subsection{The Research Question}

The research question posed in this study queries what are the specific drivers of consumer intent to purchase an EV in the GTHA as a next vehicle. Through the use of predetermined variables as identified in previous literature and studies that have focused on consumer intent, this research addresses the key regional socio-technical interests and barriers hindering the mass commercialization of EVs. This aforementioned question is addressed towards those who already drive an EV and drivers who do not. Amongst ICE drivers, the intent is to evaluate the likelihood of eventual adoption, and amongst EV drivers, the intent is to evaluate the likelihood of re-purchase. This research question, while perhaps not allencompassing, is a well-suited initial focal point to ideally inspire further research on the matter and guide the commercialization potential of other emerging clean technology options.

\subsection{Research Objectives}

This thesis explores perception towards EVs in the GTHA. The objective of this study is to implement a modified theoretical model with previously identified predictive variables from relevant literature to understand how individuals of different socio-demographic backgrounds in the region perceive EVs based on their experiences and knowledge. The outputs aim to better inform stakeholders in the transportation and utilities sectors through highlighting key information regarding relevant decision-making patterns in Ontario, evaluating the effectiveness of current and possible programs and policies, and identifying optimal areas to establish new or refine existing regulatory efforts. Given that there is currently virtually little to no literature 
pertaining to perception towards electrified transportation options in Toronto, the intention of this work is to inform transportation planning and enlighten future initiatives. Specific objectives of the study include:

1. Developing a holistic and comprehensive review of the current state of literature and information pertaining to electrified transportation in Toronto and other relevant jurisdictions;

2. Conducting a web-based survey for electric vehicle owners and gasoline- and dieselvehicle owners to understand their attitudes and perceptions towards the technology; and

3. Interpreting the results of the survey to inform how public policy can best reflect the demands and interests of both the growing existing and prospective future EV community.

\section{$1.4 \quad$ Importance of Research}

The state of a market becomes adversely impacted when new products or services are introduced and gain public traction. Technological innovation is a clear case as to how disruptive forces can challenge the status quo and as a result amend consumer interest and priorities. EVs were initially positioned as a revolutionary technology that in many cases were predicted to have far greater global uptake in a shorter timeframe than the current sales figures represent. However, today in Canada, EVs represent less than one per cent of the total mode share of vehicles (Statistics Canada, 2016; Schmidt, 2017). Yet, electrified technology has been viewed as particularly complimentary to an increasingly sustainable agenda in many developed countries. This begs for further exploration as to why EVs are underrepresented in urban environments and what the optimal pathways are that may lead to the vehicles representing a competitive modal share to ICE vehicles. The outputs of this research will become a useful informational source for 
audiences outside of a traditional academic silo, such as prospective and existing EV drivers, key decision-makers and stakeholders, governmental officials and public servants, original equipment manufacturers (OEMs), local distribution companies (LDCs), environmental advocates and non-governmental organization (NGO) representatives, as well as for future research endeavors that will focus on similar emerging technologies. As an overview of EV development, this work may also be valuable to those interested in perceptions towards environmental sustainability and alternative transportation technologies available for consumers.

\subsection{Operational definitions}

The definitions explained in this sub-section are essential to foster a more holistic understanding of the technology discussed in this work. The wording and structure of the definitions were inspired by the forthcoming Ontario EV Technology \& Innovation Roadmap publication, with permission from the author (Petrunic, 2017). The decision to use definitions from an external source was made to ensure that the language provided to survey respondents and readers of this study remain accurate and consistent with the accepted content in existing Canadian publications. In the survey, all participants were provided simplified versions of the definitions below to aid their general understanding of the vehicular technologies relevant to the research being undertaken. The definitions were readily available throughout the survey, as the participant's accurate interpretation of the language used remained fundamental to the successful completion of the survey.

For the purposes of this thesis, reference to an 'EV' from herein will refer to plug-in electric vehicles (PEVs), which includes plug-in hybrid electric vehicles (PHEVs) and battery electric vehicles (BEVs). The use of the term 'EV' will therefore not include fuel cell electric vehicles (FCEVs) and hybrid electric vehicles (HEVs). The rationale of this decision is that both 
FCEVs and HEVs do not rely on the electrical grid network to propel the vehicle, and therefore can be argued to not have a meaningful impact on the study of electrification of transportation sector broadly. An assessment of the relationship between the EV driver and the grid that fuels their car is essential to evaluate the opportunities and implications of their assumed uptake. Usergrid interactions in Ontario have been a clear area of concern amongst government and relevant public sector operations as reflected in their evident policy aimed at better optimizing the usage of the grid given past investments in improving the infrastructure.

\subsubsection{Electric vehicle (EV)}

\section{Electric vehicle}

Electric vehicles (EVs) are available in a multitude of makes and models as discussed in this sub-section. An EV can be defined broadly as any vehicle which employs one or more electric motors for propulsion (Tazerart et al., 2015).

\section{Fuel cell electric vehicles}

Fuel cell electric vehicles (FCEVs) are entirely electric vehicles propelled by electricity generated onboard through a fuel cell conversion device (Chan, 2002). The fuel cell converts hydrogen fuel into electricity and water creating a hydrogen gas, which powers the vehicle (Momirlan \& Veziroglu, 2005).

\section{Hybrid electric vehicles}

Hybrid electric vehicles (HEVs) are electrified vehicles that carry both a carbon fuel and electrical energy stored in a small battery pack (Burke, 2007). The gasoline-powered ICE engine is the main source of propulsion and the electrification is an auxiliary source (Panday \& Bansal, 2014). HEVs operate predominately in "hybrid mode," meaning the gasoline or diesel engine works in tandem with the onboard battery and motor to power the vehicle (Amjad et al., 2010). 
Batteries in HEVs operate exclusively through regenerative braking, the act of converting the existing motor into a generator of electricity (Ahn et al., 2009). HEVs are therefore primarily powered through means of fossil fuels. The energy savings as a result of driving an HEV are not as substantial as plug-in hybrid electric vehicles (PHEVs) because no electricity is generated as a result of the grid.

\section{Plug-in hybrid electric vehicle}

Plug-in hybrid electric vehicles (PHEVs) are also partial EVs that carry the same fuels as the HEV (Clement-Nyns et al., 2010). The main difference, however, is that PHEVs recharge through plugging the vehicle into the grid through a standard or upgraded electrical outlet and regenerative braking (Srivastava et al., 2010). Contrary to the HEV, the PHEV battery-powered electric motor is often the main power source. The engine is seen as a complementary function of the electric motor to extend the car's range (Li et al., 2011). The PHEV also has the additional option to operate in "EV Mode," and when activated the car operates exclusively through electricity (Bradley \& Frank, 2009).

\section{Battery electric vehicle}

Battery electric vehicles (BEVs) are entirely electric cars, which means the car carries no carbon fuel onboard (Eaves \& Eaves, 2004; Zhang et al., 2015). The only fuel available onboard is electricity stored in a battery pack. BEVs are charged through plugging the vehicle into the main electrical grid system as well as regenerative braking (Kempton \& Tomić, 2013).

\subsubsection{Internal combustion engine (ICE) vehicle}

\section{Internal combustion engine vehicle}

Internal combustion engine (ICE) vehicles possess a heat engine that undergoes a combustion process to propel the engine (Van Basshuysen \& Schäfer, 2004). A combustion 
engine converts chemical energy to mechanical energy as a result of the incineration of a mixture of air and fuel (ibid.). 


\section{Chapter 2 Literature Review}

This chapter will introduce and describe the research relevant to the development of this thesis project. To date, much of the literature surrounding contemporary EVs has been focused on the macro-level environmental influences that compel certain stakeholders to opt for its commercial uptake, particularly to achieve emissions reduction targets. Such influences include the potential to reduce GHG emissions and improve local air quality. As EVs are more noticeably integrated into societies, the niche associations the vehicles once possessed such as being symbolic for deep ecological care and technological savviness will likely evolve as it becomes adopted by a more mainstream audience without clear and guided interests.

\subsection{History of the contemporary electric vehicle}

The EV has existed since near the inception of the vehicle. Yet, gasoline- and diesel-fuel sources have been so widely available that societies have relied on such fuels to propel their vehicles despite the widely known consequences of usage. Path dependencies have been historically reinforced in the transportation sector even though alternatives have existed in differing capacities. This perpetuates the idea of a 'carbon lock-in,' which is defined as the inability to diffuse or adopt innovative carbon-saving technologies due to the persistent reliance on fossil fuel-based technological systems despite their pre-identified environmental externalities (Unruh, 2000). The single passenger vehicle has served as a long-standing case to substantiate this concept, while the EV is demonstrative of the disruptive potential of the technology if capable of re-defining the driving habits of others (Cowan \& Hultén, 1996; Klitkou et al., 2015). The formative years of the automobile industry to the mid-1990s is argued as a period of technological lock-in, as dependency on gasoline became increasingly entrenched into the minds of a generation of drivers (Kurani et al., 1994; Cowan \& Hultén, 1996; Chéron \& Zins, 1997). 
Greater public awareness levels regarding poor air quality in the 1960s and energy instability in the 1970s and 1980s contributed to a revival of public interest towards what is now understood to be the 'modern' EV (Azzone \& Bertelè, 1994; Rahman \& Ehsani, 1996; Chau et al., 1999). However, through the early stages of their resurgence, EV owners, particularly in Western European countries, were considered a near homogenous group of middle-aged, well-educated, high income earning males with a family (Campbell et al., 2012; Peters \& Dütschke, 2014; Kawgan-Kagan, 2015; Mohamed et al., 2016). While as public policy was becoming refocused to emphasize mitigating what were considered to be looming environmental catastrophes, automakers responded with the introduction of their initial EV models that in many cases were unintended to become commercialized, rather act as a vessel to explore their potential future uptake. The aims of these models were often to merely accommodate the looming possibility of a forthcoming zero-emissions vehicle (ZEV) mandate. Yet, throughout this time period, historically low gas prices prevented EVs from captivating the interests of a mainstream audience (Kessler et al., 1994; Noori et al., 1999). Despite the poor fuel economy relative to the standard car, SUVs and trucks rapidly gained public intrigue (Smart, 2000; Wenzel \& Ross, 2005). Leading up to the millennium, there was noted interest in the HEV model, which was understood as possessing some gasoline- or diesel-fuel onboard yet utilizing electricity which became intermittently viewed as an environmentally-friendly attribution. The electrification of a personal car, specifically the capabilities of the battery technology, was becoming subject to processes of incremental changes with continual minor improvements culminating in the regular release of new models. In the early 2000s, the HEV was considered a radical product innovation, specifically the 1997 introduction of the Toyota Prius model (Santini et al., 2000; Lave \& MacLean, 2002; De Haan et al., 2006; Nonaka \& Peltokorpi, 2006). From that point forward, the 
legislated introduction of EVs acted as the impetus to models more closely resembling their ICE counterparts with improved technical specifications, eventually boasting full highway capability for most EVs (Brown, 2013; Lee et al., 2013). In today's marketplace, EVs appear to be poised for continual growth to represent greater modal shares through the complementary nature of the climate change agenda as well as public interest in technological innovation.

\section{$2.2 \quad$ Environmental sustainability}

Thematic areas in research pertaining to environmental sustainability and GHG emissions reduction efforts were not substantial in mainstream literature until the 1980s. In large part, the shift in language is indicative of the United Nations' (UN) acceptance of the principles of 'sustainable development' during this same timeframe. The recognition that the world is facing immense environmental issues that are interconnected to its social and economic wellbeing changed the cultural discourse and empowered future movements focused on reducing energy consumption. The widely accepted definition of sustainable development came from the UN's 1987 Our Common Future publication, which accentuates that ideal global development will meet the needs of the present without compromising the ability of future generations to meet their own needs (Brundtland, 1987). The emphasis of living with limitations drastically altered the way in which humans viewed and interacted with the earth. Prior to the initial waves of environmentalism, research pertaining to the natural world was regularly unlinked to the now widely accepted phenomenon that human activity is inherently linked to anthropogenic induced climate change.

The policies, technologies, and practices that built transportation systems exhibit and operate within have been and will continue to act as a source of environmental disturbances and risk. The evolution of environmental sustainability has long accounted for measurements of 
individual mobility and its greater impact on the atmosphere and land-use planning (Jabareen, 2006; Uiterkamp \& Vlek, 2007; Zito \& Salvo, 2011). The movement of people and goods is highly valued throughout the world, and as a result of this fundamental need, the environmental impact of transportation may be commonly perceived by the public as non-existent or nonimportant. However, now more than ever, cutting-edge sustainable transportation solutions are widely addressed and evaluated in the literature, but still face immense challenges in terms of public implementation given the multifaceted networks involved in democratic governance and decision-making (Rezvani et al., 2015; Gong et al., 2016). This exploratory research builds off of similar models and studies from other jurisdictions to understand the opportunities and barriers of EV adoption specific to residents of the GTHA.

\subsection{Theoretical framework}

User acceptance of new products and services has previously been studied by researchers through cognitive and normative behaviour models (Ajzen \& Fishbein, 1975; Davis et al., 1993; Rogers, 2003; Peters \& Dütschke, 2014). The acquisition of knowledge as to how consumers perceive and react to innovation has a practical application that extends beyond contributing to the state of literature, as this information is extremely insightful to leaders in both policy and industry sectors. In the case of an EV, 'accepting' the technology is understood as both purchasing and utilizing the vehicle (Peters \& Dütschke, 2014). With generally low modal representations worldwide, a framework is necessary to better understand the likelihood of an eventual successful diffusion in the market.

The assertion of user decision-making gained traction with the theory of reasoned action (TRA) [Figure 1], which has seen success in using attitude as a variable to predict behaviour for a variety of actions (Ajzen \& Fishbein, 1975). 
Figure 1: Theory of reasoned action (TRA) model (Ajzen \& Fishbein, 1975)

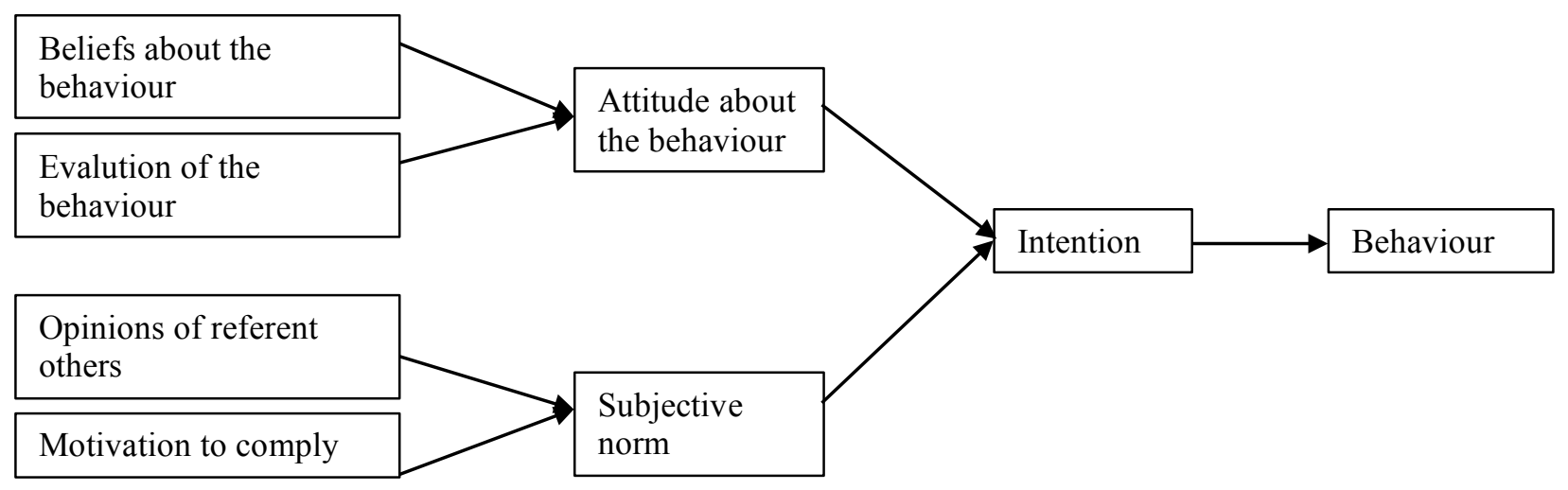

TRA is noted as a general, broad theory that describes the relationship between behavioural intent, attitude, and subjective norms to predict consumer action (Ajzen \& Fishbein, 1975). The conceptual model aims to decode the relationship between attitude and behaviour based on the principles of compatibility and behavioural intent (ibid.). The limitation of the theory is that the assumption is made that humans are rational beings and opt to use the information at their disposal to analyze the implications of their actions prior to selecting a behavioural function (Ajzen \& Fishbein, 1980). The response from the researcher was the theory of planned behaviour (TPB), which incorporates a third variable, control beliefs, designed to consider realistic constraints, indicative that intentions do not necessarily translate into behaviour (Ajzen, 1985).

While not necessarily intended to function in such a capacity, user adoption research that pre-dated the technological revolution, specifically the information and telecommunications revolution in the mid-1980s, provided greater insight to researchers as to how rapid paced advancements were to be perceived by the public. User acceptance of computer technology was modelled in the technology acceptance model (TAM) [Figure 2], which was built off of the TRA to account for the distinct attributes of information systems theory. 
Figure 2: Technology acceptance model (TAM) (Davis et al., 1993)

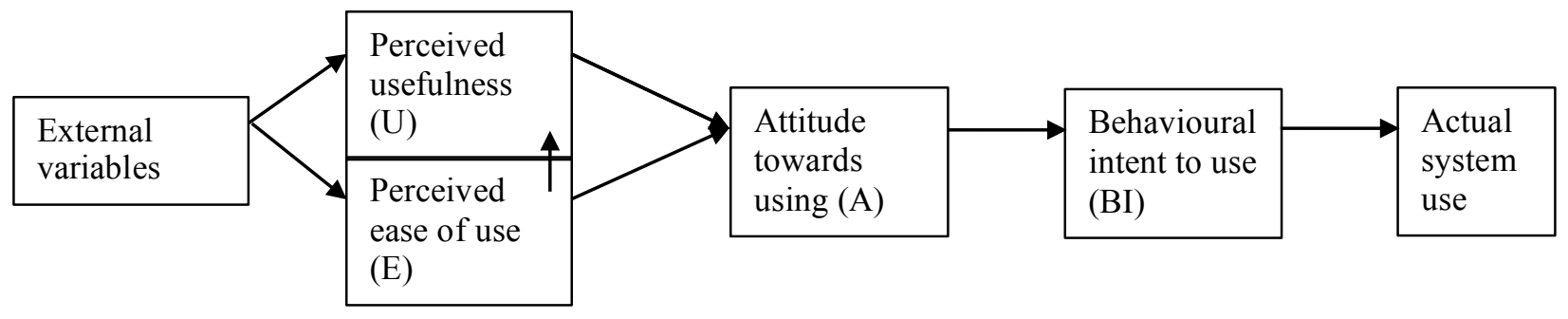

TAM predicts the likelihood of an individual using a product they had been introduced to through an analysis of two external variables: 'perceived usefulness' (PU) and 'perceived ease of use' (PEOU) (Davis et al., 1993). The TAM model was later expanded to factor 'social norms' as a variable to predict the likelihood of adoption (Taylor \& Todd, 1995). However, this research goes beyond exclusively addressing user perception, to evaluate the diffusion of the technology as informed by public policy. These two concepts merge in the case of EVs as the public sector often relies on sales targets and GHG emissions reductions as a metric to evaluate their ability to address issues involving climate change.

Recent waves of opportunistic entrepreneurs, perhaps more comfortable with absorbing risk, have stimulated innovation that can improve the state of the environment, particularly in terms of technology development in renewable energy (Kemp, 1994). The emerging interconnected relationship of the natural environment and business initiatives has spawned subsets of sustainable entrepreneurship and environmental entrepreneurship as disciplines welldeserving of deeper analysis (Dean \& McMullen, 2007). The distinction of the environmental entrepreneurship is the focus on acting in the economic and ecological needs of society, thereby emphasizing a 'double bottom line' of fusing sustainable objectives and profit-driven models (Belz \& Binder, 2017). More recently, technological innovation has been capitalized upon to improve the natural environment (Walsh, 2012). In this space, stakeholders act under the pretense that successful market potential to support and foster innovation requires knowledge 
and sophistication for consumers to adequately recognize the value proposition of the explored product or service (ibid.). User perception and market acceptance are therefore interrelated items that can dictate the direction of future policy and action. A renewable energy technology (RET) commercialization environment framework highlights market-pull (the eco-sophistication of the market) and technology-push (demand for renewable energy technology products) forces to determine more appropriate choice commercialization strategies based on the nature of the market (ibid.).

The literature surrounding innovation implies that individuals whom embody certain descriptive characteristics will adopt new innovations before their peers. Such characteristics include the perception of the individual adopters, the communication channels, time scale, and social systems of influence (Rogers, 2003). Rogers' modelled the diffusion of innovation theory which suggests that members of a given society will fall into one of five predetermined adopter groups based on their willingness to accept a new technology [Figure 3] (ibid.).

Figure 3: Diffusion of innovation theory (Rogers, 2003)

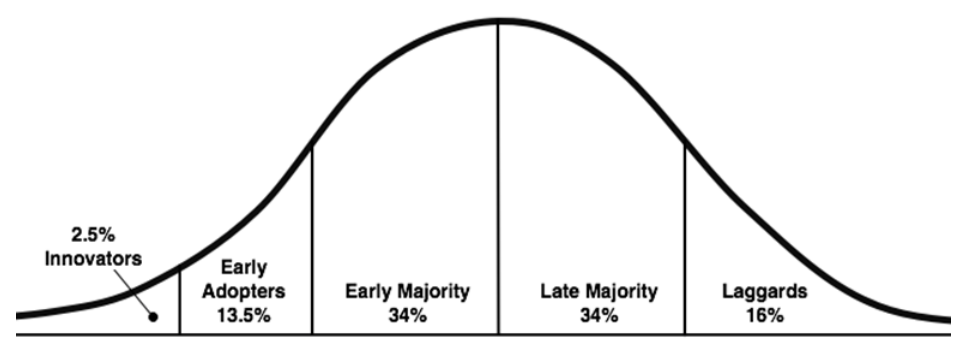

Rogers' (2003) findings suggest that of the five adopter groups, distinct marketing tactics are necessary in order to captivate and persuade potential consumers to adopt an innovative product or service. The degree of support generated as a result of the initial 'innovators' and 'early adopters' dictates a predictive pathway to understanding the rate at which adoption amongst the 'early majority', 'late majority', and 'laggard' groups may occur (ibid.). There are issues of price volatility with the model though, as Rogers' model does not specify whether the innovation 
categorized underwent development for low-operation cost consumer products or high operations costs (Al-Alawi \& Bradley, 2012). As well, the theory accounts for stated preferences but does not necessarily measure openness to innovation within the guidelines of the category (ibid.). With the intentions of better understanding EV marketing modelling, Peters and Dütschke (2014) applied preceding theories on user adoption trends towards innovation to specifically query for the intention to purchase and use an EV in a study amongst German consumers [Figure 4].

Figure 4: Intention to purchase and use an electric vehicle model (Peters \& Dütschke, 2014)

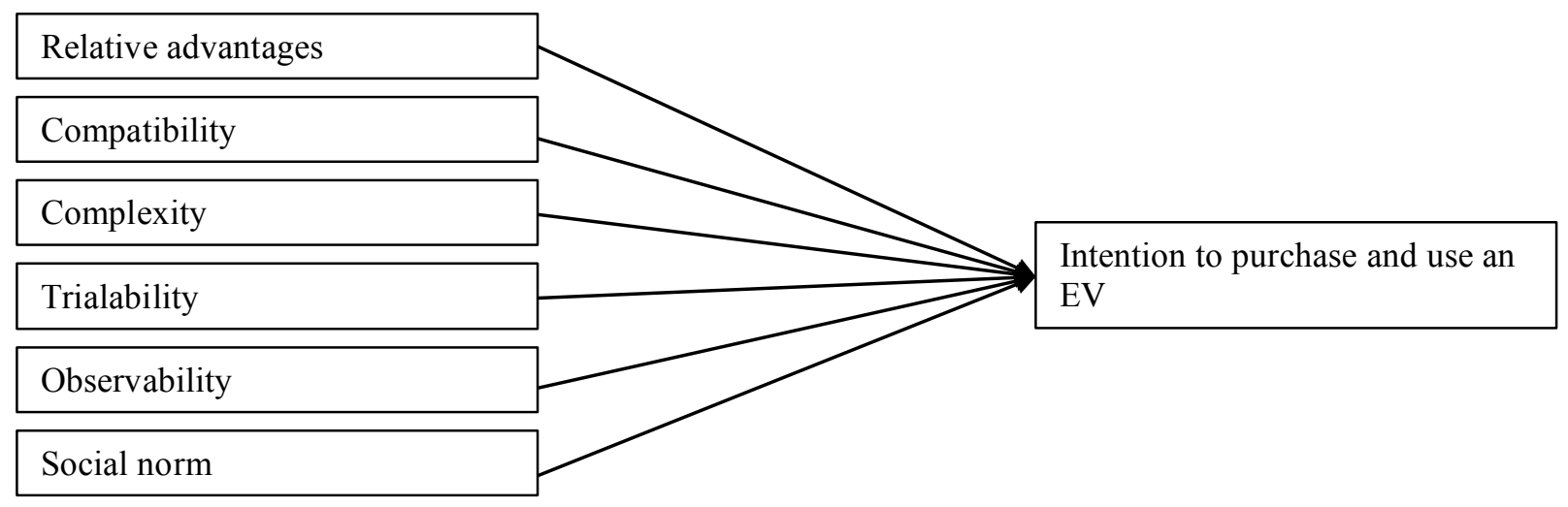

This study adapted the variables from Rogers' (2003) work on the diffusion of innovation theory. However, there was a decision to substitute by Peters and Dütschke (2014) to substitute the 'complexity' variable with the 'ease of use' for a more positive specification of the construct. For the purposes of this research, since the intent is to maintain a neutral stance on the matter, the variables will not be interchanged. The researchers used their model to distinguish four groups of prospective EV buyers differentiated by their socio-demographic variables to assess their willingness-to-pay (WTP) for an EV (Peters and Dütschke, 2014). Their objective was to use their questionnaire to highlight how predictors of the model differ among the groups under study and how they influence the target variable (intention to purchase and use an EV) in the respective consumer groups (ibid.). As well, the researchers wanted to underscore their preferences regarding the continual development of the EV landscape to assess how they differ according to 
group affiliation (ibid.). Peters and Dütschke (2014) interpreted Rogers' (2003) definitions of the categories outlined by selecting questions which corresponded to previous studies of the acceptance of innovations. Respondents in their survey usually rated their agreement on a sevenpoint response scale ranging from one (meaning not at all the case) to seven (meaning very much the case) (Peters \& Dütschke, 2014). Sixteen items were used to assess the perceived likelihood of purchase an EV through the aforementioned categories of intention (ibid.). The categories and their relevance will be further unpacked in the Results chapter of this study.

This model is well-refined to inform consumer EV purchase pattern decision-making through its organic evolution from a more general theory, and will therefore act as this study's framework to guide the development and findings of the study. The novel component of this research will measure existing EV owners with the Peters and Dütschke (2014) model to assess their prior reasons for purchase and their satisfaction (and likelihood to purchase again in the future) given the focus on policy development in the sector. While exclusively focusing on nonEV drivers may accelerate the uptake of EVs, understanding the motivations of the early adopters of EVs can provide useful insight as to what motivations and values may ultimately translate to adoption.

\subsection{Strategic management of competitive advantage and innovation}

One of the most contentious issues in the EV space has been the limited selection of models, which in large part has to do with the skepticism for brands to heavily invest in the lessconventional and less-popular EV models. Brand perception of EV makes will ultimately have a very strong influence on one's likelihood to adopt the vehicle. The ability for a firm to achieve and sustain a competitive advantage has been addressed and understood from a variety of perspectives. Strategic theory has historically attempted to safeguard competitive advantages to 
build brand profiles through the destruction of existing competences. Schumpeter (1942) derived his work from a Marxist ideology that linked processes of the accumulation and annihilation of wealth with the concept of creative destruction. His work suggested that large incumbent firms have traditionally obtained innovation advantages over smaller entrepreneurial initiatives (ibid.). However, complications arise as often those quick to commercialize an innovation are increasingly less likely to profit from the discovery (Teece, 1986). The expensive initiation of research and development $(\mathrm{R} \& \mathrm{D})$ often does not result in a return on investment $(\mathrm{ROI})$, as often the first-to-market fails to capitalize on the potential of the innovation (ibid.). The main factors of sustaining the capital advantage that comes with innovating include the imitability and complementary assets of the product or service (ibid.). Therefore, incumbent firms have historically implemented a resource-based view (RBV) to amalgamate proprietary-owned resources and competences that are difficult to imitate to earn high ROIs (Wernerfelt, 1984; Barney, 1991; Mahoney \& Pandian, 1992). Incumbents, as a result, may be less willing or unable to explore and implement radical innovation models as they lack the pre-existing products demanded by the market in which they had great influence on (Peteraf, 1993; Barney, 2001). Ultimately, this has implications as to how EVs will be perceived by consumers, as if the luxurybased models have better success in the market, the general population may be more inclined to associate such expensive models to electrified technologies more broadly.

EVs pose a compelling case for further research as the cars have become subject to a great deal of governmental intervention at various scales, framed as a mechanism to achieve environmental objectives. Especially in recent years, there have been disruptive impacts that suggest regulation is shifting the technological trajectory of the automotive sector through the creation of novel pathways that leave known competencies in the sector obsolete (Dyerson \& 
Pilkington, 2005). Traditional understandings of competitive positioning in the innovation landscape may therefore not be entirely implacable in the context of innovation that has been allocated to support a public environmental agenda. As well, existing literature pertaining to EV adoption indicates that path-dependent behaviour affects incumbent and entrepreneurial firms differently. Incumbent firms, which have been categorized as economy multipurpose vehicle (MPV) manufacturers, have more closely retreated to conform to existing business models through marketing their limited selection of initial EV models (Bohnsack et al., 2014). The observed tactics and branding strategies reflect similar outputs amongst EVs and their ICE counterparts. Yet, complementary assets (i.e. charging stations) have enabled companies who sell both ICE vehicles as well as EVs to respond more rapidly to utilize and benefit from government incentive programs (Dyerson \& Pilkington, 2005; Struben \& Sterman, 2008; Bohnsack et al., 2014). As well, additional infrastructure becomes necessary to compliment the growth of an innovation. Technological assets are thereby essential to both enable the technology to run properly and to profit from the innovation (Pinkse \& Kolk, 2010; Kyläheiko et al., 2011). In the case of EVs, the essential complementary assets are primarily identified as the additional development of corresponding charging stations (Wesseling et al., 2015). This is where entrepreneurial firms are presented with a competitive advantage, as companies such as Tesla Motors have less constrains in terms of corporate governance than incumbent firms such as General Motors or Ford, and can therefore implement greater levels of price flexibility options in their pursuit of more radical business models to earn distinction amongst the consumer market. Their presence in the broader EV landscape has been heavily disruptive through the initiation of an oligopoly high-performance luxury product (Kley et al., 2011; Bendell \& Thomas, 2013). The company's objective has in large part come to capitalize on a higher WTP, which to date has 
drastically changed the nature of the market. Early adopters may see such auspicious attributes (i.e. the opulent and/or distinctive nature of the vehicle) as benefits that compensate for the higher initial investment purchase costs. However, the saturation of high-performance vehicles amongst the market of EVs can alter public perception of the EV market more broadly, which may potentially alienate lower- and middle-class individuals from considering these options as feasible for their lifestyle. In terms of perceived acquisition of the vehicle, the market domination of a specific type of EV (i.e. one that is expensive, one that fit a certain number of occupants, etc.) may alienate mainstream prospective buyers due to clear mental associations formed as a result of such entrepreneurial pathways.

\subsection{Sustainable transportation reform in the GTHA}

The GTHA, similar to many cities, faces a number of challenges pertaining to GHG emissions reduction, air quality, and urban sprawl. Toronto's 2013 Greenhouse Gas Inventory study indicated that transportation accounts for 41 per cent of total emissions, a figure notably exceeding both national and provincial averages (City of Toronto, 2015). The dense urban environment of Toronto underscores transportation related challenges such as traffic congestion and local pollution (Koropeski et al., 1998; Levinson et al., 1998; McKirtick, 2006; Nagorsky et al., 2016). Horak (2013) describes the process of forming solutions for intricate policy issues in Toronto as not customarily addressed by one level of government acting independently, but rather through jurisdictional rescaling through the "problem-driven, multi-scalar deployment of governing authority." The lack of harmonization in decision-making and competing agendas to target municipal reform efforts have underscored the difficulties in ratifying the status-quo. With a recent rise of environmental consciousness with respect to urban reform, Canada along with its provinces and cities have set climate targets as well as emissions reductions goals to mitigate the 
environmental impact to date. As a result of this recent prioritization, the electrification of transportation has opened collaborative networks amongst ministries and agencies that previously were less inclined to work together to synchronize the priorities involved in decarbonizing the transportation sector. For example, the distribution of electric vehicle supply equipment (EVSE) public charging stations has been a joint initiative through the Ministry of Transportation Ontario (MTO) and the Ministry of Environment and Climate Change (MOECC) collaboratively.

The GTHA operates in an abstract manner exclusive of a specific singular political identity, rather multiple individual cities or regions elect their own governments. The harmonious relationship stems from the interconnected mobility needs of residents throughout the diverse region. The establishment of Metrolinx in 2006 was in large part an attempt to unify the regions and solve the shared geopolitical transportation challenges identified by the cities and towns in silo (Metrolinx, 2008). The Big Move project proposed electrification as means to bolster the state of mobility in Toronto and surrounding regions through a greater representation of electric Light Rail Transit (LRT), electric subway trains, and electrified Regional Express Rail (RER), or SmartTrack (ibid.). Notably, stage one included an electrification of the Kitchener GO line to accommodate a rail line to travel from Union Station to Toronto Pearson International Airport (ibid.). While stage two included the electrification of the existing GO line from Oshawa Station to Hamilton Station (ibid.). In early 2016, Metrolinx announced their plans to additionally electrify core areas of the GO Transit network through the Electrification Transit Project Assessment Process (TPAP) (Metrolinx, 2016). As a result of community stakeholder engagement, the findings indicate a desire to build and integrate relevant infrastructure into the ongoing rail corridor expansions (ibid.). The transportation sector has received high levels of 
public attention and scrutiny regarding the direction of prospective reform to account for improved sustainability in operations. The challenges largely stem from the plethora of stakeholder groups and community members that view the declared priorities and processes with stark differences as a result of socioeconomic status and urban-rural divisions within the GTHA. Electrification efforts in Ontario to date have been unable to acquire mass public acceptance, and therefore a theoretical model for this study proposes a line of questioning that draws the participant to explain their perception towards issues of electricity (i.e. how they perceive the range, how they perceive the supply mix). The changing context of perception of electricity in Ontario shapes potential uptake due to how an individual believes it can impact their livelihood.

\subsection{Climate change action targets in Ontario}

The province of Ontario has prided itself on evolving into a leading jurisdiction to fight climate change and cut GHG emissions. In 2007, Ontario developed the Go Green: Ontario's Action Plan on Climate Change as a result of the findings from the UN Intergovernmental Panel on Climate Change (IPCC) outputs. Ontario's action targets included an effort to reduce the province's GHG emissions to six per cent below 1990 levels by 2014, an objective that would reduce emissions by 61 megatonnes relative to a business-as-usual (BAU) scenario (Government of Ontario, 2007). As well, the Plan outlined targets for Ontario to reduce GHG emissions to 15 per cent below and 80 per cent below 1990 levels by 2020 and 2050 respectively (ibid.). In an effort to supplement such efforts, Ontario put forward the Green Energy Act (GEA) in 2009, which affirmed intentions to phase out coal usage and introduce a feed-in-tariff program to promote renewable energy implementation (Government of Ontario, 2009). In 2014, Ontario reached the aforementioned declared six per cent reduction target in large part because of the key milestone decision to phase out of coal-power to generate electricity. Ontario was the first 
jurisdiction in North America to eliminate coal in such a capacity, and this prompted greater proportions of renewable energy sources to become more integrated into the province's existing electricity supply (Government of Ontario, 2015). Ontario's electricity transmission and distribution systems now possesses a supply mix predominately reliant on nuclear and hydro power (Independent Electricity System Operator, 2017) [Figure 5].

Figure 5: Generator output by fuel type monthly report, Q1: January - April, 2017 (Independent Electricity System Operator, 2017)

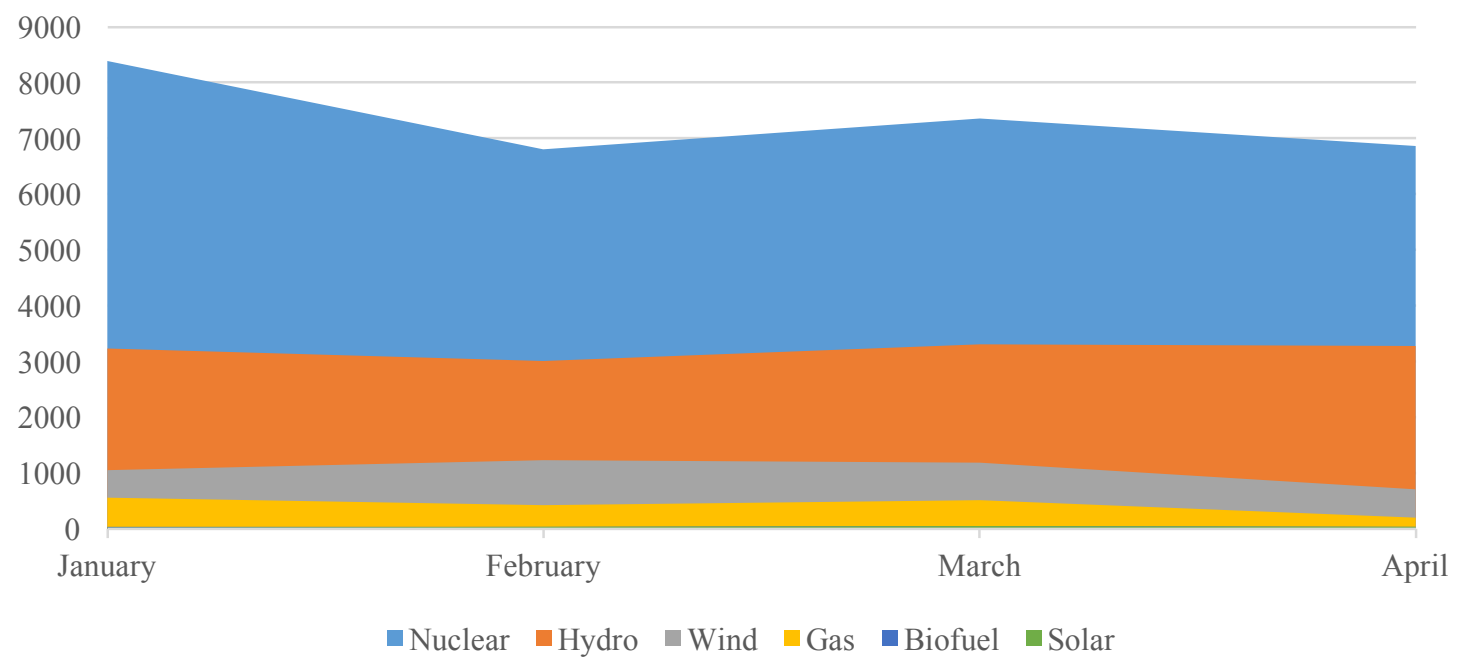

As a result of the diversified supply mix of electricity being transmitted in Ontario, the province enabled a Smart Grid system in 2011 to optimize how power is sent from stations to local electric utility companies to eventually be distributed in a unit (whether a home dwelling or business) (Ministry of Energy - Ontario, 2017). The grid network uses sensors and monitoring capabilities to optimize operations (Cavoukian et al., 2010; Richardson, 2013). This initiative inspired a cluster of environmental action at the provincial level to showcase Ontario's desire to become a leader in the effort to better utilize its electric potential to increasingly transition towards a low-carbon economy. 
The province shortly after, in April of 2015, announced it would be placing limits on the main sources of GHG pollution with the initiation of a long-deliberated cap-and-trade program, resembling action previously taken in Quebec and California (Office of the Premier, 2015). In May of 2015, the Government of Ontario announced it would be the first jurisdiction in Canada to independently set GHG pollution reduction targets for 2030, a 37 per cent reduction from 1990 baseline levels (Ministry of the Environment and Climate Change, 2015). However, with a cleaner electricity supply, the MTO and MOECC introduced joint and individual efforts to increase the commercial uptake of electrified transportation options in the province. For example, in 2015, the Electric Vehicle Chargers Ontario (EVCO) program was established by the MTO to incentivize the further uptake of plug-in electric vehicle (PEV) ownership (Ministry of Transportation Ontario, 2016). An initial capital value of $\$ 20$ million was solicited through a request for proposal (RFP) process amongst stakeholders to build Level 3 public charging stations across the province (ibid.). The intention of the program was built under the assumption that the visibility of charging stations across Ontario's pre-identified key road networks would facilitate an uptake in EV interest and eventual adoption. Ultimately, 24 public and private sector partners were selected to create a network of EV charging stations in cities, along highways, and at workplaces and public places in the province (ibid.). The selected locations of public charging stations can have influence on exposure and therefore is tested in this study through measuring the perceived ease of use by participants.

The recent culmination of public engagement for more sustainable transportation was reflected in the Government of Ontario's Climate Change Action Plan, released in 2016. The Plan was labelled the province's "five-year plan to fight climate change, reduce GHG pollution and transition to a low-carbon economy" (Government of Ontario, 2016). Transportation was 
identified as one of eight 'action areas' with a provincial electric and hydrogen passenger vehicle sales target of five per cent by 2020 (ibid.). Given that the modal share of EVs is assumed to be less than one per cent by today's standard, these targets are quite ambitious (Statistics Canada, 2016; Schmidt, 2017). Table 1 indicates the specific intentions as outlined in the Plan.

Table 1: Relevant components of Ontario's Climate Change Action Plan to electric vehicle adoption (Government of Ontario, 2016)

\begin{tabular}{|c|c|c|c|}
\hline $\begin{array}{l}\text { Category } \\
\text { number }\end{array}$ & Category objective & $\begin{array}{l}\text { Specific policy proposal from the } \\
\text { Government of Ontario }\end{array}$ & Timeline indicated in the Plan \\
\hline 1.1 & $\begin{array}{l}\text { Maintain incentives } \\
\text { for EVs }\end{array}$ & $\begin{array}{l}\text { Extend existing rebate program to } 2020 \\
\text { for leasing or buying an eligible EV }\end{array}$ & Implemented \\
\hline 1.2 & $\begin{array}{l}\text { Eliminate HST on } \\
\text { ZEVs }\end{array}$ & $\begin{array}{l}\text { Work with federal government to explore } \\
\text { ways to provide full-HST relief for new } \\
\text { BEVs }\end{array}$ & Exploratory: proposed for 2018 \\
\hline 1.3 & $\begin{array}{l}\text { Free overnight EV } \\
\text { charging }\end{array}$ & $\begin{array}{l}\text { Establish a four-year free overnight EV- } \\
\text { charging program for residential and } \\
\text { multi-unit residential customers }\end{array}$ & Exploratory: proposed for 2017 \\
\hline 1.4 & $\begin{array}{l}\text { Replace older } \\
\text { vehicles }\end{array}$ & $\begin{array}{l}\text { Intention to help get older and less fuel- } \\
\text { efficient vehicles off the roads through a } \\
\text { rebate to low- and moderate-income } \\
\text { households to replace old cars with new } \\
\text { or used EVs (including PHEVs) }\end{array}$ & Exploratory: no set date \\
\hline \multirow[t]{3}{*}{1.5} & $\begin{array}{l}\text { Ensure charging } \\
\text { infrastructure is } \\
\text { widely available }\end{array}$ & $\begin{array}{l}\text { Intention to invest in more charging } \\
\text { stations for workplaces, multi-unit } \\
\text { residential buildings, downtowns, and } \\
\text { town centers. }\end{array}$ & Exploratory: no set date \\
\hline & & $\begin{array}{l}\text { Intention to require all new homes and } \\
\text { townhomes with garages to be } \\
\text { constructed with a } 50 \text {-amp, } 240 \text {-volt } \\
\text { receptacle }\end{array}$ & Exploratory: no set date \\
\hline & & $\begin{array}{l}\text { Intention to require all new commercial } \\
\text { office buildings and appropriate } \\
\text { workplaces to provide charging } \\
\text { infrastructure }\end{array}$ & Exploratory: proposed for 2018 \\
\hline 1.6 & $\begin{array}{l}\text { Electric and } \\
\text { Hydrogen } \\
\text { Advancement } \\
\text { Program }\end{array}$ & $\begin{array}{l}\text { Vehicle manufacturers that offer } \\
\text { customers access to EVIP will need to } \\
\text { participate in the program (recognize } \\
\text { manufacturers that exhibit outstanding } \\
\text { performance) }\end{array}$ & Implementation: 2017 \\
\hline 1.7 & $\begin{array}{l}\text { Increased public } \\
\text { awareness }\end{array}$ & $\begin{array}{l}\text { Collaboration with Plug'n Drive (non- } \\
\text { for-profit) to establish an EV education } \\
\text { facility }\end{array}$ & $\begin{array}{l}\text { Exploratory: no set date } \\
\text { The Electric Vehicle Discovery } \\
\text { Centre opened in May of } 2017 \\
\text { (Plug'n Drive, 2017) }\end{array}$ \\
\hline
\end{tabular}

In 2016, the Government of Ontario in collaboration with the MTO announced that nearly $500 \mathrm{EV}$ charging stations at over 250 charging station locations would be implemented across the province as part of Ontario Green Investment Fund (OGIF) (Ministry of 
Transportation Ontario, 2016). A series of public- and private-sector partners were selected to improve the network of charging stations in priority areas available to drivers. According to their official press release, the intention of this program was to ease 'range anxiety,' commonly identified as the distance an EV can be driven before having to recharge, which is documented as a key concern of current and prospective EV drivers. In addition, the federal government invested $\$ 62.5$ million in 2016 in EV charging stations dispersed across the country (CTV News, 2016). Divided amongst the total allocated capital, $\$ 16.4$ million incentivized the deployment of approximately 70 Level 3 charging stations and two hydrogen refueling stations in strategic transport corridors (Clean Tech Canada, 2016). The funds were intended to foster partnerships amongst private industry actors and key public stakeholders as the federal portion is intended to cover 50 per cent of the costs concomitant (ibid.). The larger components of the funds will be put forth to support R\&D efforts for the future implementation of relevant technologies (ibid.). Consumer preferences for electric vehicles

An analysis of consumer acceptance towards EVs is essential for their successful diffusion in the market. The state of literature regarding EV perception is limited, albeit growing in the North American context, yet virtually non-existent specific to the province of Ontario. The largest North American study to date regarding EV preference took place in the U.S., in which a survey was distributed to over 2,300 drivers in 21 large cities. Nearly two-thirds of respondents provided erroneous responses to basic factual questions about PEVs (Krause et al., 2013). Over 94 per cent of respondents were unaware of the local incentives in their municipality to encourage PEV purchase and use (ibid.). In addition, although not necessary 'erroneous,' an overwhelming majority were unaware of the EV makes and models available at their local dealerships (ibid.). These findings were delivered in the context of attitudinal characteristics to 
assess what components of an individual's lifestyle would have influence on the likelihood of them obtaining a positive view of electrified transportation and its potential integration into their life (ibid.). The findings indicate that there is widespread misinformation and misunderstandings of many aspects of the EV (the technology, infrastructure, performance, market availability) as well as that government policy is often too focused on few aspects of EV deployment (initial purchase subsidies, charging stations) as opposed to their overall marketability (ibid.). There has been a resulting ongoing sustained assumption suggesting that misguided beliefs regarding EVs may lead to less interest amongst a general population due to perceived difficulties in adoption. Studies in the North American context express widespread dissatisfaction with the initial costs amongst prospective EV buyers. In a web-based design simulation game, over 500 participants from San Diego, California were assessed as to their likelihood of EV purchase based on the inclusion or exclusion of specific aspects of their desired vehicle. Participants were able to select models ranging from ICE to a HEV and PHEV to BEV. The findings demonstrate that when participants selected an ICE vehicle, they often cited concerns of the vehicle's range, perceived charging availability, and the higher initial purchase cost as the main indicators preventing them from considering an electrified alternative (Axsen \& Kurani, 2013). Yet, when the barrier of upfront cost was controlled for, there was a notably higher preference in electrified design options amongst participants who otherwise would have opted for an ICE vehicle (ibid.). Positive interest in the electrified models were drawn out of participants associated the EV with a sense of intelligent purchase decision-making, responsibility, and support of the environment and nation, which also alluded to those more inclined to purchase an EV perceiving themselves as more intelligent and cognizant of environmental issues. 
Canadian research focused on consumer perception towards EVs have in large part been from urban areas in British Columbia (Axsen et al., 2015; Bailey \& Axsen, 2015; Bailey et al., 2015; Axsen et al., 2016; Axsen et al., 2017). The outputs reflect the somewhat heterogeneous nature of research trends noting that poor consumer education levels hinder EV uptake and marketability. There is a widely held belief amongst EV stakeholders of the notion of perceived 'range anxiety' being particularly relevant as a widespread barrier in Canada. The implication is that fewer drivers will purchase an EV as a result of public charging stations being substantially less visible and frequent in contrast to gas stations. The 'anxiety' is the impeding fear that one's vehicle will run out of electricity without charging stations nearby, which is thought to obstruct the increase of EV sales (Eberle \& Von Helmolt, 2010). Range anxiety is particularly believed to impact Canadian consumers due to the pronounced culture of auto dependency and often far distances covered by the average Canadian driver, relative to smaller countries in which cities are less dispersed and/or congested (Dong et al., 2014; Bailey et al., 2015; Loiselle-Lapointe et al., 2017; Perera et al., 2017). In a 2015 survey of over 1,700 new vehicle buyers, a mere one in five Canadian participants recall noticing at least one public charging station (Bailey et al., 2015). The findings surrounding public charger awareness were concluded to not be an accurate indicator of PEV purchase intent (ibid.). Such results largely countered the common narrative amongst the OEM and utilities stakeholder community that more charging stations would result the acceleration of EV ownership.

With respect to vehicle ownership, a targeted survey of over 1,700 Canadian EV owners and EV-oriented car buyers was conducted and the results were categorized by outlooks towards attributes of ownership. The findings indicated that the PHEV model is the most likely to have a mass appeal once a consumer has accepted the possibility of EV ownership (Axsen et al., 2015). 
The rationale supporting this finding is that both categories of participants did not possess much difference in terms of vehicle preferences despite more perceptible distinctions in lifestyle identification (ibid.). The findings indicate that those who have already purchased or are interested in purchasing an EV may not differ much from a policy motivator perspective. The recommendations suggest that the early adopting community does not differ much from those potentially interested in purchasing a vehicle, and therefore, policies to support EV uptake can be extended across the community. In Ontario, a 'mystery shop' study was completed throughout 24-EV certified dealerships to observe EV sales interaction experiences. The researchers identified both the limited options available on site and the vacuous nature (perceived poor knowledge) of the salespeople were common barriers to inhibit their uptake (Matthews et al., 2017). The barrier to adoption was identified by provincial actors as an inability for consumers to effectively interact with the technology (ibid.). This barrier is especially relevant to consumers interested in purchasing a vehicle without loyalty to a specific make or model.

Outside of North America, more substantial impacts have been made in the commercialization of EVs, mainly clustered in California, Scandinavia, and Western Europe as these are regions experiencing explosive growth rates of adoption. With respect to Ontario, the majority of research relevant to EVs have focused on electricity-grid interactions and battery development from a more technical perspective (Hajimiragha et al., 2010; Jarrett \& Kim, 2011; Musavi et al., 2011; Liu et al., 2013; Ahmadi et al., 2014). This trend amongst the literature is in large part a result of the distinctly intelligent grid distribution network Ontario has invested in and fostered. The assumption of this trend is that Ontario's grid system is an anomaly compared to most of the province's other North American counterparts, and exploratory research provides key insight to the lessons they may be learned from such a system. Therefore, the emphasis of 
research in Ontario is not on consumer perception, but rather the technical processes associated with the operation. The amount of content pertaining to the marketability and consumer perception is underwhelming in the current state of literature, which leaves significant gaps in potential information that can better shape public policy and assist industrial players. As a result of a relatively complex network of electricity transmission and distribution and the welldocumented barriers to adoption of new products or services, consumer education pertaining to electricity and EVs is unsurprisingly lacking and misperceptions are common in the broader discourse of energy (Rowlands, 2007; Vyn \& McCullough, 2014). The current state of knowledge lends itself to exploratory studies from other locations in which the findings cannot necessarily be extrapolated to indicate the perceptions and attitudes of the GTHA's population given relevant and distinct socio-geographic characteristics (potential examples may include expensive living conditions, weather conditions, traffic and congestion, alternative transit systems, etc.).

Three of Canada's ten provinces are encouraging the adoption of EVs through government-led incentive programs. In Ontario, the Electric Vehicle Incentive Program (EVIP) began in 2010, and was most recently updated in January of 2017, with the intention of encouraging PEV uptake to support the goals of Ontario's recent Climate Change Action Plan (Ministry of Transportation, 2017). The government of Ontario offers up to $\$ 14,000$ CAD off the purchase of an electric car, up to $\$ 1,000 \mathrm{CAD}$ off the purchase and installation of a home charging station, and a green license plate that allows drivers to use high-occupancy vehicle (HOV) and high-occupancy toll (HOT) lanes when driving regardless of the number of individuals in the vehicle (ibid.). The methodology of the parameters is that vehicles with a battery capacity from 5 to 16 kilowatt-hours $(\mathrm{kWh})$ are eligible for incentives ranging between 
$\$ 6,000$ to $\$ 10,000$ based on battery size and vehicles with a battery capacity of larger than 16 $\mathrm{kWh}$ are additionally eligible for the $\$ 3,000$ incentive (ibid.). As well, vehicles with five or more seats are eligible for an additional $\$ 1,000$ incentive (ibid.). The rebates are then determined as to whether the vehicle is a PHEV or BEV based on a manufacturer's suggested retail price (MSRP) (ibid.).

Table 2 demonstrates the current fleet of electric car makes and models available in Canada, and the associated costs and rebates using the EVIP program. There are currently 26 models available for purchase in Canada, with new makes and models expected in the near future.

Table 2: Financial information of available electric vehicles in Canada, as of August 2017

\begin{tabular}{|c|c|c|c|}
\hline Vehicle & Type of PEV & $\begin{array}{l}\text { Cost before } \\
\text { rebate (MSRP) }\end{array}$ & Rebate through EVIP \\
\hline Audi A3 Sportback e-tron & PHEV & $\$ 40,900$ & $\$ 8,095$ \\
\hline BMW 330e & PHEV & $\$ 52,100$ & $\$ 7,730$ \\
\hline BMW 740 Le xDrive & PHEV & $\$ 107,900$ & $\$ 3,000$ \\
\hline BMW i3 & BEV & $\$ 47,300$ & $\$ 13,000$ \\
\hline BMW i8 & PHEV & $\$ 150,000$ & $\$ 3,000$ \\
\hline BMW X5 xDrive40e & PHEV & $\$ 74,000$ & $\$ 8,460$ \\
\hline Chevrolet BOLT & BEV & $\$ 42,895$ & $\$ 14,000$ \\
\hline Chevrolet VOLT & PHEV & $\$ 39,590$ & $\$ 14,000$ \\
\hline Chrysler Pacifica PHEV & PHEV & $\$ 50,995$ & $\$ 14,000$ \\
\hline Ford C-Max Energi & PHEV & $\$ 39,729$ & $\$ 7,730$ \\
\hline Ford Focus EV & BEV & $\$ 31,998$ & $\$ 14,000$ \\
\hline Ford Fusion Energi & PHEV & $\$ 36,399$ & $\$ 7,730$ \\
\hline Hyundai IONIQ & BEV & $\$ 35,649$ & $\$ 14,000$ \\
\hline Hyundai Sonata PHEV & PHEV & $\$ 43,999$ & $\$ 8,460$ \\
\hline Kia Optima PHEV & PHEV & $\$ 42,995$ & $\$ 8,460$ \\
\hline Kia Soul EV & BEV & $\$ 35,395$ & $\$ 14,000$ \\
\hline Mercedes-Benz GLE 550e & PHEV & $\$ 83,000$ & $\$ 3,000$ \\
\hline Mercedes-Benz S 500e & PHEV & $\$ 102,600$ & $\$ 3,000$ \\
\hline Mitsubishi i-MiEV & BEV & $\$ 27,998$ & $\$ 10,000$ \\
\hline Nissan LEAF & BEV & $\$ 37,398$ & $\$ 14,000$ \\
\hline Porsche Cayenne S E Hybrid & PHEV & $\$ 89,400$ & $\$ 3,000$ \\
\hline Porsche Panamera S E Hybrid & PHEV & $\$ 106,600$ & $\$ 3,000$ \\
\hline Tesla Model S & BEV & $\$ 95,300$ & $\$ 14,000$ \\
\hline Tesla Model X & BEV & $\$ 132,000$ & $\$ 14,000$ \\
\hline Volkswagen e-Golf & BEV & $\$ 35,995$ & $\$ 14,000$ \\
\hline Volvo XC90 T8 Twin Engine PHEV & PHEV & $\$ 73,400$ & $\$ 3,000$ \\
\hline
\end{tabular}

Of the total vehicle models currently offered in today's market, 62 per cent are PHEVs and 38

per cent are BEVs. There is an assumed perception that the hybrid models enable an easier 
transition towards considering electrification as a fuel source amongst prospective drivers. The MSRP amongst EVs range from the high $\$ 20,000$ s to $\$ 150,000$, which demonstrates perhaps a greater financial range amongst the cars from the unaffordable price perception that consumers may attribute to the cars.

In large part, the current state of literature does not address why electrified transportation uptake has been lackluster in Ontario compared to other jurisdictions that utilize similar strategies and programs. As a result, there appears to be unidentified barriers in Ontario's landscape that hinder the mass uptake of these vehicles amongst the mainstream population. Therefore, past and present policies and programs have been created in somewhat of an ad-hoc manner, lacking insight that could be acquired from consultation with individuals directly impacted by the content of the policies itself. Further knowledge as to how current and prospective EV drivers perceive the technology and policies will better enlighten its effectiveness. This current predicament creates an opportune pathway for exploratory research as to how engagement with EVs can be best mapped out through policy.

Electric vehicle innovation and adoption in Canada

PEV sales in Canada have recently exceeded the 20,000-unit mark and annual sales since 2011 have been increasing at rapid rates, and in some years achieving exponential growth from the previous total [Figure 6]. 


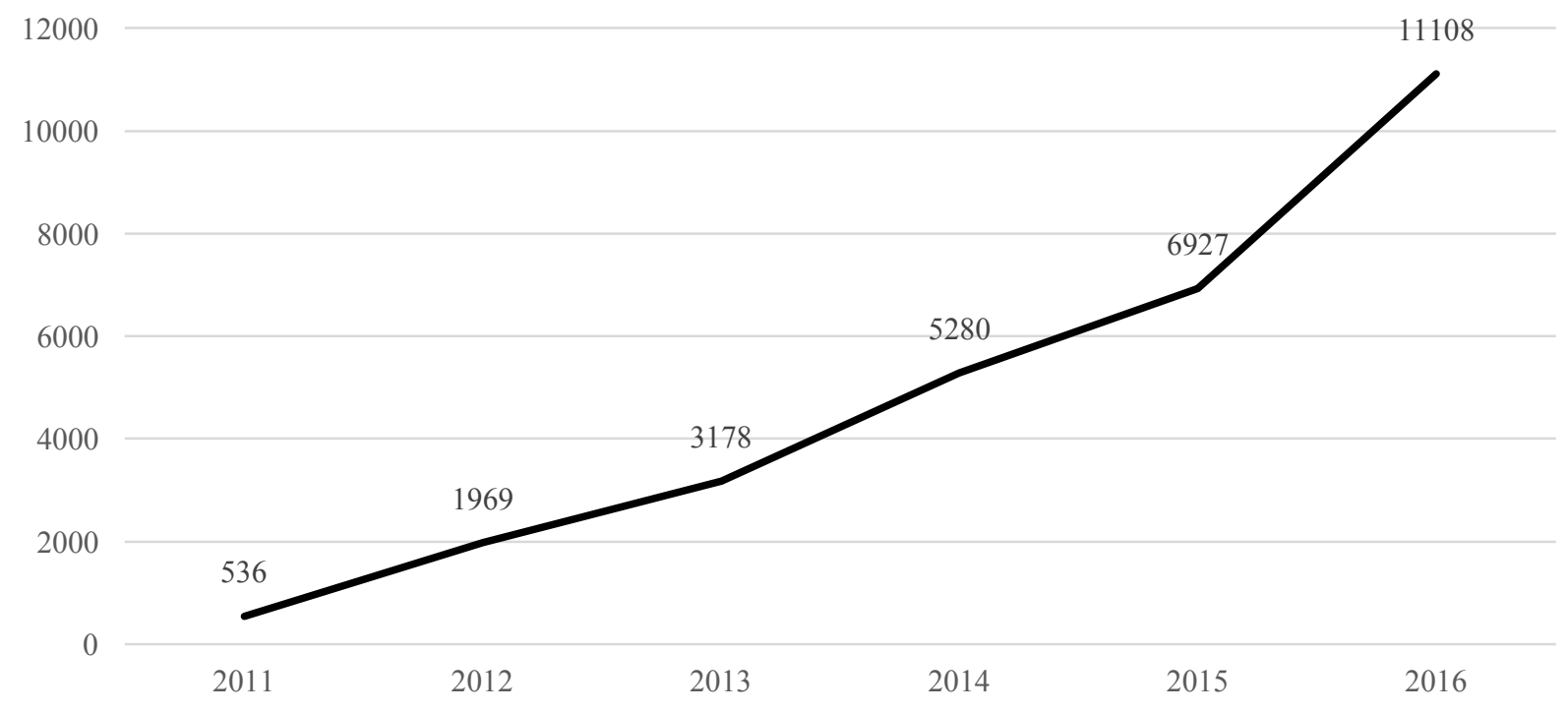

While the rate of adoption is promptly accelerating largely due to the short-term incentive programs that may have adverse effects (i.e. merely temporarily boosting sales until the incentives are removed), the modal share is still representative of less than one per cent of Canada's current registered vehicle fleet (Statistics Canada, 2016; Schmidt, 2017). However, this rate of uptake is not applicable in all parts of the country, as certain provinces and territories have not endorsed EVs as a mechanism to mitigate climate change to the same degree in which their counterparts have.

When crafting policy for public implementation, decision-makers can formulate content in a mandatory or voluntary nature. The City of Toronto operates on a Tier 1 (mandatory or required) and Tier 2 (voluntary) structure to identify environmental policies, in conformity with the city's Green Standards (City of Toronto, 2015). An example of a Tier 1 policy is that in residential buildings future planning efforts will include physical provisions for EV charging for a surfeit of parking spaces provided with the minimum zoning by-laws required (ibid.). Alternatively, a Tier 2 policy is that electrical provision for at least two per cent of residential 
parking spaces for future EV charging in accordance with the Ontario Electrical Safety Code

(ibid.). The manner in which policy decisions are framed for emerging technologies such as the

EV will drastically impact its market performance. Table 3 decodes the advantages and

disadvantages of implementing specific policy mechanisms, which has remains a persistent

debate in the automotive industry to date.

Table 3: Contrasting policy mechanisms

\begin{tabular}{ll}
\hline Type of policy & Feature \\
\hline Voluntary policy implementation & \\
Advantages & No need for costly regulation (Alberini \& Segerson, 2002) \\
& Likely easier to implement (Delmas \& Montes-Sancho, 2011) \\
Can draw upon market mechanisms and market forces (Stavins, 2003) & Relies on co-operative actions of industry (Smyth, 2014) \\
& Could lack incentive to participate (Henderson et al., 2014) \\
& Lack of centralized coordination may create inefficiencies (Mackendrick, \\
& 2005; Hall, 2011) \\
& Perception of 'greenwashing' if targets are not clearly identified (Lyon \& \\
& Maxwell, 2007; Matisoff, 2012) \\
& \\
Mandatory policy implementation & Provides a statutory and regulatory basis for enforcement and \\
penalization of non-compliance (Zou et al., 2017) & Can provide framework for monitoring progress or measuring \\
& effectiveness (Hassan \& Duncan, 1994) \\
& Efforts of producers can be consolidated and collectively managed by a \\
& producer responsibility organization (Conrad et al., 2017) \\
& Regulation may be costly (Alberini \& Segerson, 2002) \\
& Producers can pass cost on to consumers (Alberini \& Segerson, 2002) \\
& Each jurisdiction must pass legislation and develop regulations, which \\
& could lead to implementation gaps (Eckerberg \& Forsberg, 1998)
\end{tabular}

Researchers at Simon Fraser University in British Columbia produced the Canadian

Plug-in Electric Vehicle Study, a three-part mixed-mode survey with samples of PEV owners ( $n$

$=94)$ and ICE vehicle owners $(n=1,754)$ (Axsen et al., 2015). The research outputs have been

classified by four distinct sub-projects, each serving differing yet complimentary functions to

better understand the future EV market. Firstly, a background questionnaire was completed to

illicit basic information and measure technological awareness. Secondly, a driving diary and

assessment was completed by respondents in order to allow researchers to understand their

driving activity (including charging for EV drivers) over multi-day period. Thirdly, a survey was 
completed regarding preferences towards varying technologies and the associated attributes of what is available in the Canadian market. Lastly, a small subset sample of EV drivers in British Columbia were interviewed to address their motivations and preferences. An output of the survey data was the identification of three groups of PEV buyers: (1) PEV "Pioneers" (current PEV owners); (2) the potential "Early Mainstream Buyers" (next PEV buyers); and (3) "Later Mainstream Buyers" (not PEV buyers) (ibid.). These segment groups were formed as a result of a design game which tested for design and specification preference, and then tests willingness to apply one's desired vehicle to an electrified model.

Key aspects of the Canadian Plug-in Electric Vehicle Study were highlighted in a study focused on enlightening the framework of purchasing a new vehicle in order to compare the characteristics, preferences, and motivations of the three segment group (Axsen et al., 2016). The research filters the data to determine who likely EV buyers are, and identifies the key differences they may possess relative to a larger mainstream buying population. Mainstream buyers (those who do not drive an EV) were found to have lower incomes and educational levels than the Pioneer respondents (ibid.). In addition, the Mainstream drivers had slightly lower environmental- and technological-orientation compared to Pioneers (ibid.). Notably, the Mainstream drivers believed they had less access to charging, had much lower awareness of PEV technologies, and expressed preference in PHEV models instead of BEV models (ibid.). The study also found that Pioneers were five times more likely than the Mainstream respondents to possess a graduate degree, two times more likely to have a household income of $\$ 90,000$ or more per year (or in the case of Tesla drivers, three times more likely), and a difference in the level of engagement respondents have in environmental and technological initiatives (ibid.). Of all the respondents, those with home charger access (most likely living in a single-detached home 
dwelling) were more interested in a PEV as a next new vehicle (ibid.). The awareness levels amongst the Mainstream population were particularly low, and as a result a great deal of fallacious information was shared (ibid.). Less than one-third of the Mainstream population were able to correctly identify how certain BEV and PHEV models are charged (ibid.). This research highlights that the transition towards electric mobility will need to better consider how potential future PEV buyers may have different preferences and priorities relative the Pioneers who were willing to immediately adopt the vehicle.

From a public policy standpoint, Melton et al. (2017) identified 96 supply- and demanddriven policies in Canada that support EV uptake, of which 77 per cent of that total were implemented by provincial governments. Despite the controversial nature of government-led incentive programs to discount the cost of $\mathrm{EV}$ purchase, the three provinces with incentive programs represent over 95 per cent of national EV sales to date. However, in a holistic impression, the researchers believe that all provinces fall short of likely achieving the 2040 goal of a 40 per cent PEV market share, and the landscape of PEV-readiness is underwhelming (ibid.). Their results indicate that there is no clear trajectory towards achieving national and regional climate targets. As a result, six provinces received an 'F' grade, representing a BAU scenario that 2040 PEV market share will not exceed even five per cent by 2040 (ibid.). Québec received the highest rating in the country with a 'B-' with an expected market share of 23 per cent, while Ontario and British Columbia followed both receiving a 'C-' (ibid.). The researchers highlight Norway (strong and long-duration financial incentives) and California (ZEV mandate) models as examples of particularly effective policies (ibid.). While the pathway towards the optimal implementation and uptake of these vehicles remains unclear, it is evident that the rate of 
growth of EVs still faces key barriers as a result of a fragmented and scattered execution of policies with virtually no national unity.

\section{Conclusion}

The literature to date regarding public perception of EVs in the automotive space suggests that consumer awareness of PEV technology is low, yet when a greater understanding of the technology is fostered more new vehicle buyers become increasingly interested in purchase. Hybrid models of EVs are of greatest interest to prospective buyers with less perceived knowledge of the technology, large in part because of the gasoline option available to diffuse concerns of range anxiety. Hybrid models are seen to possess greater flexibility for the consumer to adapt to the lifestyle they have become accustomed to. Similar to querying for public perceived knowledge, awareness remains low as well. The majority of Canadians do not recall witnessing public charging infrastructure for EVs, and this is also not expected to impact demand for PEVs. In addition, the lack of models available in traditional mediums (dealerships) and poor knowledge and lack of incentives for salespeople to 'push' such models contribute to their underwhelming sales performance.

The current state of Canadian policy to support EVs is unlikely to penetrate the market for low-carbon technologies such as the EV. Currently, the sales of EVs in Canada are disjointed and fragmented across provinces, but no provinces are expected to exceed five percent of EV market share by 2040 , which illustrates that the status quo is not effective or transformative. While EVs are experiencing what can be argued to be a present-moment hype, more is likely necessary to displace the engrained societal reliance on fossil fuels. Ultimately, in order to overcome limited consumer awareness and a lack of availability of supply, stronger policy is necessary that goes beyond exclusively promoting more sales of EVs but rather a more 
aggressive and broad zero-emission or emissions trading policy scheme may prove to be more

effective.

Table 4: Relevant outputs from a literature review of North American sources based on the Peters and Dütschke, 2014 model

\begin{tabular}{|c|c|}
\hline $\begin{array}{l}\text { Model category (from Peters \& } \\
\text { Dütschke, 2014) }\end{array}$ & $\begin{array}{l}\text { Trends in the literature } \\
\text { Phrasing is edited to articulate the essence of the question }\end{array}$ \\
\hline \multicolumn{2}{|l|}{ Relative advantages } \\
\hline Fuel economics & $\begin{array}{l}\text { In qualitative interviews, a response included that PHEVs can be } \\
\text { interpreted as a useful way to save money and avoid trips to the gas } \\
\text { station (Axsen \& Kurani, 2012) } \\
\text { The fuel economy associated with an HEV was a factor a focus group } \\
\text { considered to save money (Flamm \& Agrawal, 2012) } \\
\text { Public awareness of a low-carbon fuel standard is low, but general } \\
\text { support can persist in areas of intensive fossil fuel extraction if explained } \\
\text { (Rhodes } \text { et al., 2015) }\end{array}$ \\
\hline Battery range & $\begin{array}{l}\text { Empirical studies indicate that battery range is a persisting concern } \\
\text { preventing adoption amongst non-EV owners (Hidrue et al., 2011; Pierre } \\
\text { et al., 2011; Egbue \& Long, 2012; Larson et al., 2014; Axsen et al., } \\
\text { 2017; Matthews et al., 2017) } \\
\text { The hybrid model can alleviate concerns of 'range anxiety' amongst } \\
\text { prospective users (Tamor et al., 2013; Axsen et al., 2015; Axsen et al., } \\
\text { 2016) }\end{array}$ \\
\hline Maintenance and repair costs & $\begin{array}{l}\text { There is recognition that EV drivers can profit from the lower costs of } \\
\text { maintenance (Cardoso et al., 2014; Stokes et al., 2014; Yavuz et al., } \\
\text { 2015; Hagman et al., 2016) } \\
\text { Repair costs were perceived to be minimal throughout the EV buyers } \\
\text { experience (Graham et al., 2014; Wagner, 2017) }\end{array}$ \\
\hline \multicolumn{2}{|l|}{ Compatibility } \\
\hline Environmental sensitivity & $\begin{array}{l}\text { Drivers of EVs are inclined (in some cases more than an average } \\
\text { population) to believe climate change is a present day threat compared to } \\
\text { average populations (Axsen \& Kurani, 2012; Krause et al., 2016; } \\
\text { Mohamed et al., 2016; Silvia \& Krause, 2016; Axsen et al., 2017; } \\
\text { Degirmenci \& Breitner, 2017) }\end{array}$ \\
\hline Perception of supply mix options & $\begin{array}{l}\text { Canadians are not overly concerned with energy in terms of other social } \\
\text { and economic issues the population is faced with (Eisler, 2016) } \\
\text { North Americans remain generally uneducated or misinformed about } \\
\text { energy issues (DeWaters et al., 2013; Knox-Hayes et al., 2013; } \\
\text { Stoutenborough \& Vedlitz, 2016) }\end{array}$ \\
\hline \multicolumn{2}{|r|}{ (2) } \\
\hline $\begin{array}{l}\text { Perceived knowledge regarding } \\
\text { technology }\end{array}$ & $\begin{array}{l}\text { Public knowledge regarding EVs is generally lackluster (Krause et al., } \\
\text { 2013; Larson et al., 2014; Dumortier } \text { et al., 2015; Haddadian et al., 2015; } \\
\text { Krause } \text { et al., 2016) } \\
\text { EV prospective buyers have become skeptical of dealerships (lack of } \\
\text { knowledge and expertise) and as a result of have utilized an online } \\
\text { medium in some cases for research (Bohnsack et al., 2014; Larson et al., } \\
\text { 2014; Matthews et al., 2017) }\end{array}$ \\
\hline $\begin{array}{l}\text { Perceived knowledge regarding } \\
\text { incentive programs }\end{array}$ & $\begin{array}{l}\text { North Americans are generally unaware of the incentives available to } \\
\text { them for EV purchase (Mahlia et al., 2013; Larson et al., 2014; Naor et } \\
\text { al., 2015; Matthews et al., 2017) }\end{array}$ \\
\hline
\end{tabular}

Trialability 
Test drive

\section{Observability}

Inquiry prior to purchase

Social norm

Introduction in network
There is great difficulty in ensuring a dealership has available EV makes and models for test drive (Bohnsack et al., 2014; Chen \& Midler, 2016; Matthews et al., 2017)

The literature is not conclusive on purchase-making decision processes, and is assumed to be mixed of those seeking traditional mediums (dealership and test drive) and newer alternatives (online search) (Hardman et al., 2017; Matthews et al., 2017; Wolinetz \& Axsen, 2017)

One's social network can be influential in increasing the likelihood of those who have directly witnessed or tried the car to eventually adopt an EV (Al-Alawi \& Bradley, 2013; Axsen et al., 2013; Green et al., 2014; Rasouli \& Timmermans, 2016; Adepetu \& Keshav, 2017; Pettifor et al., 2017) 


\section{Chapter 3 Methodology}

This chapter discusses the methods used to meet the objectives of the research study. The survey was hosted by Plug'n Drive, a non-for-profit aimed at accelerating the rate of EV adoption in Canada. Plug'n Drive retains full ownership of the data and this research is meant to act as a supplement to evaluate perception in the GTHA in an exploratory manner to contribute to the research being conducted in this sector. The organization formed an advisory committee team with experts in the automotive, utilities, environmental non-governmental organization (ENGO), and public sectors to facilitate feedback on the survey format and provide commentary on the results. The survey questionnaire was designed so that outputs could reflect both the mandate and intentions of Plug'n Drive as well as for this research project. Previous literature (theoretical frameworks) was consulted to develop the survey format and all questions were vetted by the team responsible for administering the survey. All individuals involved in the advisory committee volunteered their time throughout this process. The views and recommendations expressed in this thesis do not necessarily reflect those of the organization and its affiliates. Rather, this is an interpretation of the results of Plug'n Drive's survey in the context of the broader trends in the current state of research.

\subsection{Case study}

Case study research in this study was performed involving quantitative methods. Research that utilizes case studies can contribute to knowledge in a variety of ways. The implementation of case study research is encouraged when the focus is on a contemporary phenomenon existing in a real-life context (Yin, 2013). Exploratory case study research is typically applied when researchers opt to investigate situations where the phenomena have no to little clear and singular sets of outcomes (ibid.). The case of this research becomes the use of 
EVs in the GTHA to highlight a Canadian urban case study which can inform other interested regions in Canada, or developed countries more broadly. This interpretation of the GTHA is meant by the six jurisdictions in colour in the image below (City of Hamilton, Region of Halton, Region of Peel, City of Toronto, Region of York, and Region of Durham).

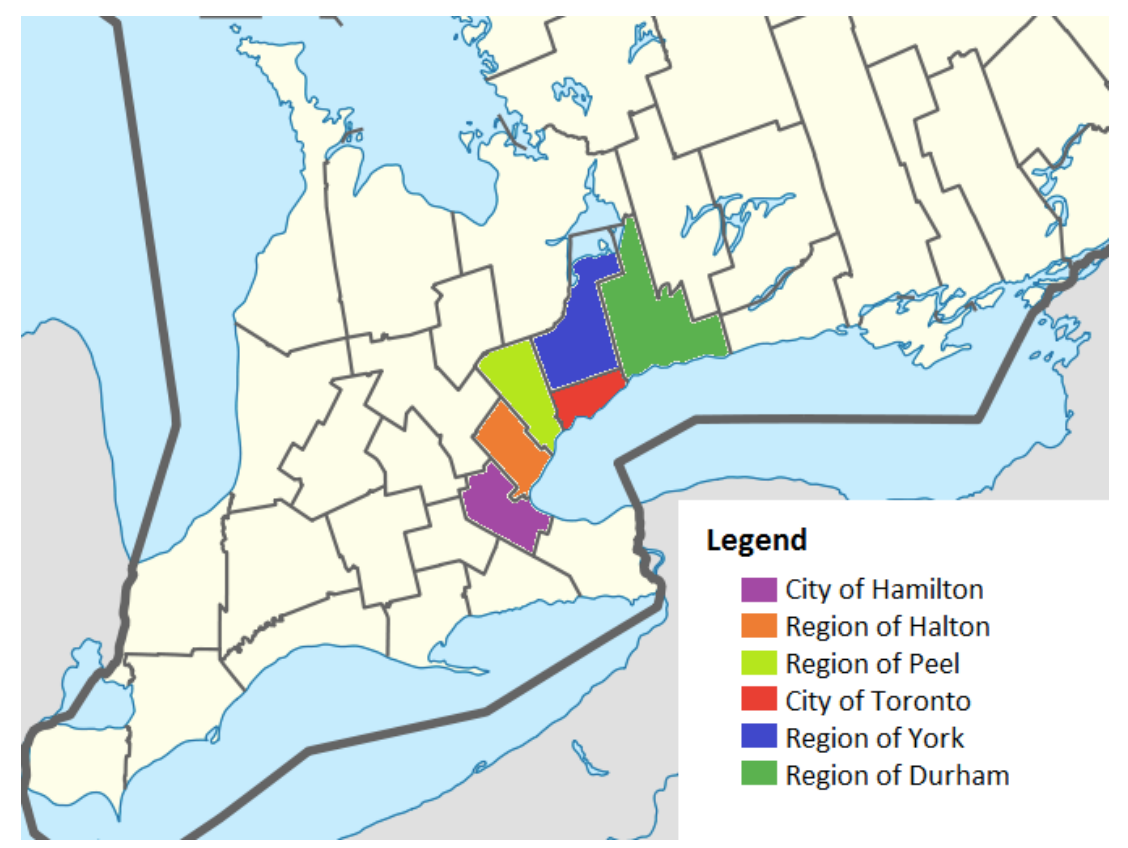

Source: https://upload.wikimedia.org/wikipedia/commons/3/3a/GTHA_map.png Image labeled for reuse from the Wikimedia Commons

This study adopts a case study methodology to answer the initial research question:

"What are the specific drivers of consumer intent to purchase an EV as a next vehicle?" The research uses the GTHA as geographic location to provide insight through the adoption of Peters and Dütschke's (2014) model on intention and usage of an EV. The expectation is that EVs will eventually achieve strong uptake soon in Canada, especially in the country's metropolitan areas given the recent uptake per annum (Schmidt, 2017). Yet, the literature indicates that EV success has been attributed to a variety of factors outside of citizenry environmental consciousness (Axsen \& Kurani, 2012; Axsen et al., 2017). 
The online survey was designed to query both gasoline- and diesel-vehicle owners as well as existing EV owners regarding their attitudes and perceptions towards EVs. The web is a useful medium of implementing surveys as it enables visual aids, automates the user experience and collection of data, and expedites the data for an easier analysis (Zheng, 2000; Berrens et al., 2004; Smyth et al., 2010). There is a possible limitation that the technologically-savvy nature of participants acquired from an online medium may influence the results of this survey, but given the economic means necessary to own or lease a vehicle, this factor is understood as a minimal influence (Evans \& Mathur, 2005). Surveys conducted over the internet through a secure platform allow for perhaps greater confidentiality in comparison to paper surveys or interviewadministered surveys (Ahern, 2005; Coutts \& Jann, 2011).

Figure 7 provides an overview of the questions and corresponding ordering invoked in this study. The initial queries of the survey screened respondents to make sure they fit the criteria of the study as well as categorize eligible participants based on the vehicle type that the individual owns or leases. Participants must be of legal driving age, possess a valid driver's license, own or lease at least one vehicle, possess residency in the GTHA, and be willing to complete the survey in order to proceed in the survey. As indicated in Figure 7, all participants were queried on the same topics including vehicle interactions, driving patterns, vehicle commitment, considerations for purchase decision-making, satisfaction of EV drivers, environmental considerations, provincial incentive programs, and use of transit systems. The areas of questions in the survey were designed with influence previous studies, using frequently repeated queries in similar literature with slight variation to conform with the policy trends of Ontario (Peters \& Dütschke, 2014). 


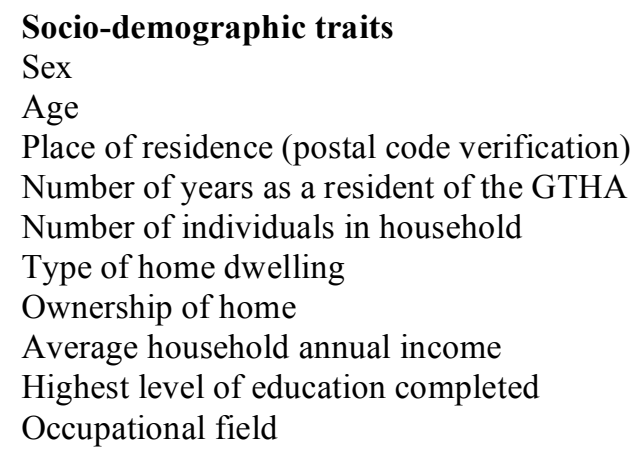

\section{Driving patterns}

Frequency of vehicle usage for work commutes

Estimation of driven kilometers per day for work commutes

Frequency in which work functions requires vehicle travel

Estimation of driven kilometers per day for work functions

Frequency of vehicle usage to transport dependents

Estimation of driven kilometers per day to transport dependents

Frequency of vehicle usage on weekends

Estimation of driven kilometers per dav on weekends

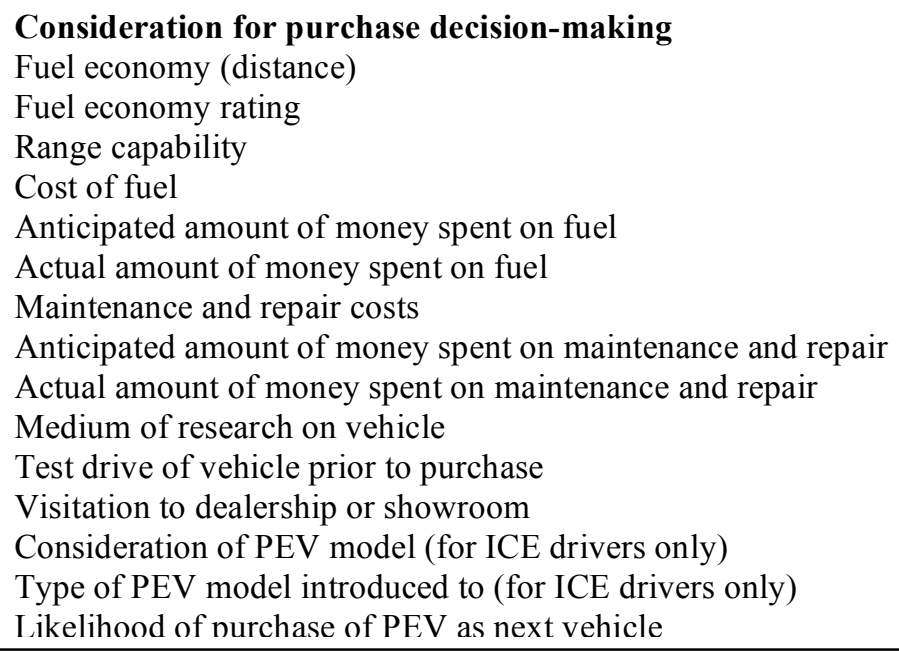




\section{Satisfaction of EV drivers}

Ability to travel adequate distance on a single charge

Ability to connect to electrical wall outlets

Ability to understand charging patterns of the vehicle

Noise levels

Affordability for average Canadian to possess an EV

Affordability for average Canadian to install a charging station

Ability to help a household save money on fuel costs

Ability to help a household save money on maintenance costs

Performance of the vehicle in colder weather conditions

Time until a full charge is complete

Availability and accessibility of public charging infrastructure

Methods to come to a decision about purchase

Perceived knowledge of EV sales staff regarding EVs

Usage of peak and non-peak electricity times to reduce rates

Ability to drive on the highway

\section{Environmental attitudes}

Human activity contributes to climate change

Transportation as exacerbating the impacts of climate change

Electrification of cars to reduce impacts of climate change

Perception towards energy and/or electricity supply mix options

Level of concern towards GHG emissions in the GTHA

Level of concern towards air quality in the GTHA

Personal responsibility to mitigate global climate change

Perceived knowledge pertaining to 'alternative vehicles'

\section{Provincial incentive programs}

Awareness of Ontario's incentives for PEV purchase

Awareness of Ontario's incentives to purchase charging station

Awareness of Ontario's incentives to install charging station

Utilization of Ontario's incentives programs (rebate)

Utilization of an external provincial/state incentive program

Estimation of value received from incentive programs

\section{Use of transit systems}

Frequency of ridership on public transit services

Amongst the areas being queried are the six factors in the Peters and Dütschke model [Figure 4]

to determine intention to purchase and use an EV [Figure 8]. While the majority of model

categories had multiple questions that were relevant to the objective, the key query was

identified in order to demonstrate the relationship amongst covariates. All queries pertaining to

each category that will later be elucidated in the results are illustrated in Table 4. 


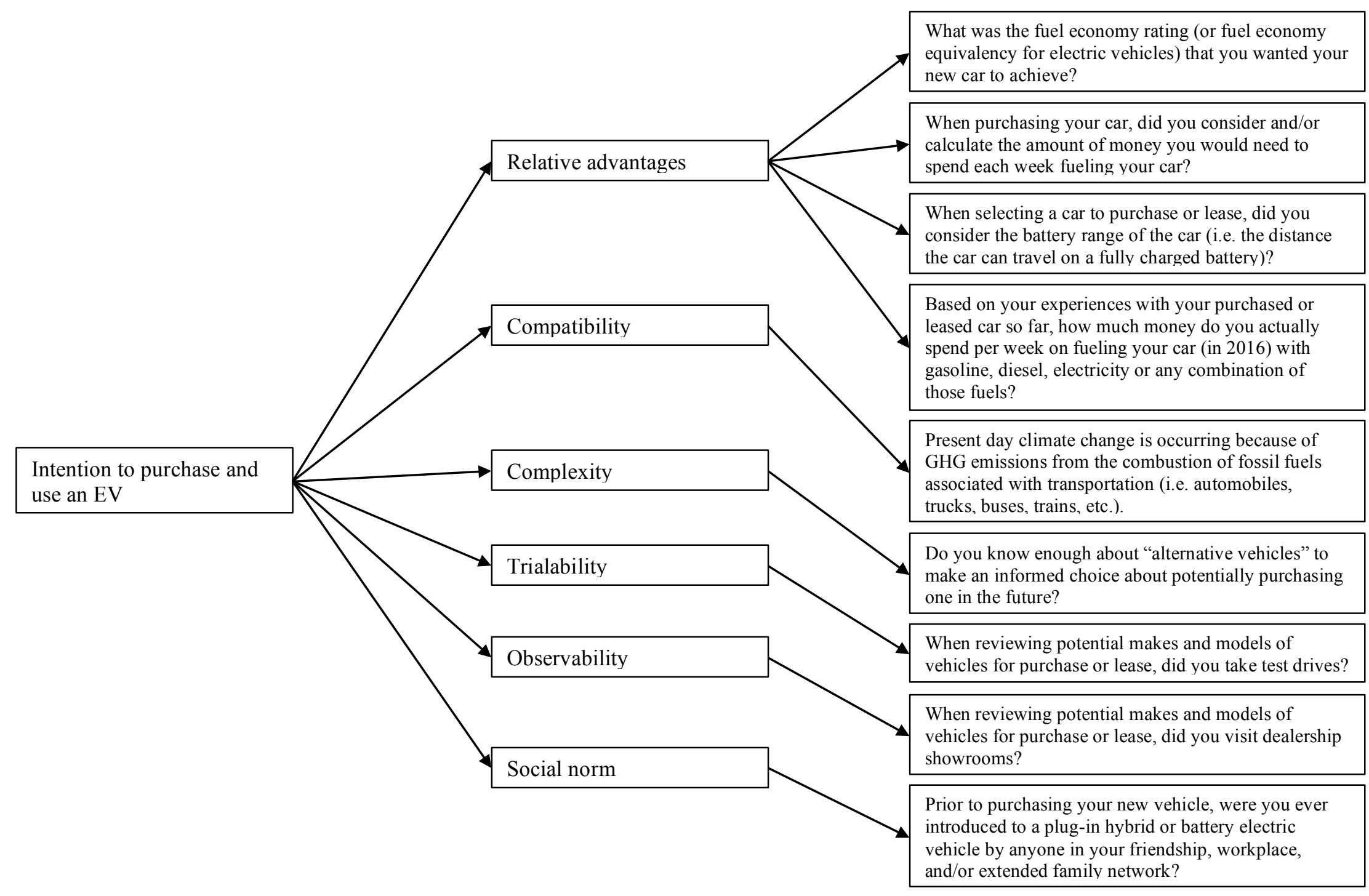


Table 5: Survey questions to provide insight to model

\begin{tabular}{ll}
\hline $\begin{array}{l}\text { Model category (from Peters \& } \\
\text { Dütschke, 2014) }\end{array}$ & $\begin{array}{l}\text { Query } \\
\text { Phrasing is edited to articulate the essence of the question }\end{array}$ \\
\hline $\begin{array}{l}\text { Relative advantages } \\
\text { Fuel economics }\end{array}$ & $\begin{array}{l}\text { Did you consider the fuel economy prior to purchasing your vehicle? } \\
\text { What is the total amount of money you assume to have spent fueling } \\
\text { your vehicle? } \\
\text { Do you believe that an EV can help a household save money on fuel } \\
\text { costs compared to a gasoline or diesel car? }\end{array}$ \\
$\begin{array}{l}\text { Do you believe that EVs can travel more than } 150 \text { kilometers on a single } \\
\text { battery charge even if the air conditioning or heating system is turned }\end{array}$ \\
on? \\
$\begin{array}{l}\text { Are you satisfied with the distance your EV can travel based on a fully } \\
\text { charged battery? }\end{array}$ \\
$\begin{array}{l}\text { Did you consider the maintenance costs prior to purchasing your } \\
\text { vehicle? }\end{array}$ \\
$\begin{array}{l}\text { How much did you assume you would spend on the cost of maintenance } \\
\text { for your vehicle? }\end{array}$ \\
$\begin{array}{l}\text { How much did you actually spend on the cost of maintenance for your } \\
\text { vehicle? }\end{array}$
\end{tabular}

\section{Compatibility}

Environmental sensitivity

Perception of supply mix options

\section{Complexity}

Perceived knowledge regarding technology

Perceived knowledge regarding incentive programs

\section{Trialability \\ Test drive}

\section{Observability \\ Inquiry prior to purchase}

\section{Social norm}

Introduction in network
Do you believe that present day climate change is occurring because of GHG emissions from the combustion of fossil fuels associated with transportation?

Do you believe that the use of an automobile has a negative effect on the environment?

Do you believe that switching the majority of the world's transportation systems to PEVs would help stop climate change at a global level?

Do you believe that you have a personal role to play in stopping global climate change?

Which of the following supply mix options to you believe should be categorized as a 'fossil fuel'?

Do you believe that you possess enough knowledge about "alternative vehicles" to make an informed choice for potential future purchase? Do you believe that you found sufficient information about EVs online?

Do you believe that you were more knowledgeable than the sales staff at dealerships?

Are you aware of Ontario's provincial incentives for PHEV and BEV purchases?

Are you aware of Ontario's provincial incentives for electric vehicle supply equipment purchases?

Are you aware of Ontario's provincial incentives for electric vehicle supply equipment installation?

Did you complete a test drive amongst potential makes and models considered for purchase?

Have you test driven an electric vehicle?

How did you review potential makes and models of vehicles for purchase or lease?

Did you consider a PHEV or BEV as a result of anyone in your social network? 
Were you ever introduced to a PHEV or BEV by anyone in your social network?

A single survey was created using skip logic functions for both the EV and ICE driving participants. Prior to the release of the final survey in the summer of 2016, two beta test iterations of the survey were completed by select individuals who volunteered to participate and provide feedback over a secure network. Feedback of the initial two beta tests helped ensure the language and phrasing of questions and definitions were both applicable and easy for respondents to understand. Initially, the survey asks participants for their city or town of residency, and this is again confirmed through the forward sortation area alpha-numeric components of one's Canadian postal code to better ensure they live in the GTHA. The survey queried for information regarding demographics, vehicle ownership, attitudes towards environmental issues, EV knowledge, and lifestyle habits. The survey was designed to take 1520 minutes to complete, and those who did not complete the survey to the final question were excluded from the final results. Nonetheless, all non-mandatory questions provided options to not answer the question (including either a skip function or an unsure option). It is recognized that this is imperative as some of the information being requested is of a sensitive nature (e.g. income).

\subsection{Participant acquisition}

The online survey was distributed to PEV owners $(n=192)$ and ICE vehicle owners $(n=$ 1,000) within the GTHA. All participants were provided with a secure link to complete the survey through the email they provided to opt into the survey. Participants were acquired from 49 municipalities within the GTHA, allowing for fair representation across the region. This method improved the likelihood that an individual respondent would only complete one iteration of the survey through a more formalized registration process. No incentives were provided for 
participation by the organization or research team. Therefore, all respondents were individuals pre-registered with their consent willing to complete the survey.

\subsubsection{PEV drivers}

The PEV driving population of the GTHA is assumed to represent less than one per cent of the total driving population (Statistics Canada, 2016; Schmidt, 2017). Therefore, the database of Plug'n Drive's EV Owners Club of Canada group, a digital network designed to connect EV owners and share relevant updates, was utilized to acquire participation and raise awareness about this initiative. Self-declared EV owners were contacted and asked to send a message to a designated survey-specific secure email with their preferred email address if they were an EV driver living in the GTHA interested in participating in the survey. The initial response rate was comprised of approximately 150 eligible participants. In the hopes of expanding the survey population group, additional private owners' clubs in the area were contacted, mainly through targeted social media platforms. Given that the EV driving community is niche and limited in numbers, there were relatively high response rates amongst these networks (although the exact number cannot be certain due to widespread advertising). This informs that EV drivers may be proud of their decision to purchase their car, and are willing to complete the survey without incentive. More participants were acquired when Plug'n Drive hosted an EV Owners Day to promote and celebrate electric vehicles. All participants of the survey were informed of the purpose and objective of this survey and self-identified themselves as willing to take part in completing a survey. The assumption is that because specific groups were targeted in prospective respondents seek out, these may be individuals particularly dedicated to the EV community, however there was no other possible way to seek out a sample set for such specific qualifications. 


\subsubsection{ICE drivers}

The ICE driving population was recruited by Research Now, an online market research company with an internal participant pool. Research Now participants are from three in-house programs, which are recruited from global online publishers and hundreds of websites as well as online communities. Research Now was commissioned by Plug'n Drive and the research team to distribute the survey to the ICE driving population, as this would ensure greater participation rates than the research team attempting this individually. As well, outsourcing the recruitment of the non-owners' population to a large database ensured that the sample size was more random than if the researchers targeted individual test takers within their own networks or distribution channels. While no direct incentives were offered by the research team, Research Now offers a point system for participants who complete the survey amongst their own internal database. Any compensation provided for participation was not directly provided by the researchers.

\subsection{Limitations}

There are identified limitations in the preparation and execution of this study. Data was collected through an internet survey, which limits the sample to those who have access to a computer and internet, as well as possess the competency to complete a survey through an online platform. The PEV driver sample likely possess an overrepresentation in Toronto (17 per cent), as a result of the host organization and research team being based in that city for the duration of the recruitment process. Given the limited number of EV drivers, the research team and advisory committee did invite personal contacts in their networks who were known to drive an EV. In addition, EV drivers were contacted at events and through known networks designed to foster an EV community. Therefore, it can be assumed that there is somewhat of a bias in that the individuals participating in the survey may be more willing to share their positive attributions 
towards EVs more so than a general population given they are a part of groups aimed at accelerating the adoption of EVs. In addition, the application of the model used was exclusively designed for non-EV drivers, yet given the compelling findings from Axsen et al. (2015) and Axsen et al. (2016) in a Canadian context, there was a concerted effort to adapt the existing Peters and Dütschke (2014) model to include current EV drivers. As a result, the interpretation of the categories imposed by this study to understand intention to purchase and use an EV from current EV drivers may be subject to critique given this novel approach. The model also does not account for many governance and policy issues, and therefore some areas (i.e. knowledge of changing incentives, regulations) cannot be adequately addressed to exclusively querying the individual's reaction to the vehicle. Therefore, the importance of these broader themes were recognized theoretically but not entirely examined empirically.

The survey asked participants to self-report their behaviour, often through estimating consumption of financial information per year. This study therefore suggests that participants will accurately report such data, and are always remaining honest. That being said, the purpose of this study is focused on perception, which acknowledges that information may not always be accurate but rather the intent is to understand how people perceive their own actions.

\subsection{Data analysis}

The way in which data from this survey will be analyzed varies as a result of the specific area being queried. When assessing basic socio-demographic and single variables, the results of all participants who answered that question will be available. The majority of the sociodemographic questions will provide a full data set because the question was mandatory in order to proceed in the digital survey. However, when assessing the relationships between variables to build on the aforementioned model, the results will account for participants who completed every 
selected question to drive the model. In this case, the options for 'no response' or 'not sure' (or other non-descriptive options) were eliminated in a data clean-up. As a result, the minimum possible response based on the original 1,000 ICE drivers is reduced to $(n=563)$ and the $192 \mathrm{EV}$ drivers is reduced to $(n=144)$ for a combined total of $(n=707)$ participants. However, when correlations are being assessed between two variables, the maximum number of responses (the number of participants who gave descriptive answers for both queries) will be used to evaluate the relationship. Once the data was acquired from Research Now in a spreadsheet format, an analysis was run on IBM Statistical Package for Social Science (SPSS) for nonparametric correlations (bivariate correlations and multivariate ordinal regression) to assess the initial research question: what are the specific drivers of consumer intent to purchase an $\mathrm{EV}$ in the GTHA as a next vehicle. Utilizing a regression analysis has been common practice in previous EV studies accounting for socio-economic influences that may lead to purchase (Franke et al., 2012; Axsen et al., 2013; Franke \& Krems, 2013; Sierzchula et al., 2014) Amongst the larger survey, certain relevant indicators were selected to determine and categorize results based on existing EV drivers (to measure the likelihood of re-purchase and satisfaction) and ICE drivers (to measure likelihood of purchase and barriers to adoption). Bivariate correlations modelling was completed with a dependent variable accounted for, which was the likelihood to purchase an EV (regardless of if the individual has ever driven an EV prior to). Ordinal scale questions were used in order to assess not only the preferences of participants, but also the degree in which those variables accounted for correlation to the dependent variable. Therefore, a Spearman's rho test was implemented as the variables under consideration were measured on an ordinal (rank order) scale. Spearman's rho builds on the regular Pearson product moment correlation coefficient test to account for ranked preferences (Magliocca, 2012). Once the data 
was extracted, statistically significant relationships were highlighted to illustrate which covariates could influence the model and form predictive measures to better guide future EV policy decision-making. 


\section{Chapter $4 \quad$ Results and Discussion}

This chapter analyzes the user preferential data collected with the online survey as described in the previous chapter through selected correlative measures. The content details the sample population's attitudes and perceptions towards the technology, in an attempt to speak to trends from the residents of the GTHA more broadly. The results are presented and contrasted to the current state of knowledge from the literature and relevant regional environmental and EV policy. The decision to combine the results and discussion together was made to draw clear parallels between the findings and the specific research questions and hypotheses gathered from the literature review.

\subsection{Sampling strategy}

The act of sampling is particularly challenging when addressing issues of choice analysis and modelling (Hensher et al., 2005). While simple random sampling techniques are generally preferred in research, in the case of measuring the lived experiences of the early adopters of emerging technologies such as an EV, the market share of ownership is truncated, making such an endeavor extremely challenging. As of March 2017, there is believed to be 10,385 PEVs in Ontario, which is representative of less than one per cent of total registered vehicles in the province as of the end of 2016 (Statistics Canada, 2016; Schmidt, 2017). Therefore, if a random sample method was enforced in this instance, the odds of targeting even one PEV owner would be extremely unlikely. As a result, targeted efforts were utilized as described in Section 3.3.1 to acquire the representation necessary to adequately address the perception of EV drivers in the GTHA.

Of the entire sample set (both ICE and EV drivers), the margin of error was $-/+2.8$ with a percentage of 50 per cent and confidence interval of 95 per cent. This includes the consideration 
of 1,000 ICE drivers and 192 EV drivers. However, although 1,192 individuals were surveyed, those who did not answer the specific queries of interest with definitive responses were eliminated in the modelling exercise. Upon the data clean-up there were $141 \mathrm{EV}$ drivers and 563 ICE drivers who completed the survey in its entirety, which leaves a maximum of $50 \mathrm{EV}$ drivers and 293 ICE drivers that could have been eliminated dependent on the relationship being evaluated. Nonetheless, in the case of the maximum number of participants being eliminated from the data set, confidence intervals remained significant despite the elimination of surveys that were either incomplete or articulated uncertainty in their answer. In the scenario of the maximum number of responses being eliminated, the updated confidence interval is $-/+3.7$ for ICE drivers and -/+ 8.2 for EV drivers with a percentage of 50 . 
Table 6: Socio-demographic information of survey participants

\begin{tabular}{|c|c|c|c|c|}
\hline \multirow{2}{*}{$\begin{array}{l}\text { Information } \\
\text { Total sample size }\end{array}$} & EV drivers & \multicolumn{2}{|c|}{ ICE drivers } & \\
\hline & 192 & & 1,000 & \\
\hline \multicolumn{5}{|l|}{ Sex } \\
\hline Woman & 58 & $30 \%$ & 497 & $50 \%$ \\
\hline Man & 134 & $70 \%$ & 499 & $50 \%$ \\
\hline Transgendered & 0 & & 2 & $(>1 \%)$ \\
\hline Other & 0 & & 1 & $(>1 \%)$ \\
\hline Not sure & 0 & & 0 & \\
\hline No response & 0 & & 1 & $(>1 \%)$ \\
\hline \multicolumn{5}{|l|}{ Age } \\
\hline $18-29$ & 33 & $17 \%$ & 210 & $21 \%$ \\
\hline $30-39$ & 54 & $28 \%$ & 180 & $18 \%$ \\
\hline $40-49$ & 39 & $20 \%$ & 200 & $20 \%$ \\
\hline $50-59$ & 39 & $20 \%$ & 180 & $18 \%$ \\
\hline $60-69$ & 19 & $10 \%$ & 176 & $18 \%$ \\
\hline $70-79$ & 7 & $4 \%$ & 49 & $5 \%$ \\
\hline $80+$ & 1 & $>1 \%$ & 5 & $>1 \%$ \\
\hline \multicolumn{5}{|l|}{ Time lived in GTHA } \\
\hline Less than 1 year & 4 & $2 \%$ & 7 & $(>1 \%)$ \\
\hline Between 1 and 5 years & 25 & $13 \%$ & 56 & $6 \%$ \\
\hline Between 5 and 10 years & 22 & $11 \%$ & 92 & $9 \%$ \\
\hline Between 10 and 20 years & 32 & $17 \%$ & 176 & $18 \%$ \\
\hline More than 20 years & 109 & $57 \%$ & 669 & $67 \%$ \\
\hline \multicolumn{5}{|l|}{ Number of residents per home } \\
\hline 1 & 23 & $12 \%$ & 175 & $18 \%$ \\
\hline 2 & 52 & $27 \%$ & 352 & $35 \%$ \\
\hline 3 & 51 & $27 \%$ & 211 & $21 \%$ \\
\hline 4 & 49 & $25 \%$ & 170 & $17 \%$ \\
\hline 5 & 11 & $5 \%$ & 68 & $7 \%$ \\
\hline $6+$ & 6 & $3 \%$ & 24 & $2 \%$ \\
\hline \multicolumn{5}{|l|}{ Home type } \\
\hline House & 160 & $83 \%$ & 659 & $66 \%$ \\
\hline Condo building (or town house) & 21 & $11 \%$ & 231 & $23 \%$ \\
\hline Apartment building & 10 & $5 \%$ & 105 & $11 \%$ \\
\hline Another type or dwelling & 1 & $>1 \%$ & 5 & $>1 \%$ \\
\hline \multicolumn{5}{|l|}{ Residence ownership } \\
\hline Owned & 164 & $85 \%$ & 767 & $77 \%$ \\
\hline Rented & 25 & $13 \%$ & 217 & $22 \%$ \\
\hline \multicolumn{5}{|l|}{ Household average yearly income } \\
\hline Less than $\$ 40,000$ per year & 7 & $4 \%$ & 95 & $10 \%$ \\
\hline$\$ 40,001-\$ 60,000$ per year & 21 & $11 \%$ & 147 & $15 \%$ \\
\hline$\$ 60,001-\$ 80,000$ per year & 26 & $14 \%$ & 169 & $17 \%$ \\
\hline$\$ 80,001-\$ 100,000$ per year & 19 & $10 \%$ & 144 & $14 \%$ \\
\hline$\$ 100,001-\$ 120,000$ per year & 14 & $7 \%$ & 111 & $11 \%$ \\
\hline$\$ 120,001-\$ 140,000$ per year & 17 & $9 \%$ & 60 & $6 \%$ \\
\hline$\$ 140,001-\$ 160,000$ per year & 16 & $8 \%$ & 60 & $6 \%$ \\
\hline$\$ 160,001-\$ 180,000$ per year & 10 & $5 \%$ & 26 & $3 \%$ \\
\hline$\$ 180,001-\$ 200,000$ per year & 14 & $7 \%$ & 28 & $3 \%$ \\
\hline More than $\$ 200,000$ per year & 32 & $17 \%$ & 49 & $5 \%$ \\
\hline Not sure & 3 & $2 \%$ & 30 & $3 \%$ \\
\hline No response & 12 & $6 \%$ & 81 & $8 \%$ \\
\hline \multicolumn{5}{|l|}{ Highest level of education completed } \\
\hline No high school diploma & 1 & $>1 \%$ & 14 & $1 \%$ \\
\hline High school diploma & 14 & $7 \%$ & 141 & $14 \%$ \\
\hline Trade certificate & 13 & $7 \%$ & 64 & $6 \%$ \\
\hline $\begin{array}{l}\text { University undergraduate degree or similar } \\
\text { college degree }\end{array}$ & 82 & $43 \%$ & 472 & $47 \%$ \\
\hline $\begin{array}{l}\text { Graduate degree or professional graduate } \\
\text { degree }\end{array}$ & 76 & $40 \%$ & 279 & $28 \%$ \\
\hline Other & 5 & $3 \%$ & 25 & $3 \%$ \\
\hline No response & 1 & $>1 \%$ & 5 & $>1 \%$ \\
\hline
\end{tabular}


The survey responses assert that the current owners of EVs are a rather homogenous group, which in large part conforms to findings in the literature (Savacool, 2009; Campbell et al., 2012; Peters \& Dütschke, 2014; Kawgan-Kagan, 2015; Mohamed et al., 2016). Over two-thirds of the existing EV driving community in the GTHA are men. The EV owners portion of the survey was not limited to a single participant from a dwelling, and the concept of 'driver' was therefore interpreted by the user, and in many cases as evidenced by certain queries of the study, men completed the survey who live in a home dwelling of two or more perhaps on behalf of other potentially eligible survey participants. This perhaps speaks to the idea that men are more likely to attribute themselves as the spokesperson for the vehicle. The relationship between women and the automotive sector has always been strained, as a result of a systemic lack of access for women to necessary technical training and employment as well as from the impacts of sex-role stereotyping in the sector and financial inequities (Cockburn, 1983; Wajcman, 1991; Grint \& Gill, 1995; Gjøen \& Hård, 2002). Furthermore, the automotive industry has been found to use women as sexualized symbols to improve sales of vehicles thereby associating gender norms to rising or declining technologies, which includes the immediate feminization of the early EV models (Daniels, 2009; Ranga \& Etzkowitz, 2010; Burgess et al., 2013).

Over 80 per cent of EV owners in this survey articulated they have a post-secondary degree, and approximately half of that population has a graduate or professional level of education, which for the purposes of this survey was addressed as a graduate or professional degree beyond an undergraduate education. Over half of EV owners make over $\$ 100,000$ per annum, while nearly 20 per cent of the overall sample group make over $\$ 200,000$ per annum. EV owners are disproportionately more wealthy and educated than their ICE driving counterparts, which is similar to what has been presented in Canadian literature to date (Axsen et al., 2015; 
Axsen et al., 2016). As well, research suggests that higher income earners in Canada are more likely to be supportive of environmental initiatives such as low-carbon fuel standards (Rhodes et al., 2015; Smith et al., 2017).

The EV owning cohort is also more likely to live in a detached single-dwelling house, as opposed to a condo or an apartment. This trend is likely in some part attributed to the challenges of owning a home charging station in parking areas without dedicated space and/or individual ownership of such space. This finding supports the commentary of the North American literature on barriers for EV drivers residing in condos (Hidrue et al., 2011; Higgins et al., 2017). In addition, EV owners are more likely to have a greater number of people living in their homes compared to ICE drivers. Yet, the owners of ICE vehicles have spent greater amounts of time living in the GTHA, compared to their EV driving counterparts. The basic socio-demographic findings did not deviate much from the commentary of the limited volume of literature available. EV drivers in the GTHA are predominately young-to-middle aged men who are highly educated and high income earners living in detached houses with additional residents.

Figure 9 indicates the occupational sectors of survey respondents. Over half of the EV driving community works in the engineering or technical field, and this has not been explored in existing literature to date. The second greatest representation of 19 per cent was EV drivers working in business, finance, and the administrative sector. However, amongst ICE drivers, the distribution of jobs was more dispersed, with 17 per cent indicating they are retired and 16 per cent indicating they work in business, finance, and administration. The significance of the most amount of ICE driving respondents being retirees puts forward the possibility that innovative technology is perhaps more strongly received from young professional crowds. 
Figure 9: Occupations of survey respondents

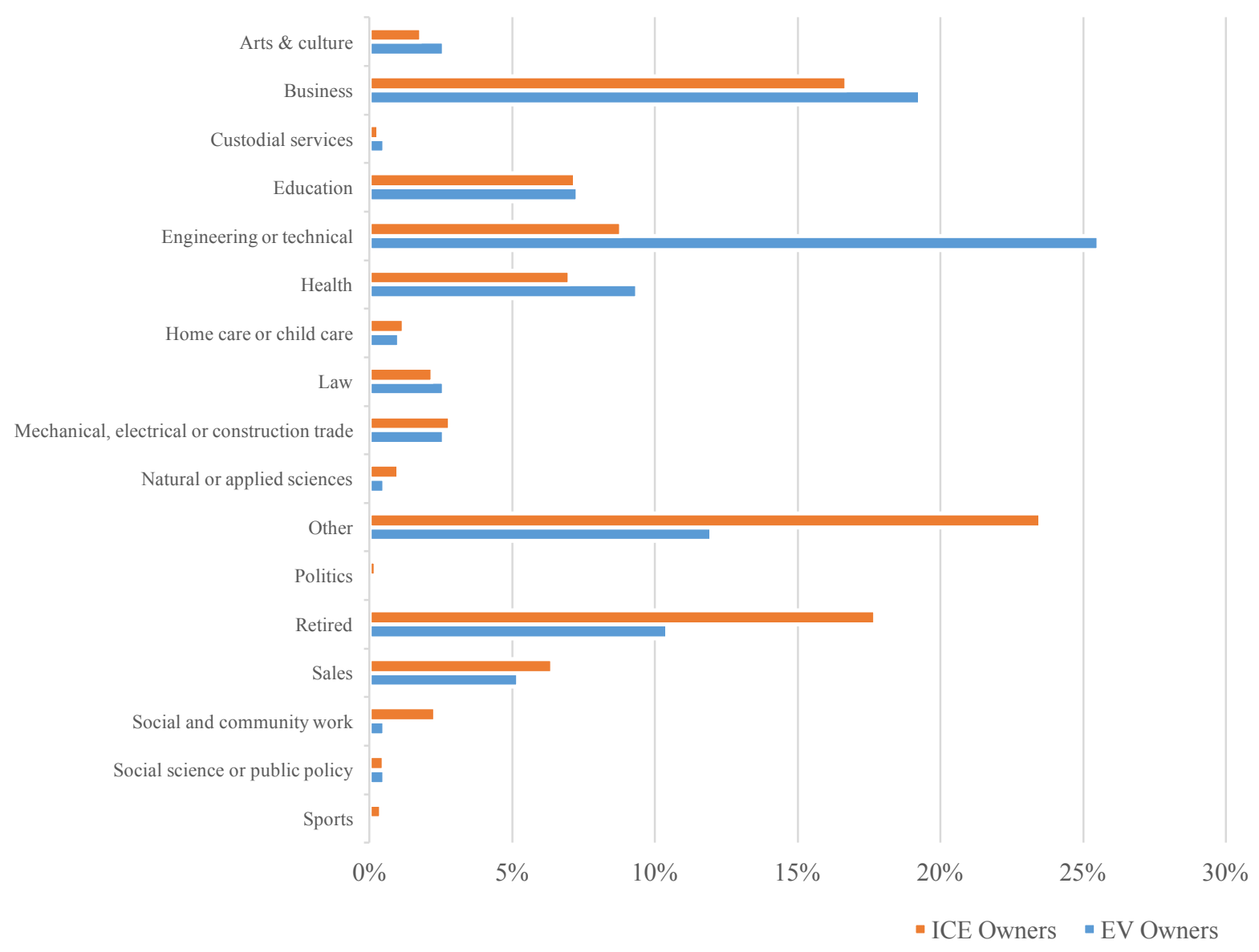

The digital survey verified postal codes to determine the city in which participants resided in. The majority of EV owners in the GTHA live in Toronto (17 per cent), North York (13 per cent), Mississauga (10 per cent), Brampton ( 5 per cent), and Etobicoke ( 5 per cent), thus making the total more representated in the Toronto area and less so in and nearby Hamilton. All of the aforementioned areas are in or surround the downtown core of Toronto and are particularly urban-oriented compared to the more suburban or rural parts of the region with less EV representation. This finding is consistent with research suggesting EVs will more likely gain public traction in urban environments (Al-Alawi \& Bradley, 2013; Sierzchula et al., 2014). The 
ICE owners had fewer cities or towns with high concentrations when their proportions in the sample size were contrasted with the region's actual populations.

Figure 10 indicates that EV drivers typically own a greater number of vehicles (that may also include gasoline- or diesel-options) than ICE drivers on average, particularly when considering the number of participants also in possession of three or four vehicles.

Figure 10: Number of vehicles owned or leased by survey participants

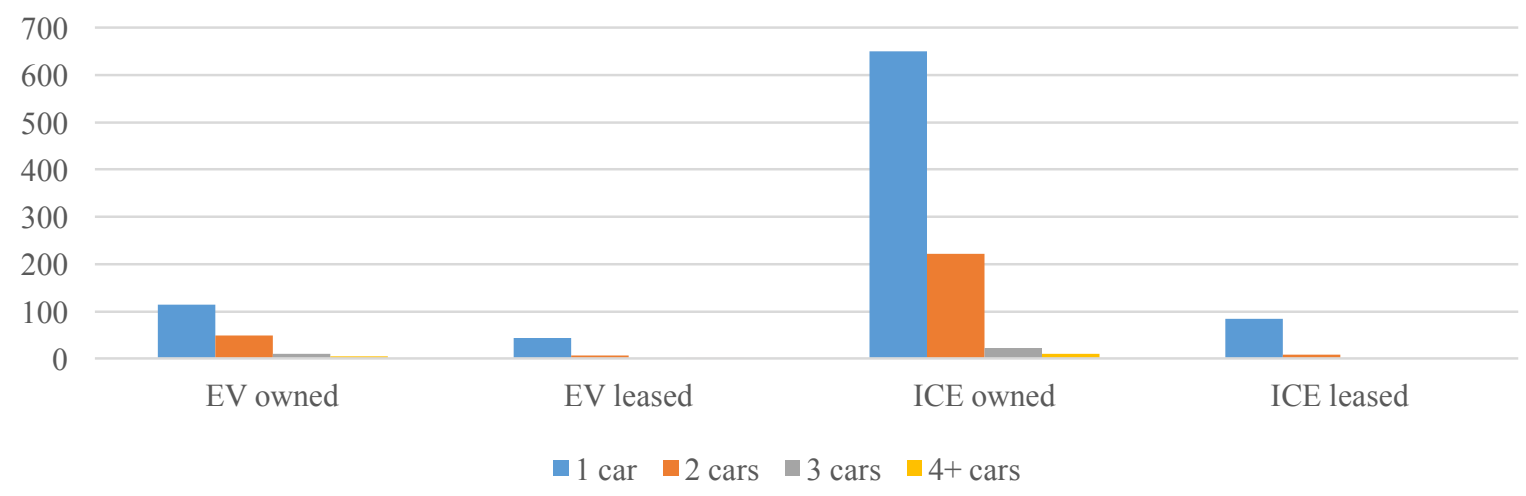

EV owners are overwhelmingly more likely to own their vehicle compared to leasing it, which can perpetuate the notion that EV drivers are wealthier than ICE vehicle drivers on average, as well that the extended battery insurance offered in virtually all makes and models available in the market today instills confidence in the buyer to acquire ownership of the vehicle (Darcovich et al., 2017). Notably, 56 per cent of EV drivers own a secondary vehicle while 30 per cent of ICE drivers do. The majority of ICE drivers do not own a secondary vehicle, especially in the case in which the driver leases their vehicle.

In order to facilitate a more in-depth analysis, nonparametric correlations were used in order to determine the statistically significant relationships of the aforementioned sociodemographic variables for ICE and EV drivers in the tables below.

Table 7: Statistically significant relationships amongst socio-demographic variables amongst ICE drivers

\begin{tabular}{lllllll}
\hline Gender & Age & $\begin{array}{l}\text { Household } \\
\text { number }\end{array}$ & Dwelling & Own/rent & Income & Education \\
\hline
\end{tabular}




\begin{tabular}{|c|c|c|c|c|c|c|}
\hline \multicolumn{7}{|l|}{ Gender } \\
\hline $\begin{array}{l}\text { Correlation } \\
\text { coefficient }\end{array}$ & $0.172 * *$ & --- & --- & $-0.091 * *$ & --- & --- \\
\hline Sig. (2-tailed) & 0.000 & 0.503 & 0.061 & 0.004 & 0.568 & 0.366 \\
\hline$n$ value & 1000 & 1000 & 1000 & 1000 & 1000 & 1000 \\
\hline \multicolumn{7}{|l|}{ Age } \\
\hline $\begin{array}{l}\text { Correlation } \\
\text { coefficient }\end{array}$ & & $-0.225 * *$ & --- & $-0.214^{* *}$ & --- & $-0.072 *$ \\
\hline Sig. (2-tailed) & & 0.000 & 0.380 & 0.000 & 0.268 & 0.022 \\
\hline$n$ value & & 1000 & 1000 & 1000 & 1000 & 1000 \\
\hline \multicolumn{7}{|l|}{$\begin{array}{l}\text { Household } \\
\text { number }\end{array}$} \\
\hline $\begin{array}{l}\text { Correlation } \\
\text { coefficient }\end{array}$ & & & $-0.315^{* *}$ & $-0.075^{*}$ & $0.255^{* *}$ & --- \\
\hline Sig. (2-tailed) & & & 0.000 & 0.017 & 0.000 & 0.985 \\
\hline$n$ value & & & 1000 & 1000 & 1000 & 1000 \\
\hline \multicolumn{7}{|l|}{ Dwelling } \\
\hline $\begin{array}{l}\text { Correlation } \\
\text { coefficient }\end{array}$ & & & & $0.454 * *$ & $-0.255^{*}$ & --- \\
\hline Sig. (2-tailed) & & & & 0.000 & 0.000 & 0.486 \\
\hline$n$ value & & & & 1000 & 1000 & 1000 \\
\hline \multicolumn{7}{|l|}{ Own/rent } \\
\hline $\begin{array}{l}\text { Correlation } \\
\text { coefficient }\end{array}$ & & & & & $-0.241 * *$ & --- \\
\hline Sig. (2-tailed) & & & & & 0.000 & 0.129 \\
\hline$n$ value & & & & & 1000 & 1000 \\
\hline \multicolumn{7}{|l|}{ Income } \\
\hline $\begin{array}{l}\text { Correlation } \\
\text { coefficient }\end{array}$ & & & & & & $-0.186 * *$ \\
\hline Sig. (2-tailed) & & & & & & 0.000 \\
\hline$n$ value & & & & & & 1000 \\
\hline $\begin{array}{l}\text { Education } \\
\text { Correlation } \\
\text { coefficient } \\
\text { Sig. (2-tailed) } \\
n \text { value }\end{array}$ & & & & & & \\
\hline
\end{tabular}

Table 8: Statistically significant relationships amongst socio-demographic variables amongst EV drivers

\begin{tabular}{|c|c|c|c|c|c|c|c|}
\hline & Gender & Age & $\begin{array}{l}\text { Household } \\
\text { number }\end{array}$ & Dwelling & Own/rent & Income & Education \\
\hline \multicolumn{8}{|l|}{ Gender } \\
\hline $\begin{array}{l}\text { Correlation } \\
\text { coefficient }\end{array}$ & & $0.271^{* *}$ & --- & --- & --- & $0.231 * *$ & --- \\
\hline Sig. (2-tailed) & & 0.000 & 0.841 & 0.059 & 0.105 & 0.001 & 0.801 \\
\hline$n$ value & & 192 & 192 & 192 & 192 & 192 & 192 \\
\hline \multicolumn{8}{|l|}{ Age } \\
\hline $\begin{array}{l}\text { Correlation } \\
\text { coefficient }\end{array}$ & & & --- & $-0.263 * *$ & $-0.263^{* *}$ & $0.381 * *$ & --- \\
\hline Sig. (2-tailed) & & & 0.777 & 0.000 & 0.000 & 0.000 & 0.270 \\
\hline$n$ value & & & 192 & 192 & 192 & 192 & 192 \\
\hline \multicolumn{8}{|l|}{$\begin{array}{l}\text { Household } \\
\text { number }\end{array}$} \\
\hline $\begin{array}{l}\text { Correlation } \\
\text { coefficient }\end{array}$ & & & & -- & -- & --- & --- \\
\hline Sig. (2-tailed) & & & & 0.063 & 0.937 & 0.067 & 0.517 \\
\hline$n$ value & & & & 192 & 192 & 192 & 192 \\
\hline \multicolumn{8}{|l|}{ Dwelling } \\
\hline $\begin{array}{l}\text { Correlation } \\
\text { coefficient }\end{array}$ & & & & & $0.427^{* *}$ & $-0.240 * *$ & --- \\
\hline
\end{tabular}




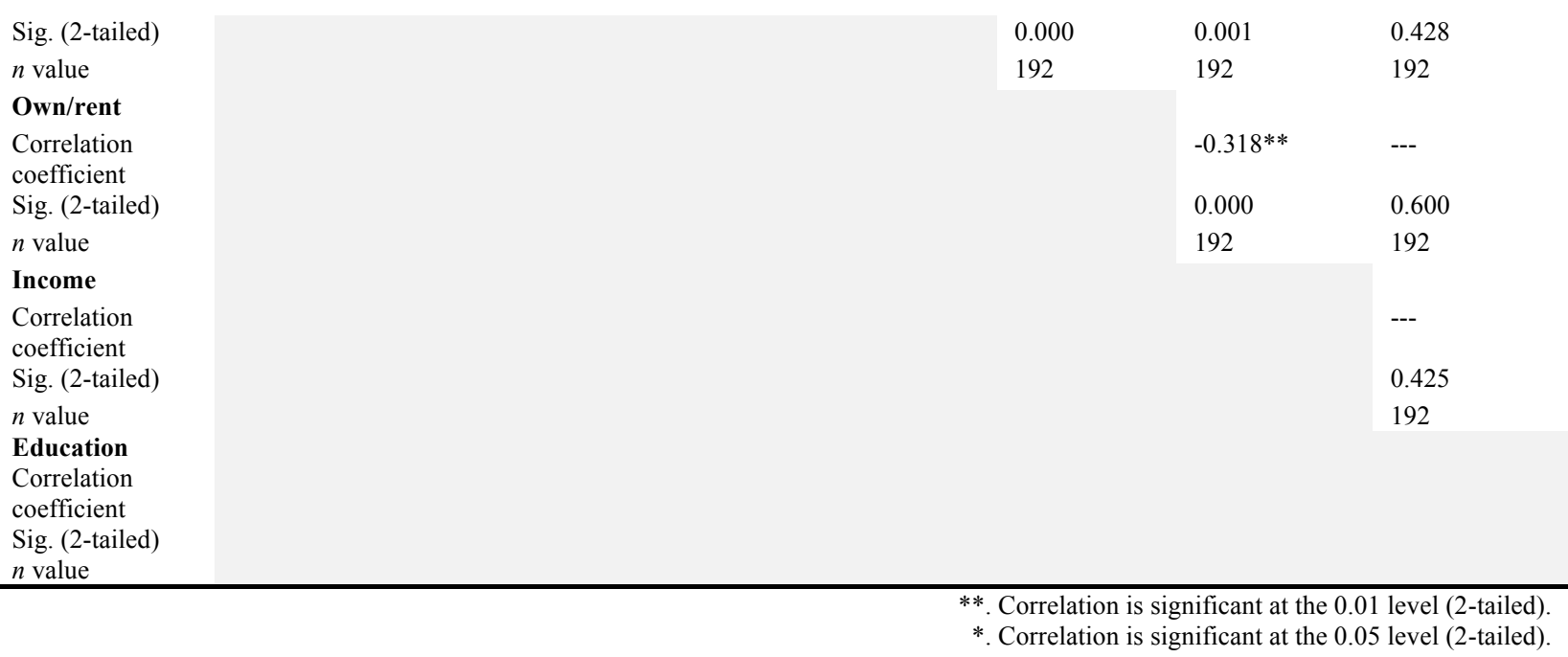

The bivariate calculations in the tables above act as predictive tools to characterize the demographic attributes of the two sample population cohorts. When testing for correlative strength, for the purposes of this study, any figures that exceed 0.5 are indicative of a strong correlation, any figures in between 0.3 and 0.5 are indicative of a moderate correlation, and any figures under 0.3 are indicative of a weak correlation. Amongst both ICE and EV drivers, the relationship with the strongest significance is that of the ownership status of one's vehicle and the type of dwelling one resides in. In this case, the more likely an individual is to own a vehicle, the more likely that person is to also live in a detached home dwelling, amongst both ICE and EV drivers. With a focus on EV drivers, this trend largely resembles the state of the literature to date that has emphasized the challenges of installing necessary charging infrastructure in public spaces (e.g. shared condo parking lots) (Krause et al., 2016; Robinson \& Erickson, 2016). Other noteworthy correlations amongst the socio-demographic data include findings that suggest: (1) younger people and those with lower annual incomes have less people living in their home dwelling; (2) younger people and those with lower annual incomes are more likely to rent their home dwelling; and (3) households with more occupants have a higher combined annual income 
and are more likely to live in a detached household. In summary, the findings from the sociodemographic data predominately resemble of the trends of the literature to date.

\subsection{Perception of driving patterns}

EV drivers perceive themselves to use their vehicles more than ICE drivers both in terms of commuting to and from work as well as to transport dependents (e.g. children, spouses, partners, or other individuals to social, educational, or leisure activities) on a daily basis. This runs counter to an interesting narrative evident in earlier literature that suggests EVs can be a 'second car' solution, especially given the perceived limited range of the cars (De Haan et al., 2006; Pierre et al., 2011; Skippon \& Garwood, 2011; Schuitema et al., 2013). This trend indicates that 'range anxiety' may not plague EV drivers as much as previously considered, especially given the continual improvement of the technology (i.e. battery capacity).

Figure 11: Estimated frequency of vehicle travel amongst survey respondents

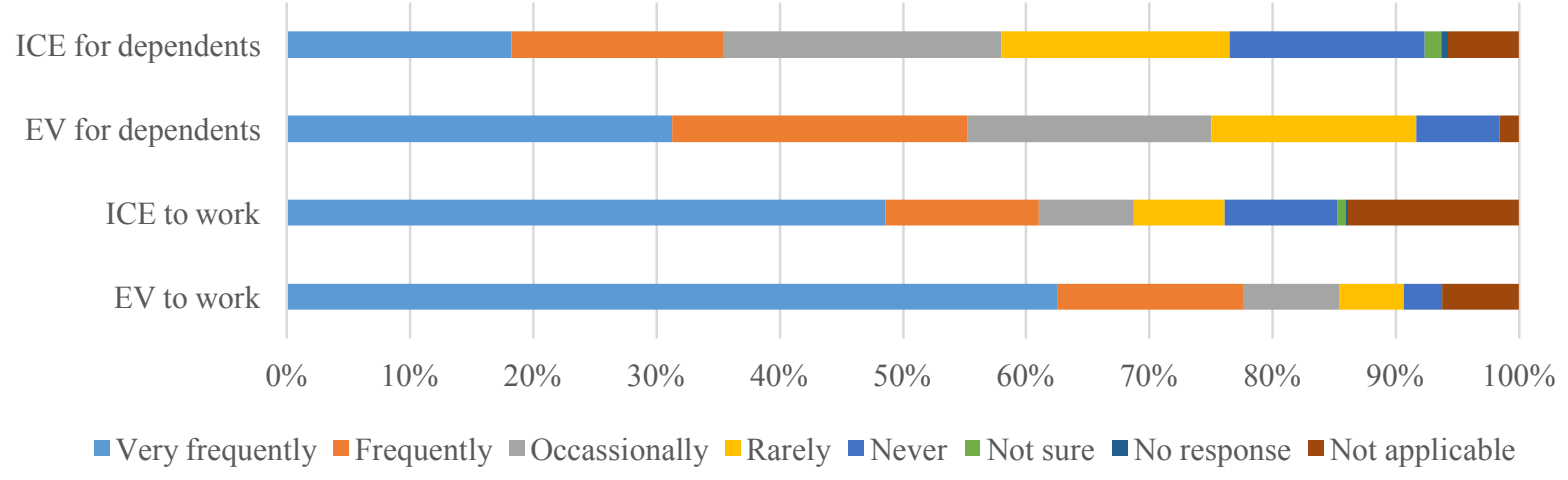

Over three-quarters of EV driving respondents use their car very frequently or frequently to get to and from work on a daily basis. Yet, the most common average round trip estimate of an EV driver's distance from home to their place of work is 21 to $30 \mathrm{~km}$, accounting for 14 per cent. The most common average round trip estimation for the same query amongst ICE drivers is 11 to $20 \mathrm{~km}$, account for 25 per cent. The trends indicate that EV drivers believe they travel more often and cover further distances with their vehicles compared to ICE drivers, a finding relatively 
unexplored in recent literature. This may also be a notion that challenges a misinformed non-EV drivers perception of the technical specification and capabilities of a modern EV.

\subsection{Loyalty and upfront commitment in the automotive sector}

Consumers seeking a new vehicle may be indifferent as to whether the fuel in the engine is electric or gasoline or diesel. However, as recent literature has underscored, if EVs are not available at dealerships or the salespeople are not adequately knowledgeable in selling these vehicles, the consumer experience may be in greater jeopardy (Bohnsack et al., 2014; Chen \& Midler, 2016; Matthews et al., 2017). The automotive industry places high valuations on advertising in the hopes of building meaningful and unwavering brand loyalty amongst a consumer base. Nonetheless, different brands have pursued EV integrated business models with vastly different strategies and have channeled varying amounts of resources towards their uptake. In the findings of this research, 56 per cent expressed brand loyalty when selecting a car to own or lease, while 39 per cent also expressed loyalty amongst ICE vehicle owners. In both cohorts of respondents, the EV driver's loyalty to Tesla was the strongest with a commitment rate of 45 per cent, likely attributed to their radical luxury business model which exclusively operates in the extremely modern EV space (Kley et al., 2011; Bendell \& Thomas, 2013). However, the most consistent brand loyalty to vehicles regardless of their fuel sources is Toyota, with essentially one quarter of both EV and ICE participants expressing loyalty to the brand. Based on findings from the literature, this may be influenced by a presumed legacy of the Prius models as a landmark option in the resurgence of private electrification transportation options (Santini et al., 2000; Lave \& MacLean, 2002; De Haan et al., 2006; Nonaka \& Peltokorpi, 2006). 
Figure 12: Brand loyalty commitment amongst survey participants

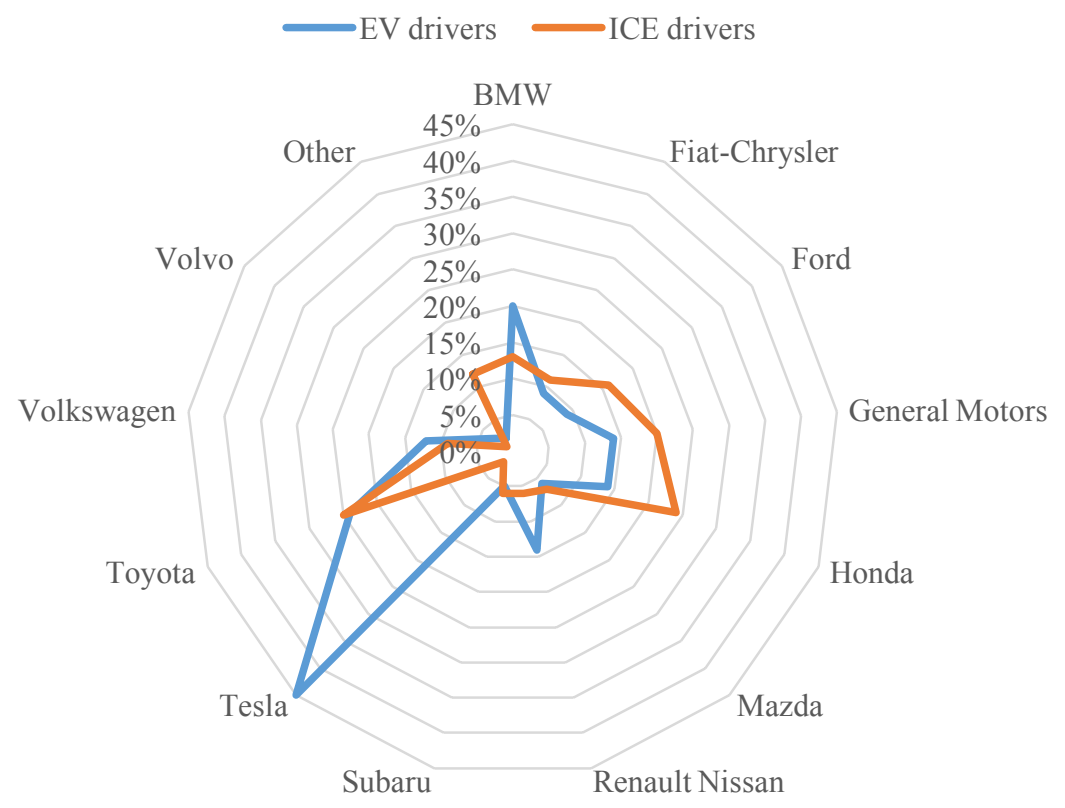

The loyalty one has to the type of vehicle they opt to drive is beneficial for automakers to understand. Such information can enlighten their efforts of determining salient priority areas to electrify certain types of cars. Amongst EV drivers, the stated preferences are predominately sedans (47 per cent), sport utility vehicles (SUVs) (34 per cent), and hatchbacks (33 per cent). Interestingly, ICE drivers possess similar patterns of commitment to sedans (46 per cent) and SUVs (36 per cent). The most notable difference was that 13 per cent of EV drivers express a commitment to crossover vehicles, while 6 per cent of ICE drivers do. EV drivers had higher levels of commitment, likely due to their desire to continue to purchase electrified technologies as well as the limited options available compared to ICE cars. 
Figure 13: Type of car commitment amongst survey participants

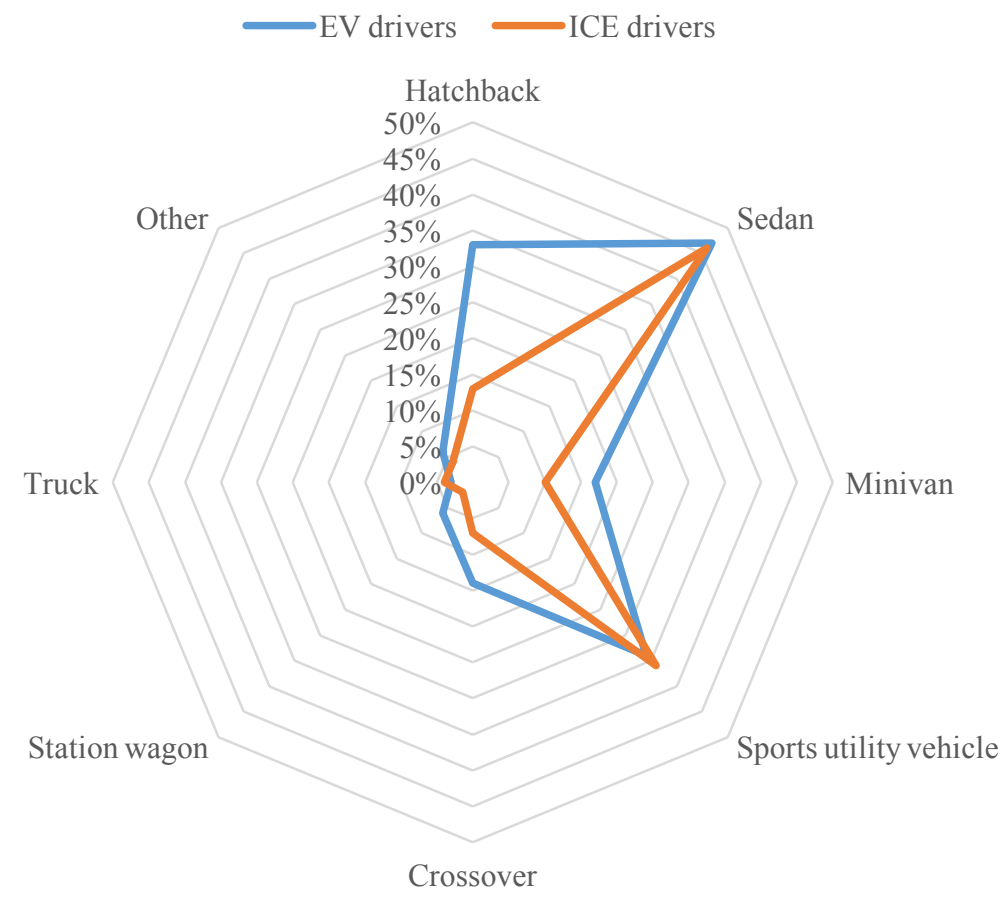

The majority of both EV drivers and ICE drivers indicated that they had an upfront price range. For EV owners, 67 per cent expressed commitment to a specific price range. For ICE owners, 75 per cent expressed a commitment to a price range. The higher value for ICE drivers is likely representative of a more limited and lower price range compared to an early adopter of an EV. The perception of affordability of EVs is reflected in Figure 14, which measures consumer commitment to a particular upfront price range for the vehicle one would intend to purchase or lease. Evidently, EV owners have a greater budget when obtaining a new vehicle.

Figure 14: Percentage of survey respondents committed to a particular upfront price range for their vehicle purchase or lease

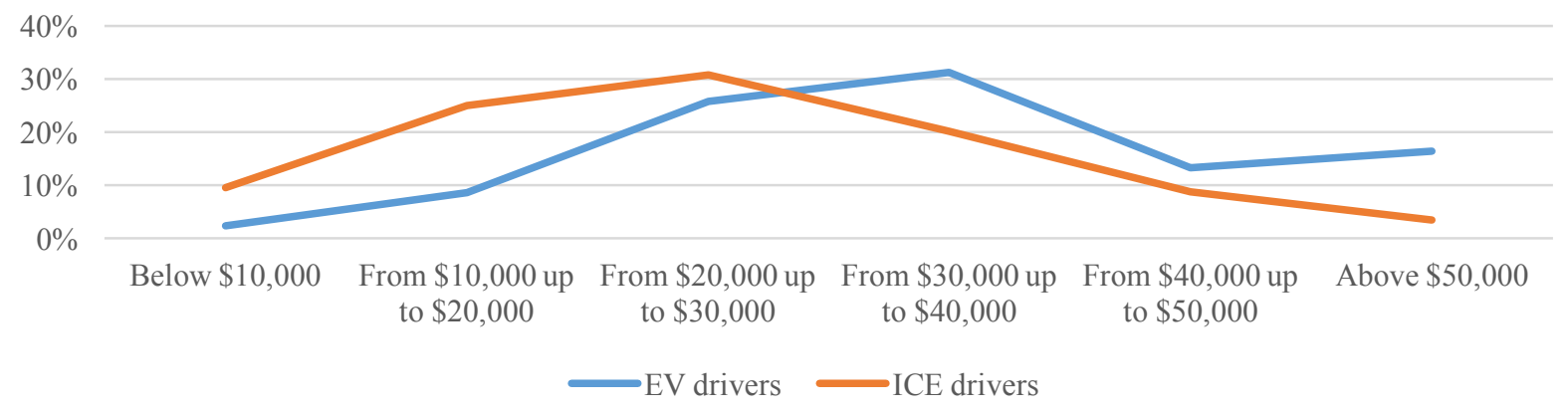


All participants of the survey were queried as to the likelihood as to whether their next vehicle purchase may be an EV or not. The results are indicated in Figure 15, which illustrates that almost 90 per cent of current EV drivers are either very likely or likely to purchase an EV again as their next vehicle. The most common response amongst non-EV owners is that they are neither likely nor unlikely to purchase an EV as their next vehicle, which accounted for 34 per cent of the responses. This suggests there are many 'fence-sitters' who are undecided as to what their next vehicle purchase may be, in terms of re-shaping public policy to accelerate the uptake of these vehicle, this is likely the group integral to the further commercialization of the EVs. Over 20 per cent of ICE vehicle owners were likely or very likely to purchase an EV as their next vehicle and 34 per cent were unlikely or very unlikely. Given the discrepancies and low rates of WTP amongst current non-owners, it is worth utilizing the likelihood to purchase as the dependent variable to measure the other factors that would contribute to consumer decisionmaking.

Figure 15: The likelihood of purchasing an EV as a next vehicle among survey respondents

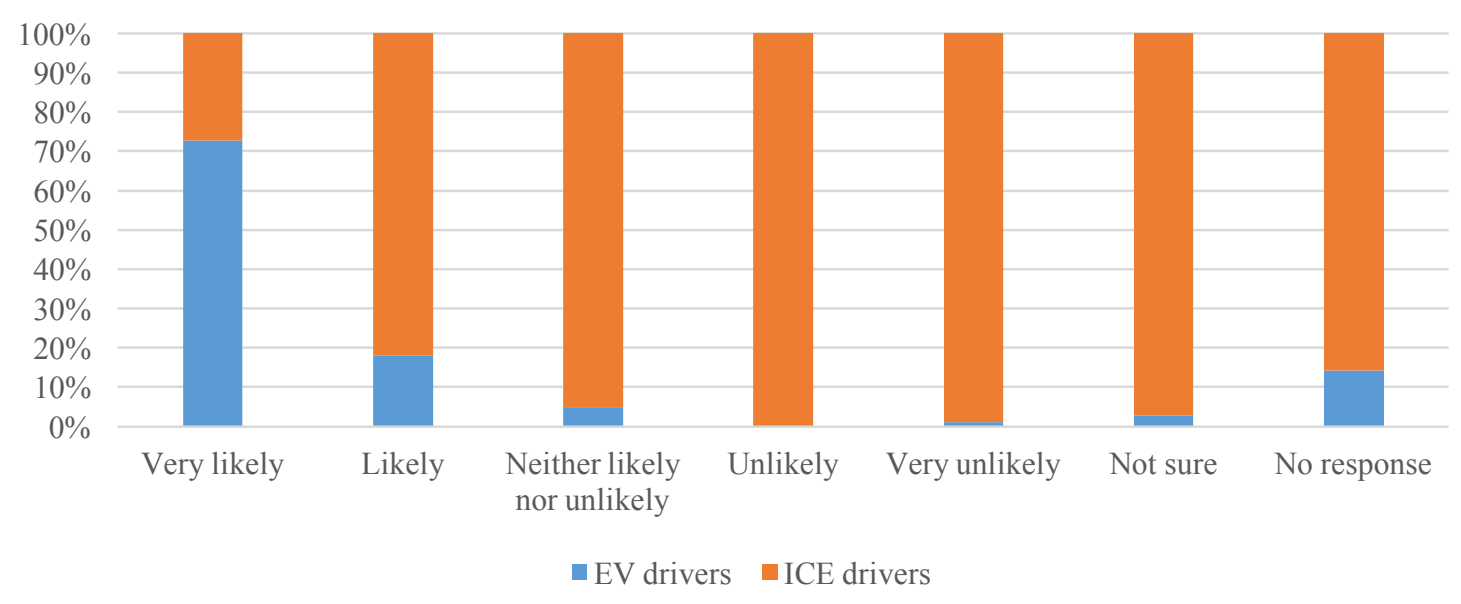


The dependent variable is then used to measure correlative strength amongst the factors that may influence purchase, which include: relative advantages; compatibility; trialibility; observability; and perceptions of social norms (Peters \& Dütschke, 2014). The results of the modelling study are shown in the tables below, which sets the context to a more in-depth analysis and discussion regards EV uptake in the GTHA.

Table 9: Case processing summary of ICE driver data

\begin{tabular}{lllll}
\hline Variable & Value & Response & n value & $\begin{array}{l}\text { Marginal } \\
\text { percentage }\end{array}$ \\
\hline Likelihood of purchase & 1.00 & Very likely & 38 & $6.3 \%$ \\
& 2.00 & Likely & 115 & $18.9 \%$ \\
& 3.00 & Neither likely nor unlikely & 221 & $36.4 \%$ \\
& 4.00 & Unlikely & 110 & $18.1 \%$ \\
Fuel costs & 5.00 & Very unlikely & 123 & $20.3 \%$ \\
& 1.00 & Yes & 242 & $39.9 \%$ \\
Maintenance & 2.00 & No & 365 & $60.1 \%$ \\
& 1.00 & Yes & 314 & $51.7 \%$ \\
Environmental & 2.00 & No & 293 & $48.3 \%$ \\
& 1.00 & Yes & 530 & $87.3 \%$ \\
Test drive & 2.00 & No & 77 & $12.7 \%$ \\
Visit to dealership & 1.00 & Yes & 455 & $75.0 \%$ \\
& 2.00 & No & 152 & $25.0 \%$ \\
Social network & 1.00 & Yes & 485 & $79.9 \%$ \\
& 2.00 & No & 122 & $20.1 \%$ \\
Knowledge & 1.00 & Yes & 111 & $18.3 \%$ \\
& 2.00 & No & 496 & $81.7 \%$ \\
Valid & 1.00 & Yes & 290 & $47.8 \%$ \\
Missing & 2.00 & No & 317 & $52.2 \%$ \\
Total & & & 607 & $100.0 \%$ \\
\hline
\end{tabular}

The statistical analysis of the ICE drivers included 2,388 (79.9 per cent of the total

possible responses) cells (e.g., dependent variable levels by observed combinations of predictor variable values) with zero frequencies. In terms of the model fitting analysis, the final model had a $-2 \log$ likelihood of 1731.341 , a value of the estimated coefficients $(\beta)$. The chi-square value is $x^{2}=71.386$ with a predetermined alpha level significance of 0.000 and a degree of freedom of 14 .

Table 10: Parameter estimates of ICE driver data

\begin{tabular}{ll|ll}
\hline & & \multicolumn{2}{c}{$\mathbf{9 5 \%}$ confidence interval } \\
\cline { 3 - 4 } & & Lower bound & Upper bound \\
\hline \multirow{2}{*}{ Threshold } & Likelihood $=1.00$ & -5.962 & -3.396 \\
& Likelihood $=2.00$ & -4.221 & -1.729
\end{tabular}




\begin{tabular}{llll} 
& Likelihood $=3.00$ & -2.507 & -0.050 \\
Location & Likelihood $=4.00$ & -1.540 & 0.910 \\
Gender & -0.388 & 0.197 \\
Age & 0.069 & 0.271 \\
Household number & -0.326 & -0.069 \\
Dwelling & -0.351 & 0.141 \\
Ownership & -0.417 & 0.263 \\
Income & -0.003 & 0.094 \\
Education & -0.306 & -0.022 \\
Fuel costs $=1.00$ & -0.627 & 0.024 \\
Fuel costs $=2.00$ & -- & -- \\
Maintenance $=1.00$ & -0.389 & 0.268 \\
Maintenance $=2.00$ & --- & --- \\
Environmental attitudes $=1.00$ & -1.488 & -0.585 \\
Environmental attitudes $=2.00$ & --- & -- \\
Test drive $=1.00$ & -0.126 & 0.612 \\
Test drive $=2.00$ & --- & -- \\
Visit to dealership $=1.00$ & -0.647 & 0.161 \\
Visit to dealership $=2.00$ & --- & --- \\
Social network $=1.00$ & -0.929 & -0.158 \\
Social network $=2.00$ & --- & -- \\
Knowledge $=1.00$ & -0.314 & -0.158 \\
Knowledge $=2.00$ & --- & --- \\
\hline
\end{tabular}

The test of parallel lines accounts for the proportional odds assumption. The null

hypothesis states that the location parameters (slope coefficients) are the same across response categories. In this case, the general model possesses a $-2 \log$ likelihood of 1676.816 . The chisquare value is $x^{2}=54.524$ with a predetermined alpha level significance of 0.093 and a degree of freedom of 42 .

Table 11: Case processing summary of EV driver data

\begin{tabular}{|c|c|c|c|c|}
\hline Variable & Value & Response & $n$ value & $\begin{array}{l}\text { Marginal } \\
\text { percentage }\end{array}$ \\
\hline \multirow{5}{*}{ Likelihood of purchase } & 1.00 & Very likely & 122 & $80.3 \%$ \\
\hline & 2.00 & Likely & 21 & $13.8 \%$ \\
\hline & 3.00 & Neither likely nor unlikely & 8 & $5.3 \%$ \\
\hline & 4.00 & Unlikely & 0 & $0.0 \%$ \\
\hline & 5.00 & Very unlikely & 1 & $0.7 \%$ \\
\hline \multirow[t]{2}{*}{ Fuel costs } & 1.00 & Yes & 102 & $67.1 \%$ \\
\hline & 2.00 & No & 50 & $32.9 \%$ \\
\hline \multirow[t]{2}{*}{ Maintenance } & 1.00 & Yes & 119 & $78.3 \%$ \\
\hline & 2.00 & No & 33 & $21.7 \%$ \\
\hline \multirow[t]{2}{*}{ Environmental } & 1.00 & Yes & 143 & $94.1 \%$ \\
\hline & 2.00 & No & 9 & $5.9 \%$ \\
\hline \multirow[t]{2}{*}{ Test drive } & 1.00 & Yes & 132 & $86.8 \%$ \\
\hline & 2.00 & No & 20 & $13.2 \%$ \\
\hline \multirow[t]{2}{*}{ Visit to dealership } & 1.00 & Yes & 129 & $84.9 \%$ \\
\hline & 2.00 & No & 23 & $15.1 \%$ \\
\hline Social network & 1.00 & Yes & 67 & $44.1 \%$ \\
\hline
\end{tabular}




\begin{tabular}{lllll} 
& 2.00 & No & 85 & $55.9 \%$ \\
Knowledge & 1.00 & Yes & 134 & $88.2 \%$ \\
& 2.00 & No & 18 & $11.8 \%$ \\
\cline { 2 - 4 } Valid & & & 152 & $100.0 \%$ \\
Missing & & & 40 & \\
Total & & & 192 & \\
\hline
\end{tabular}

The statistical analysis of the ICE drivers included 441 (75.0 per cent) cells (e.g., dependent variable levels by observed combinations of predictor variable values) with zero frequencies. In terms of the model fitting analysis, the final model had a $-2 \log$ likelihood of 132.722. The chi-square value is $x^{2}=61.215$ with a predetermined alpha level significance of 0.000 and a degree of freedom of 14.

Table 12: Parameter estimates of EV driver data

\begin{tabular}{|c|c|c|c|}
\hline & & \multicolumn{2}{|c|}{ 95\% confidence interval } \\
\hline & & Lower bound & Upper bound \\
\hline \multirow[t]{3}{*}{ Threshold } & Likelihood $=1.00$ & -9.970 & -0.304 \\
\hline & Likelihood $=2.00$ & -7.755 & 1.683 \\
\hline & Likelihood $=3.00$ & -5.470 & 4.545 \\
\hline \multirow[t]{21}{*}{ Location } & Gender & -0.396 & 1.985 \\
\hline & Age & -0.995 & -0.077 \\
\hline & Household number & -0.257 & 0.527 \\
\hline & Dwelling & -0.193 & 1.588 \\
\hline & Ownership & -2.978 & 0.126 \\
\hline & Income & -0.444 & -0.48 \\
\hline & Education & -0.566 & 0.698 \\
\hline & Fuel costs $=1.00$ & -0.720 & 1.870 \\
\hline & Fuel costs $=2.00$ & --- & --- \\
\hline & Maintenance $=1.00$ & -3.805 & -1.240 \\
\hline & Maintenance $=2.00$ & --- & --- \\
\hline & Environmental attitudes $=1.00$ & -3.585 & -0.146 \\
\hline & Environmental attitudes $=2.00$ & --- & --- \\
\hline & Test drive $=1.00$ & -2.116 & 0.581 \\
\hline & Test drive $=2.00$ & --- & --- \\
\hline & Visit to dealership $=1.00$ & -1.180 & 1.743 \\
\hline & Visit to dealership $=2.00$ & --- & --- \\
\hline & Social network $=1.00$ & -1.218 & 0.887 \\
\hline & Social network $=2.00$ & --- & --- \\
\hline & Knowledge $=1.00$ & -2.413 & 0.097 \\
\hline & Knowledge $=2.00$ & --- & --- \\
\hline
\end{tabular}

The null hypothesis states that the location parameters (slope coefficients) are the same across response categories. In this case, the general model possesses a $-2 \log$ likelihood of 125.355. However, in this particular data set, the log-likelihood value cannot be further increased after maximum number of step-halving. The chi-square value is $x^{2}=7368$ with a predetermined 
alpha level significance of 1.000 and a degree of freedom of 28. However, in this particular data set, the chi-square statistic is computed based on the log-likelihood value of the last iteration of the general model, which means that the validity of this specific test is uncertain.

Table 13: Statistically significant relationships amongst purchase decision-making factors based on socio-demographic factors amongst ICE drivers

\begin{tabular}{|c|c|c|c|c|c|c|c|c|}
\hline & Fuel Costs & $\begin{array}{l}\text { Maintenanc } \\
\mathrm{e}\end{array}$ & $\begin{array}{l}\text { Environmen } \\
\text { tal attitudes }\end{array}$ & Test drive & $\begin{array}{l}\text { Visit to } \\
\text { dealership }\end{array}$ & $\begin{array}{l}\text { Social } \\
\text { exposure }\end{array}$ & $\begin{array}{l}\text { Likelihood } \\
\text { to purchase }\end{array}$ & $\begin{array}{l}\text { Perceived } \\
\text { knowledge }\end{array}$ \\
\hline \multicolumn{9}{|l|}{ Gender } \\
\hline $\begin{array}{l}\text { Correlation } \\
\text { coefficient }\end{array}$ & --- & --- & $0.119 * *$ & --- & --- & $-0.082 *$ & --- & $-0.210 * *$ \\
\hline Sig. (2-tailed) & 0.835 & 0.601 & 0.001 & 0.419 & 0.061 & 0.012 & 0.835 & 0.00 \\
\hline$n$ value & 902 & 916 & 797 & 957 & 962 & 937 & 891 & 971 \\
\hline \multicolumn{9}{|l|}{ Age } \\
\hline $\begin{array}{l}\text { Correlation } \\
\text { coefficient }\end{array}$ & $0.092 * *$ & --- & -- & --- & $-0.158 * *$ & --- & $0.169 * *$ & --- \\
\hline Sig. (2-tailed) & 0.006 & 0.584 & 0.057 & 0.262 & 0.000 & 0.867 & 0.000 & 0.169 \\
\hline$n$ value & 902 & 916 & 797 & 957 & 962 & 937 & 891 & 971 \\
\hline \multicolumn{9}{|l|}{ Household \# } \\
\hline $\begin{array}{l}\text { Correlation } \\
\text { coefficient }\end{array}$ & --- & --- & --- & --- & --- & --- & $0.106^{* *}$ & --- \\
\hline Sig. (2-tailed) & 0.511 & 0.178 & 0.481 & 0.886 & 0.586 & 0.775 & 0.002 & 0.838 \\
\hline$n$ value & 902 & 916 & 797 & 957 & 962 & 937 & 891 & 971 \\
\hline \multicolumn{9}{|l|}{ Dwelling } \\
\hline $\begin{array}{l}\text { Correlation } \\
\text { coefficient }\end{array}$ & --- & --- & $-0.080^{*}$ & --- & --- & --- & --- & $-0.070^{*}$ \\
\hline Sig. (2-tailed) & 0.885 & 0.711 & 0.024 & 0.256 & 0.113 & 0.689 & 0.817 & 0.029 \\
\hline$n$ value & 902 & 916 & 797 & 957 & 962 & 937 & 891 & 971 \\
\hline \multicolumn{9}{|l|}{ Own/rent } \\
\hline $\begin{array}{l}\text { Correlation } \\
\text { coefficient }\end{array}$ & --- & --- & -- & --- & $0.175^{* *}$ & --- & --- & $-0.064 *$ \\
\hline Sig. (2-tailed) & 0.125 & 0.207 & 0.235 & 0.083 & 0.000 & 0.228 & 0.071 & 0.046 \\
\hline$n$ value & 902 & 916 & 797 & 957 & 962 & 937 & 891 & 971 \\
\hline \multicolumn{9}{|l|}{ Income } \\
\hline $\begin{array}{l}\text { Correlation } \\
\text { coefficient }\end{array}$ & --- & --- & --- & $-0.066^{*}$ & $-0.072 *$ & --- & $0.067^{*}$ & --- \\
\hline Sig. (2-tailed) & 0.144 & 0.281 & 0.569 & 0.042 & 0.026 & 0.146 & 0.045 & 0.709 \\
\hline$n$ value & 902 & 916 & 797 & 957 & 962 & 937 & 891 & 971 \\
\hline \multicolumn{9}{|l|}{ Education } \\
\hline $\begin{array}{l}\text { Correlation } \\
\text { coefficient }\end{array}$ & --- & $-0.072 *$ & --- & --- & --- & $-0.089 * *$ & $-0.103 * *$ & $-0.098 * *$ \\
\hline Sig. (2-tailed) & 0.115 & 0.029 & 0.466 & 0.177 & 0.297 & 0.006 & 0.002 & 0.002 \\
\hline$n$ value & 902 & 916 & 797 & 957 & 962 & 937 & 891 & 971 \\
\hline
\end{tabular}

Table 14: Statistically significant relationships amongst purchase decision-making factors based on socio-demographic factors amongst EV drivers

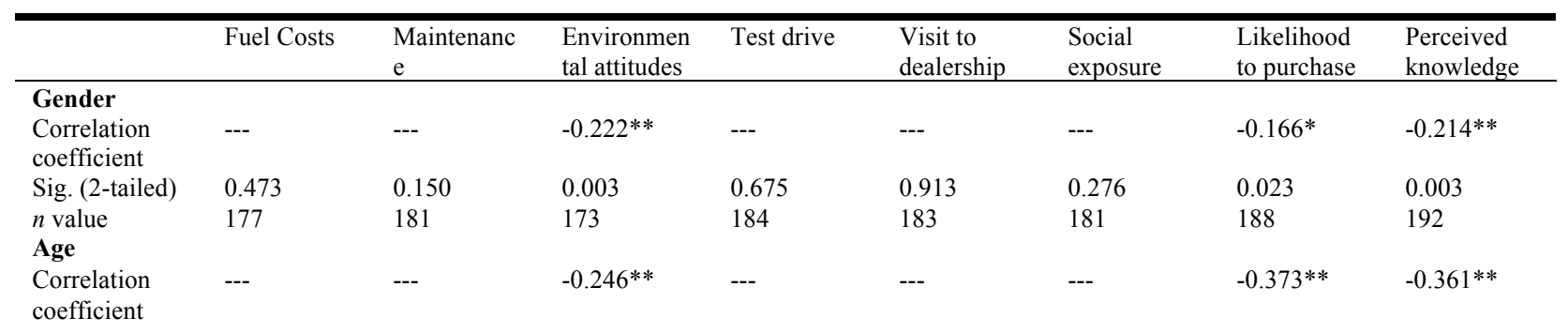




\begin{tabular}{|c|c|c|c|c|c|c|c|c|}
\hline Sig. (2-tailed) & 0.175 & 0.182 & 0.001 & 0.559 & 0.753 & 0.107 & 0.000 & 0.000 \\
\hline$n$ value & 177 & 181 & 173 & 184 & 183 & 181 & 188 & 192 \\
\hline \multicolumn{9}{|l|}{ Household \# } \\
\hline $\begin{array}{l}\text { Correlation } \\
\text { coefficient }\end{array}$ & --- & --- & --- & --- & --- & --- & --- & --- \\
\hline Sig. (2-tailed) & 0.051 & 0.749 & 0.656 & 0.463 & 0.116 & 0.346 & 0.834 & 0.276 \\
\hline$n$ value & 177 & 181 & 173 & 184 & 183 & 181 & 188 & 192 \\
\hline \multicolumn{9}{|l|}{ Dwelling } \\
\hline $\begin{array}{l}\text { Correlation } \\
\text { coefficient }\end{array}$ & --- & --- & --- & --- & --- & --- & --- & --- \\
\hline Sig. (2-tailed) & 0.553 & 0.256 & 0.669 & 0.792 & 0.497 & 0.474 & 0.120 & 0.125 \\
\hline$n$ value & 177 & 181 & 173 & 184 & 183 & 181 & 188 & 192 \\
\hline \multicolumn{9}{|l|}{ Own/rent } \\
\hline $\begin{array}{l}\text { Correlation } \\
\text { coefficient }\end{array}$ & --- & --- & --- & --- & --- & --- & --- & $-0.159 *$ \\
\hline Sig. (2-tailed) & 0.810 & 0.115 & 0.494 & 0.576 & 0.457 & 0.872 & 0.494 & 0.027 \\
\hline$n$ value & 177 & 181 & 173 & 184 & 183 & 181 & 188 & 192 \\
\hline \multicolumn{9}{|l|}{ Income } \\
\hline $\begin{array}{l}\text { Correlation } \\
\text { coefficient }\end{array}$ & --- & --- & --- & --- & --- & --- & $-0.383 *$ & $-0.224 * *$ \\
\hline Sig. (2-tailed) & 0.118 & 0.380 & 0.064 & 0.576 & 0.700 & 0.121 & 0.000 & 0.002 \\
\hline$n$ value & 177 & 181 & 173 & 184 & 183 & 181 & 188 & 192 \\
\hline \multicolumn{9}{|l|}{ Education } \\
\hline $\begin{array}{l}\text { Correlation } \\
\text { coefficient }\end{array}$ & --- & --- & --- & --- & --- & --- & --- & --- \\
\hline Sig. (2-tailed) & 0.282 & 0.236 & 0.887 & 0.243 & 0.635 & 0.060 & 0.136 & 0.405 \\
\hline$n$ value & 177 & 181 & 173 & 184 & 183 & 181 & 188 & 192 \\
\hline
\end{tabular}

Table 15: Statistically significant relationships amongst factors to influence purchase amongst ICE drivers

\begin{tabular}{|c|c|c|c|c|c|c|c|c|}
\hline & Fuel Costs & $\begin{array}{l}\text { Maintenanc } \\
\mathrm{e}\end{array}$ & $\begin{array}{l}\text { Environmen } \\
\text { tal attitudes }\end{array}$ & Test drive & $\begin{array}{l}\text { Visit to } \\
\text { dealership }\end{array}$ & $\begin{array}{l}\text { Social } \\
\text { exposure }\end{array}$ & $\begin{array}{l}\text { Likelihood } \\
\text { to purchase }\end{array}$ & $\begin{array}{l}\text { Perceived } \\
\text { knowledge }\end{array}$ \\
\hline \multicolumn{9}{|l|}{ Fuel Costs } \\
\hline $\begin{array}{l}\text { Correlation } \\
\text { coefficient }\end{array}$ & & $0.378^{* *}$ & --- & $0.084 *$ & --- & $0.091 * *$ & $0.108 * *$ & $0.105^{* *}$ \\
\hline Sig. (2-tailed) & & 0.000 & 0.856 & 0.012 & 0.250 & 0.007 & 0.002 & 0.002 \\
\hline$n$ value & & 861 & 738 & 878 & 885 & 865 & 808 & 880 \\
\hline \multicolumn{9}{|l|}{ Maintenance } \\
\hline $\begin{array}{l}\text { Correlation } \\
\text { coefficient }\end{array}$ & & & --- & $0.175^{* *}$ & $0.114 * *$ & $0.179 * *$ & --- & $0.176^{* *}$ \\
\hline Sig. (2-tailed) & & & 0.720 & 0.000 & 0.001 & 0.000 & 0.220 & 0.000 \\
\hline$n$ value & & & 754 & 893 & 899 & 882 & 821 & 893 \\
\hline \multicolumn{9}{|l|}{ Env attitudes } \\
\hline $\begin{array}{l}\text { Correlation } \\
\text { coefficient }\end{array}$ & & & & --- & --- & --- & $0.166^{* *}$ & $-0.084 *$ \\
\hline Sig. (2-tailed) & & & & 0.674 & 0.239 & 0.445 & 0.000 & 0.19 \\
\hline$n$ value & & & & 781 & 780 & 768 & 719 & 787 \\
\hline \multicolumn{9}{|l|}{ Test drive } \\
\hline $\begin{array}{l}\text { Correlation } \\
\text { coefficient }\end{array}$ & & & & & $0.375^{* *}$ & $0.126^{* *}$ & --- & $0.074^{*}$ \\
\hline Sig. (2-tailed) & & & & & 0.000 & 0.000 & 0.554 & 0.025 \\
\hline$n$ value & & & & & 939 & 918 & 859 & 931 \\
\hline \multicolumn{9}{|l|}{$\begin{array}{l}\text { Visit to } \\
\text { dealership }\end{array}$} \\
\hline $\begin{array}{l}\text { Correlation } \\
\text { coefficient }\end{array}$ & & & & & & --- & --- & $0.077 *$ \\
\hline Sig. (2-tailed) & & & & & & 0.201 & 0.237 & 0.019 \\
\hline$n$ value & & & & & & 921 & 861 & 938 \\
\hline $\begin{array}{l}\text { Social } \\
\text { exposure }\end{array}$ & & & & & & & & \\
\hline
\end{tabular}




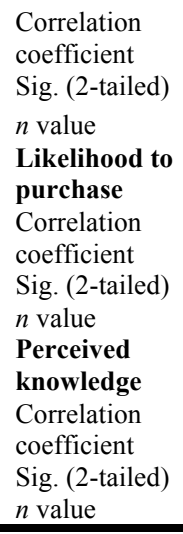

Table 16: Statistically significant relationships amongst factors to influence purchase amongst EV drivers

\begin{tabular}{|c|c|c|c|c|c|c|c|c|}
\hline & Fuel Costs & $\begin{array}{l}\text { Maintenanc } \\
\mathrm{e}\end{array}$ & $\begin{array}{l}\text { Environmen } \\
\text { tal attitudes }\end{array}$ & Test drive & $\begin{array}{l}\text { Visit to } \\
\text { dealership }\end{array}$ & $\begin{array}{l}\text { Social } \\
\text { exposure }\end{array}$ & $\begin{array}{l}\text { Likelihood } \\
\text { to purchase }\end{array}$ & $\begin{array}{l}\text { Perceived } \\
\text { knowledge }\end{array}$ \\
\hline \multicolumn{9}{|l|}{ Fuel Costs } \\
\hline $\begin{array}{l}\text { Correlation } \\
\text { coefficient }\end{array}$ & & $0.368 * *$ & --- & --- & --- & -- & --- & --- \\
\hline Sig. (2-tailed) & & 0.000 & 0.384 & 0.230 & 0.230 & 0.057 & 0.489 & 0.829 \\
\hline$n$ value & & 172 & 164 & 171 & 171 & 170 & 176 & 177 \\
\hline \multicolumn{9}{|l|}{ Maintenance } \\
\hline $\begin{array}{l}\text { Correlation } \\
\text { coefficient }\end{array}$ & & & --- & $0.218^{* *}$ & --- & --- & $0.329 * *$ & --- \\
\hline Sig. (2-tailed) & & & 0.662 & 0.003 & 0.150 & 0.477 & 0.000 & 0.499 \\
\hline$n$ value & & & 164 & 178 & 175 & 175 & 179 & 181 \\
\hline \multicolumn{9}{|l|}{ Env attitudes } \\
\hline $\begin{array}{l}\text { Correlation } \\
\text { coefficient }\end{array}$ & & & & --- & --- & --- & $0.352 * *$ & $0.182 *$ \\
\hline Sig. (2-tailed) & & & & 0.993 & 0.898 & 0.293 & 0.000 & 0.017 \\
\hline$n$ value & & & & 169 & 168 & 167 & 171 & 173 \\
\hline \multicolumn{9}{|l|}{ Test drive } \\
\hline $\begin{array}{l}\text { Correlation } \\
\text { coefficient }\end{array}$ & & & & & $0.263 * *$ & -- & $0.160^{*}$ & --- \\
\hline Sig. (2-tailed) & & & & & 0.000 & 0.478 & 0.031 & 0.932 \\
\hline$n$ value & & & & & 179 & 179 & 182 & 184 \\
\hline \multicolumn{9}{|l|}{$\begin{array}{l}\text { Visit to } \\
\text { dealership }\end{array}$} \\
\hline $\begin{array}{l}\text { Correlation } \\
\text { coefficient }\end{array}$ & & & & & & --- & --- & --- \\
\hline Sig. (2-tailed) & & & & & & 0.846 & 0.308 & 0.835 \\
\hline$n$ value & & & & & & 179 & 181 & 183 \\
\hline \multicolumn{9}{|l|}{$\begin{array}{l}\text { Social } \\
\text { exposure }\end{array}$} \\
\hline $\begin{array}{l}\text { Correlation } \\
\text { coefficient }\end{array}$ & & & & & & & --- & --- \\
\hline Sig. (2-tailed) & & & & & & & 0.733 & 0.445 \\
\hline$n$ value & & & & & & & 179 & 181 \\
\hline \multicolumn{9}{|l|}{$\begin{array}{l}\text { Likelihood to } \\
\text { purchase }\end{array}$} \\
\hline $\begin{array}{l}\text { Correlation } \\
\text { coefficient }\end{array}$ & & & & & & & & $0.372 * *$ \\
\hline Sig. (2-tailed) & & & & & & & & 0.000 \\
\hline$n$ value & & & & & & & & 188 \\
\hline $\begin{array}{l}\text { Perceived } \\
\text { knowledge } \\
\text { Correlation } \\
\text { coefficient } \\
\text { Sig. (2-tailed) }\end{array}$ & & & & & & & & \\
\hline
\end{tabular}


With the objective of reducing GHG emissions in the region, the optimal pathway is to actively convert existing ICE drivers into EV drivers through their next vehicle purchase. This assumption is made because the majority of single passenger vehicle drivers will likely continue to rely on private transportation needs to fulfill their mobility necessities instead of adopting other modes they may perceive as less conducive to their habitual lifestyle. Therefore, the tables below highlight the key findings regarding the influences that may increase the likelihood of adoption amongst drivers without an EV at the time in which they participated in the survey.

Table 17: Predictive model to determine the likelihood to purchase an EV amongst non-EV owners

\begin{tabular}{|c|c|}
\hline Variable & $\begin{array}{l}\text { Statistical significance }(p) \text { in predictive model for } \\
\text { the likelihood to purchase an EV }\end{array}$ \\
\hline Gender & 0.521 \\
\hline Age & $0.001 *$ \\
\hline Household number & $0.003 *$ \\
\hline Dwelling type & 0.403 \\
\hline Ownership of dwelling & 0.657 \\
\hline Income & 0.063 \\
\hline Education level & $0.024 *$ \\
\hline Fuel costs & 0.070 \\
\hline Maintenance costs & 0.717 \\
\hline Environmental concern & $0.000 * *$ \\
\hline Test drive & 0.197 \\
\hline Visiting a dealership & 0.238 \\
\hline Social network & $0.006 * *$ \\
\hline Perceived knowledge & 0.945 \\
\hline
\end{tabular}

Table 17 demonstrates that one's age, the number of individuals living in their household, and one's level of education are statistically significant co-variates that influence the proposed model. As well, compatibility (concern for environmental sustainability) and social norms (the influence of one's social network) were statistically significant predictive factors in measuring the non-EV owner's likelihood to purchase an EV as their next vehicle. The co-variates were 
measured in terms of significance to the dependent variable, and then the statistical significance was assessed of the predictive factors.

Table 18: Statistically significant (greater than 95 per cent confident level) correlations

\begin{tabular}{ll}
\hline Variable & $\begin{array}{l}\text { Correlation co-efficient for relationship for } \\
\text { likelihood of purchase }\end{array}$ \\
\hline Age & 0.169 \\
Household number & -0.106 \\
Income & 0.067 \\
Education level & -0.103 \\
Fuel costs & 0.108 \\
Environmental concern & 0.166 \\
Social network & 0.113 \\
Knowledge & 0.070 \\
\hline
\end{tabular}

Table 18 illustrates that those likely to purchase an EV tend to also be younger, live in

larger households, possess a higher income, are slightly more educated, are sensitive to fuel costs, believe that conventional vehicles contribute to climate change, can be influenced by their friends and family to consider the purchase of an EV, and perceive to understand how an EV works. Nonetheless, the strength of the aforementioned relationships amongst the variables and the dependent variable ranges from a classification of very weak to weak in terms of their respective correlative strength.

\subsubsection{Perceived relative advantages (operating costs) as an indicator of purchase}

The relative advantage compares an innovation to the conventional alternatives available more readily in the market. Advantages amongst EVs are attributed in large part to the lower operating costs of the vehicle. The contrast of the perception amongst the beliefs held by the non-EV driving community empowers a compelling narrative EVs are perhaps more expensive to own and operate than one may believe. EV drivers in large part believe that the initial purchase of an EV is likely to be higher than a similar make and model of a conventional vehicle, yet the associated costs of ownership (e.g., fuel, maintenance) is lower, allowing for cost-savings over a longer period of time. The data substantiates the notion that EV drivers 
devote more time and resources to research focused on their vehicle purchase. The barrier of the initial higher upfront-cost of ownership may be exacerbated when misconceptions of actual operating costs exist.

\section{Fuel economics}

Both surveyed groups articulated that the majority of drivers considered the fuel economy of the car prior to purchase. The fuel economy in the survey was described as the distance the car is able to travel on a full tank of gas, diesel, and/or electricity. EV drivers are more likely to factor this consideration into purchasing decision than ICE drivers [Figure 16].

Figure 16: Consideration of fuel economy prior to purchasing one's vehicle among survey respondents

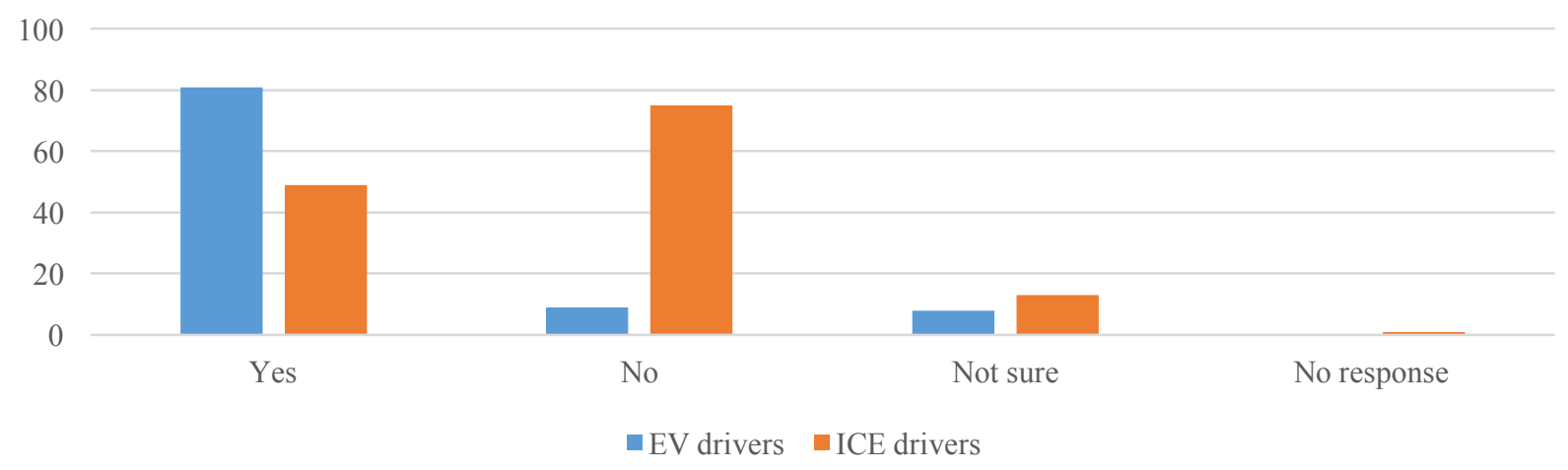

Participants were also asked what their desired fuel economy rating (or fuel economy equivalency for EVs) was prior to purchase. The most frequent response was a preferred fuel economy rating of less than $4.0 \mathrm{~L} / 100 \mathrm{~km}(26$ per cent) and less than $6.0 \mathrm{~L} / 100 \mathrm{~km}$ (20 per cent). Yet, the ICE driving respondents mainly opted for less than $8.0 \mathrm{~L} / 100 \mathrm{~km}$ (21 per cent) and less than $10.0 \mathrm{~L} / 100 \mathrm{~km}$ (22 per cent). The EV driving sample saw under 11 per cent indicate that they were either not sure or did not consider the fuel economy in their purchase decision. In contrast, the most commonly selected response amongst the EV drivers was that they were not sure, which represented 27 per cent of respondents. Similar trends were echoed in the perceived 
financial costs of fueling a vehicle in which EV drivers had a substantially higher estimate on purchase patterns compared to ICE drivers [Figure 17].

Figure 17: Perceived total amount of money assumed to spend fuelling a vehicle amongst survey respondents

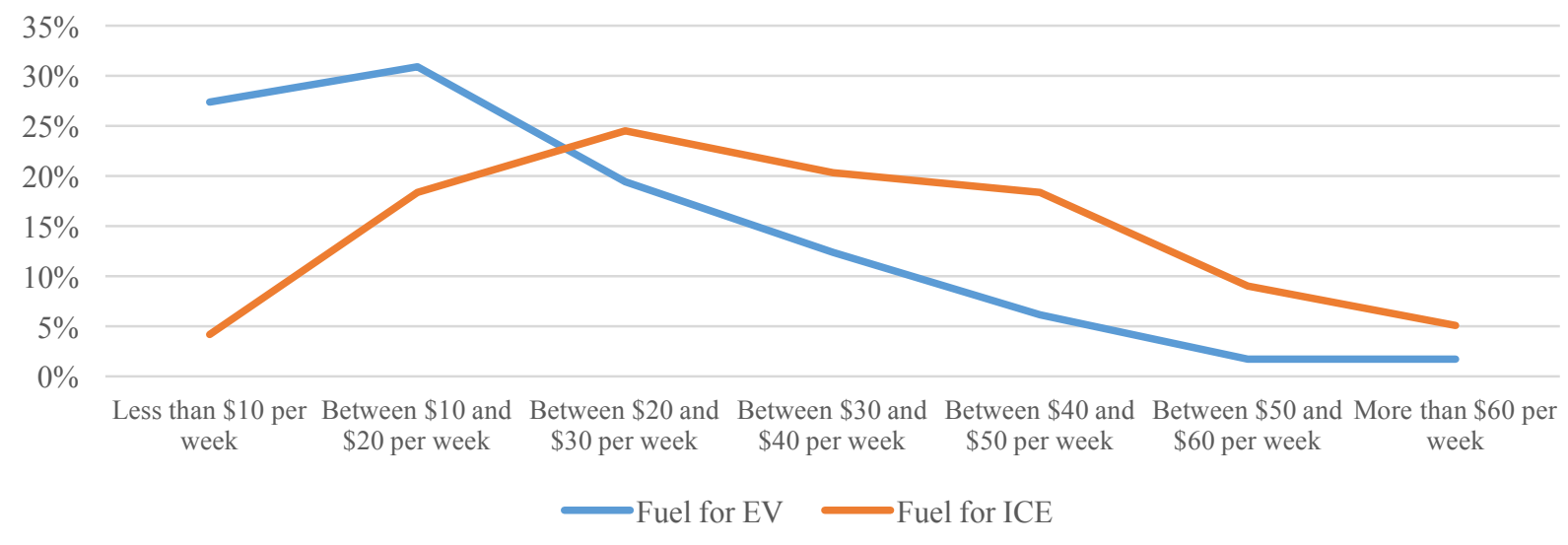

Nonetheless, the argument can be made that distinguishing the cost of charging an EV at one's personal property in which the electricity costs are amalgamated in one's entire bill results in greater challenges to deceiver the actual cost of charging an EV. Rowlands et al. (2015) found that amongst Ontarians, current levels of electricity literacy are generally low. However, in the province of Ontario, off-peak charging (e.g., overnight, weekends, statutory holidays) offers substantially lower cost than regular business hours. This invokes the possibility that perhaps Ontario's utilities providers are not clearly educating and articulating the actual costs of electricity used to power a vehicle to potential future owners.

As illustrated in Figure 18, existing EV owners believe that those who drive ICE vehicles can save money on fuel costs if they instead opt to drive an EV. This conforms with the barriers presented in the literature suggesting that the initial cost is worthwhile from a longer-term costsavings analysis perspective (Salisa et al., 2015; Mega, 2016). 
Figure 18: Belief that EVs can help a household save money on fuel costs compared to a gasoline or diesel car among EV driving respondents

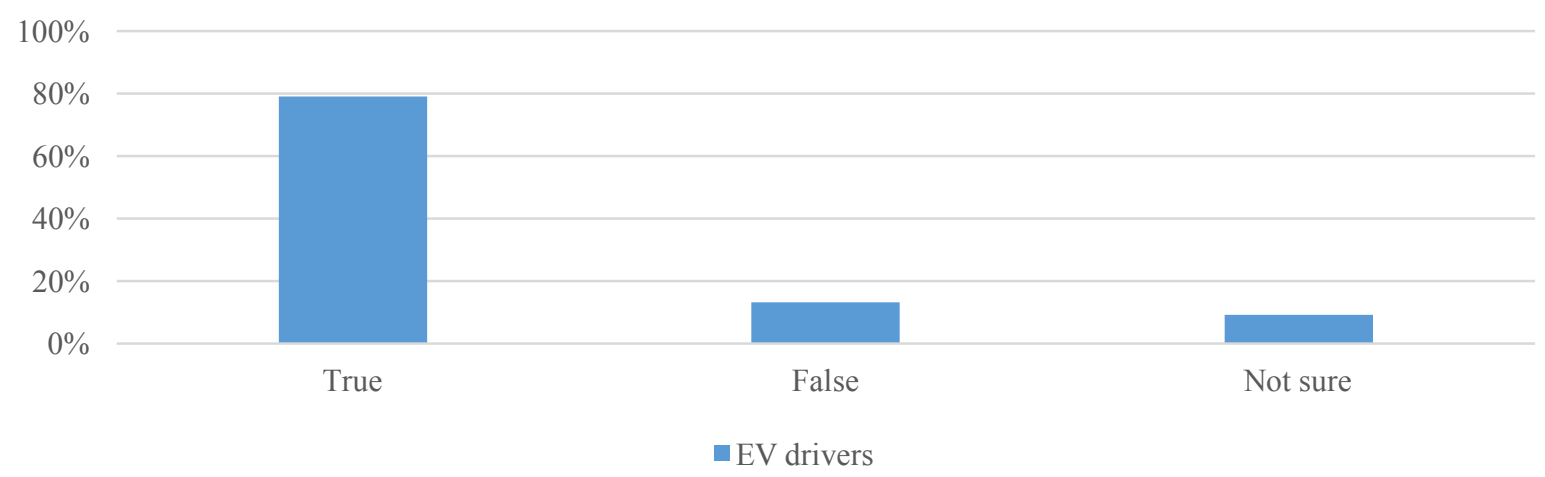

Among non-EV owners, fuel costs do not act as a significant predictor of one's likelihood to purchase an EV compared to other factors. Nonetheless, fuel costs, as a co-variate has a more significant relationship with ICE drivers compared to EV drivers. Amongst ICE drivers, one's age as well as their perception of maintenance, interest in an initial test drive, social exposure, likelihood of purchase, and perceived knowledge of technology demonstrate a more significant relationship to their desired fuel costs in purchasing a vehicle. The significance of those factors is that young people are likely the most interested in obtaining an EV, yet the benefits of acquisition are not always made clear to the individual. This provides evidence that gasoline- and diesel-car owners have greater concerns of upfront costs, which can shape their behaviour in the vehicle purchasing process.

\section{Battery range}

The EV drivers surveyed were asked whether they selected considered the battery range of the car, defined as the distance the car could travel on a full charged battery. Over 80 per cent responded that battery range was a contributing factor in their purchase decision-making process. This is unsurprising as a result of the decision to escape the carbon lock-in and therefore view battery potential as a substitute for gasoline or diesel. EV drivers were split in the belief that their 
vehicle (whether BEV or PHEV) can travel more than $150 \mathrm{~km}$ on a single battery charge, which highlights the variance in technical specifications of the models available on market today [Figure 19].

Figure 19: Belief that EVs can travel more than $150 \mathrm{~km}$ on a single battery charge even if the air conditioning or heating system is turned on among EV driving respondents

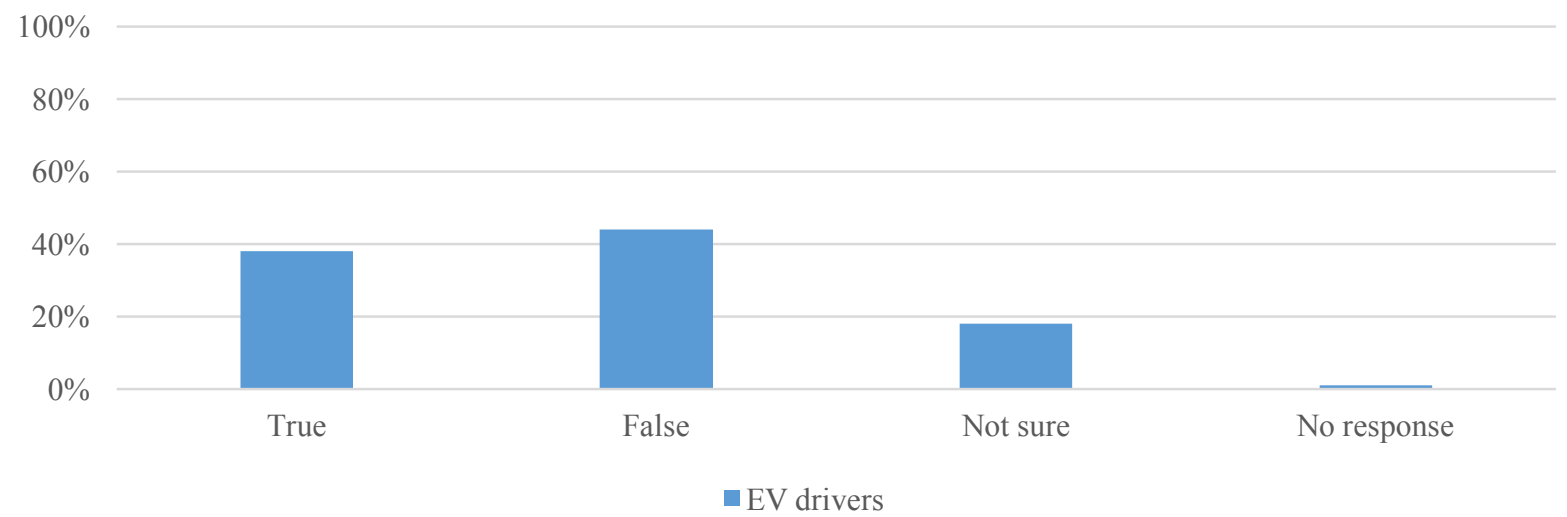

Nonetheless, two-thirds of EV drivers expressed satisfaction with the battery range their vehicle offers them [Figure 20]. A slightly fewer number of EV drivers, at 55 per cent, expressed the same level of satisfaction with their vehicle's battery performance given the cold and relatively harsh winter conditions of the GTHA. However, the literature does suggest that battery technology is becoming more robust in cold weather (Wang et al., 2015; Jaguemont et al., 2016; Reyes et al., 2016).

Figure 20: Satisfaction rates of distance one's EV can travel based on a fully charged battery among EV driving respondents

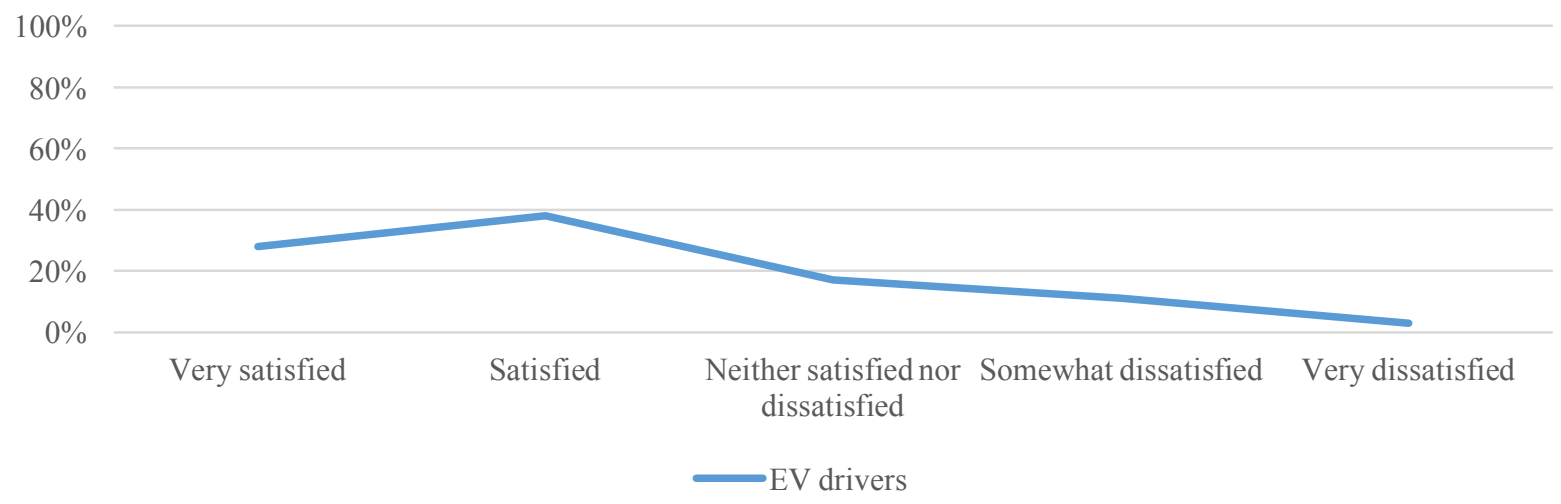


To date, the majority of Ontario's initiatives promoting EVs have been centralized around the theme of reducing 'range anxiety,' a notion often articulated in official governmental press releases and strategy briefings (Ministry of Transportation Ontario, 2016). Specifically, the decision to install DC Fast Chargers on Ontario's highways is largely symbolic of the push for a more interconnected road network to convince prospective EV drivers that even the furthest of distances within the province are achievable for drivers. Nonetheless, the literature has suggested that the visual representation of more charging stations may not entirely convince non-EV drivers to make the switch (Bailey et al., 2015). Yet, the majority of EV drivers, as indicated in Figure 20, express satisfaction with the current capabilities of their EV's battery potential. Perhaps this trend indicates that EV drivers are not using their vehicles to travel within their cities or towns, instead of travelling further distances across provinces for example.

\section{Maintenance and repair costs}

Maintenance and repair costs can be considered to be the costs of vehicle ownership less anticipated (i.e. consumers may not consider this directly in their purchase-making decision), and the multitude of dealership packages and service offerings (warranties) further exacerbate perceptions of such costs. Initiating forecasts in maintenance and repair costs can be difficult and the vehicle's performance can vary based on the interactions the user has with the vehicle among other factors more left to chance. This study's findings indicate that EV drivers are more likely to consider the cost of maintenance when selecting their intended vehicle of purchase as compared to ICE drivers [Figure 21]. The likely rationale of this finding is that the 'carbon lockin' suggests drivers are accustomed to paying for gasoline or diesel as fuel, and the transition of consideration towards using electricity as a substitute requires a more active thought process (Unruh, 2002; Schwanen et al., 2011; Wells \& Nieuwenhuis, 2012). 
Figure 21: Consideration of maintenance costs prior to purchasing one's vehicle among survey respondents

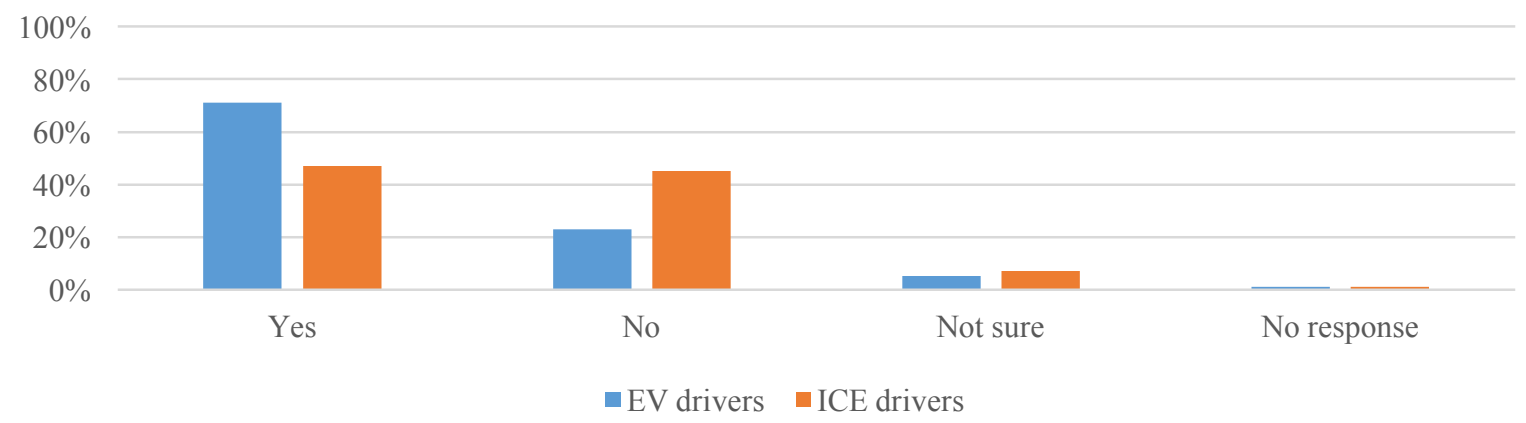

However, in Figure 22, there is indication that the disparity in perceived assumed and actual costs of maintenance for vehicles is not extremely different amongst EV and ICE drivers.

Figure 22: Perceived assumed and actual costs of maintenance for vehicles among survey respondents

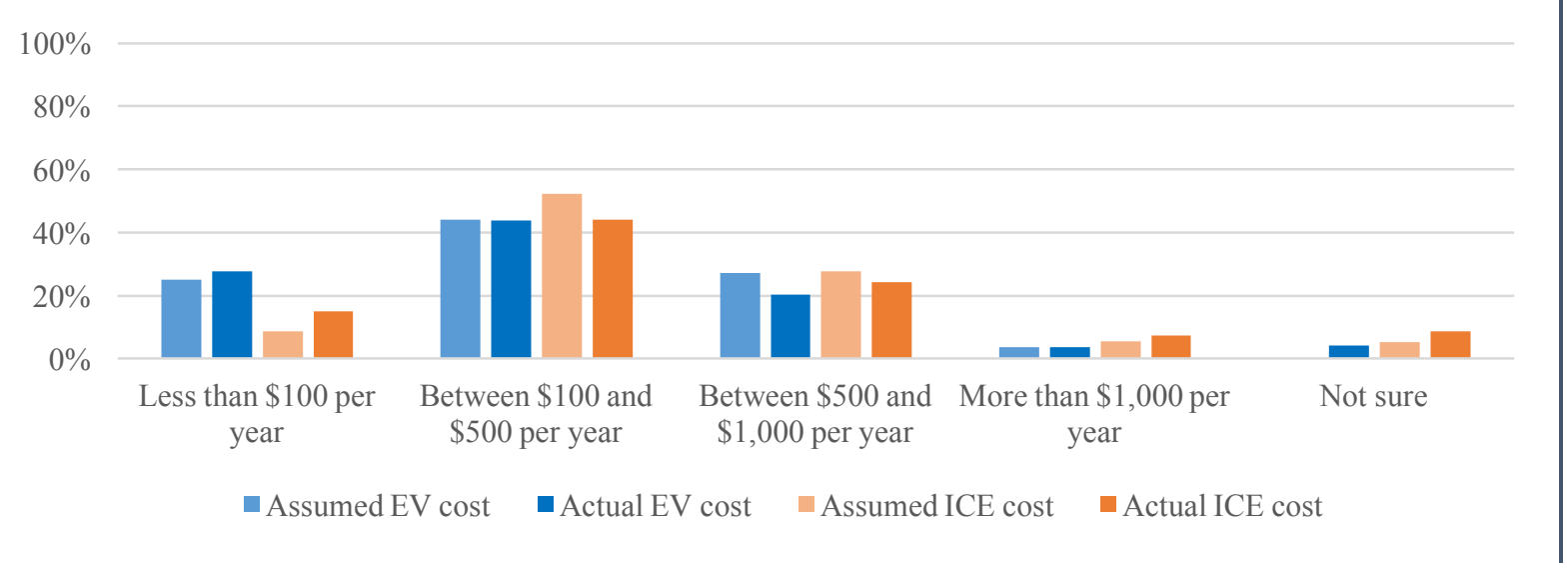

The greatest disparity amongst the two groups is evident in the 'less than $\$ 100$ per year' range, some literature suggests this may be a result of a luxury vehicle models gaining public traction in the EV landscape that perhaps require less maintenance and with no additional costs (Bubeck et al., 2016; Duarte et al., 2016; Higgins et al., 2017). However, the most prominent range for both driving groups is in between the $\$ 100$ and $\$ 500$ per year range, which offers a compelling contrast from the 79 per cent of EV owners who believed that EVs offered individuals a long-term cost savings opportunity [Figure 18]. This implies there is a notable 
difference between perceived general costs of ownership and maintenance and repair costs specifically.

\subsubsection{Compatibility as an indicator of purchase}

Compatibility is understood as the fittingness to the adopter's values, experiences and needs (Peters \& Dütschke, 2014). Perceived compatibility of an EV based on personal identified needs was deemed the most influential factor on the stated willingness to purchase an EV in the initial study in which this model stems from (ibid.). For the purposes of this study, compatibility was amended to account for the environmental attitudes amongst respondents. The rationale for this decision is that in Ontario, the government and relevant public agencies and institutions are largely framing the narrative of EVs in the context of meeting environmental targets (Environment and Climate Change Canada, 2015). The incentive programs available at the consumer level to encourage radical EV uptake in the province act as evidence for environmental prioritization.

The environmental concern participants expressed possess similar correlative relationships amongst co-variates for both EV and ICE drivers. The shared relationships were highlighted in how significant gender among socio-demographic categories and likelihood to purchase as well as perceived knowledge of the technology among the purchase decision-making variables were. The differences remained that amongst ICE drivers, there was a significant relationship with one's dwelling type and amongst EV drivers there was a significant relationship with age, and both did not exist in the other groups. A notably significant relationship was evidence between environmental concern and the likelihood to purchase, and in conformity with the literature to date can be understood as a relevant predictor of a non-EV 
owner's likelihood to purchase an EV as their next vehicle (Egbue \& Long, 2012; Krause et al., 2013; Schneider et al., 2014; Sierzchula et al., 2014; Jiang, 2016).

Figure 23: Belief that present day climate change is occurring because of GHG emissions from the combustion of fossil fuels associated with transportation

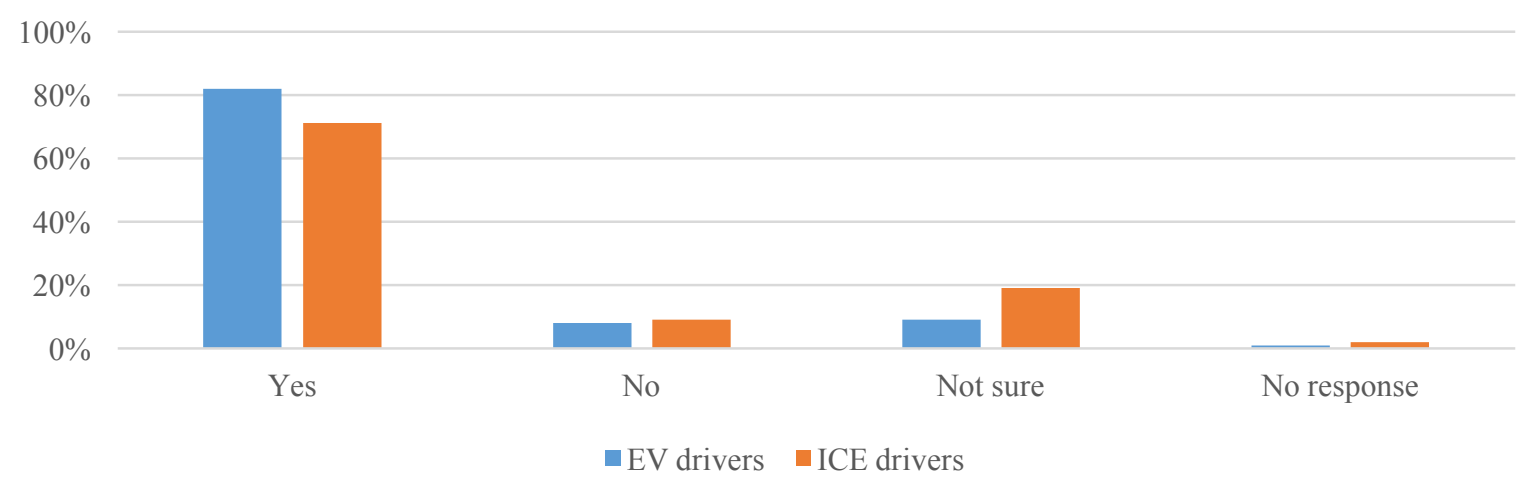

Unsurprisingly, the vast majority of participants express their view that climate change as occurring as a result of GHG emissions from the combustion of fossil fuels associated with the transportation sector. The amount of EV drivers who recognize the aforementioned threat is higher, which aligns with what past literature has suggested (Carley et al., 2013; Rezvani et al., 2015; Axsen et al., 2016).

\section{Environmental sensitivity}

Given the close association of the narrative of purchasing and using an EV with mitigating the impacts of climate change, it is expected that EV owners more commonly recognize the threat of anthropogenic climate change and place an onus on themselves to help solve the issue through their purchase power. Given the suggestion in the literature that PHEVs are the optimal, 'safer' vessels to transition non-EV owners to purchasing an EV based on their preferences and motivations, there is widespread opportunity for misperceptions about one's actual environmental footprint due to the hybrid nature of the fuel used (Axsen et al., 2015; Axsen et al., 2016). In addition, the electricity supply mix widely varies among Canada's 
provinces, and therefore the environmental benefits or consequences change as a result of the jurisdiction one is fueling their vehicle in (Bahn et al., 2013; Mallia \& Lewis, 2013; Nathwani \& Chen, 2013).

Figure 24: Belief that the use of automobiles has a negative effect on the environment

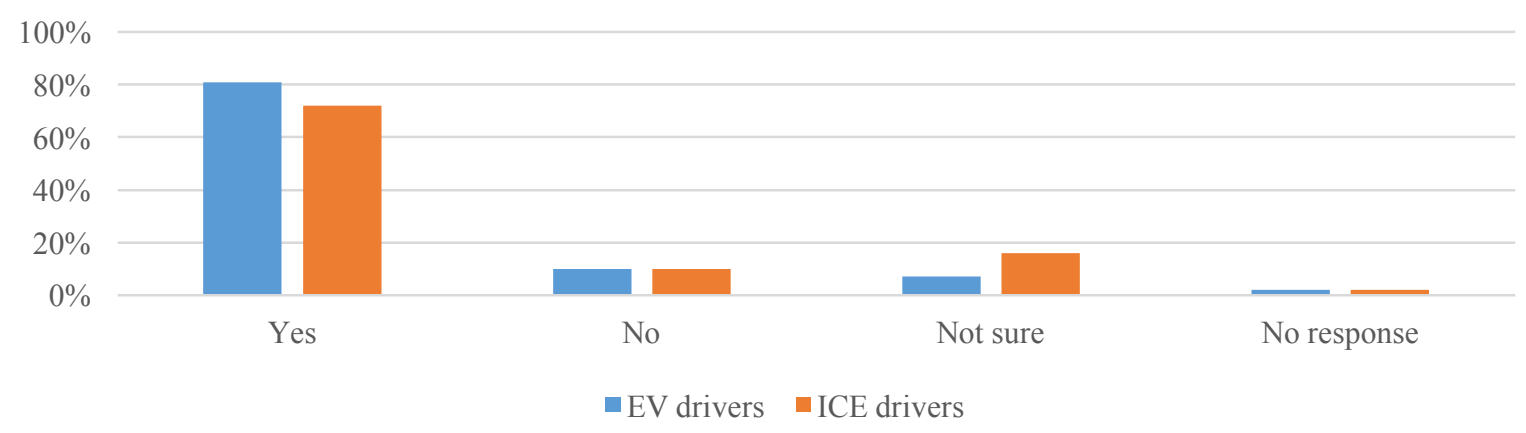

The belief that using an automobile has consequential repercussions on the environment is held by the majority of both EV and ICE drivers. Yet, a significantly greater percentage of ICE drivers are unsure that this relationship exists, and perhaps possess greater skepticism.

Figure 25: Belief that switching the majority of the world's transportation systems to PEVS would help stop climate change at a global level

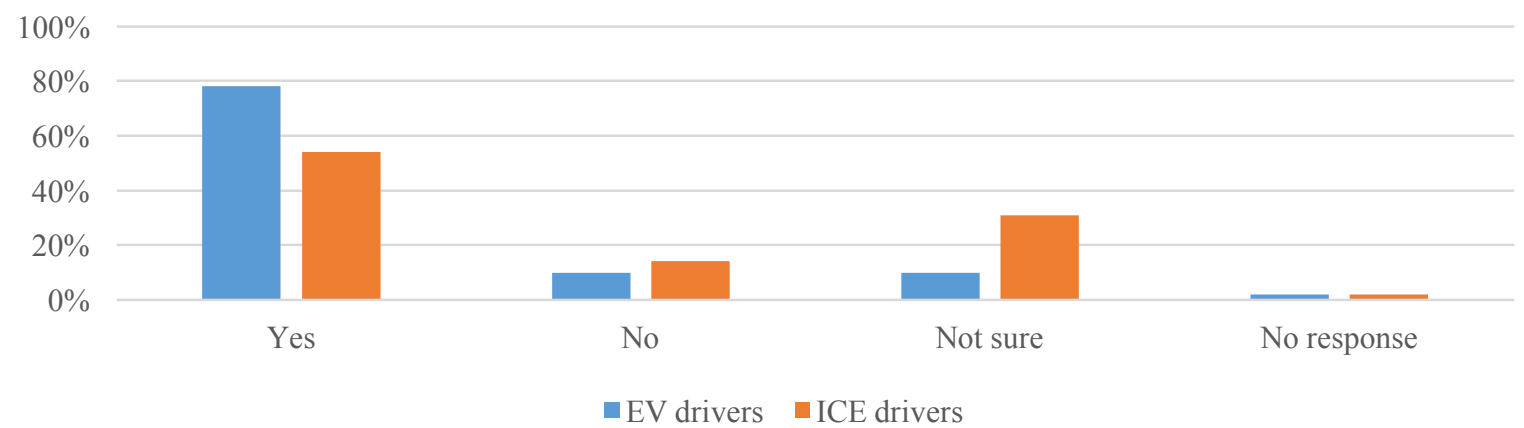

ICE drivers are nearly evenly split amongst if the vehicle fleet in the GTHA suddenly became exclusively EVs that this would help climate change. In large part, this speaks to the complex nature of addressing climate change, and what components people believe are essential or worthwhile as an investment to mitigate the issue. The argument can be made that purchasing a private vehicle, regardless of its fuel source, has a negative impact on the environment, 
especially when alternative solutions such as active transportation and public transit are readily available in most jurisdictions within the GTHA. Ultimately, the single-passenger vehicle is not a nimble and efficient solution to the region's immense transportation problems, but will remain relevant and popular for the near future.

Figure 26: Belief that one has a personal role to play in stopping global climate change

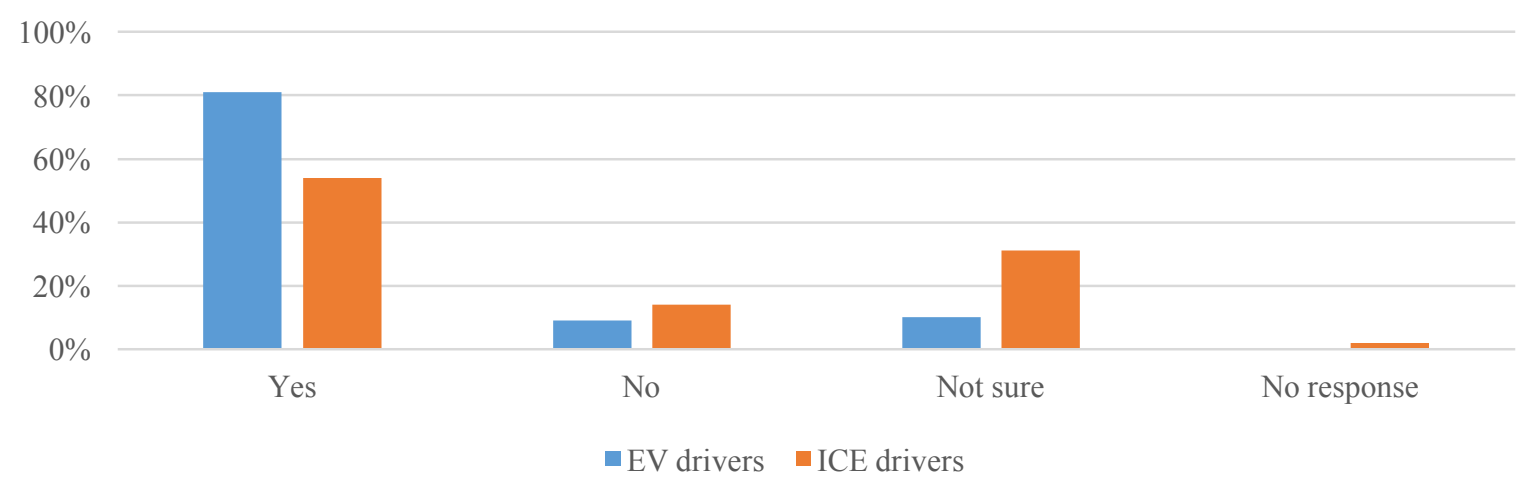

Similarly, the individual acceptance that one's actions have an impact on solving climate change is somewhat disputed, more so amongst the ICE driving respondents. This creates a challenge when EVs are marketed primarily as 'green' technologies for a niche group of consumers with a WTP of a higher initial upfront cost (Barkenbus, 2010; Sexton \& Sexton, 2014; Axsen et al., 2015; Krause et al., 2016). While this particular research study did not find a significant relationship between annual income and environmental concern, the duality of perception amongst EVs being for those with a deep ecological concern and/or a higher income group imposes barriers for their widespread adoption. Without acknowledgement that an individual has a personal responsibility to mitigate their environmental impact, the marketing of EVs as environmental solutions may prove to be relatively ineffective (perhaps unless an educational piece is built into the marketing strategy) beyond the current early adopting group.

\section{Perception of supply mix options}


Accelerating the level of public literacy regarding electricity and energy has historically posed great challenges to utility organizations and relevant public agencies. In Ontario, the majority of electricity comes from renewable energy sources, with limited proportions of natural gas mainly used during peak hours throughout work days (Independent Electricity System Operator, 2017). Several supply mix options were selected for this study to query perception towards the potential fuel sources amongst respondents, as illustrated in Figure 27.

Figure 27: Supply mix options perceived to be categorized as a 'fossil fuel' among survey respondents

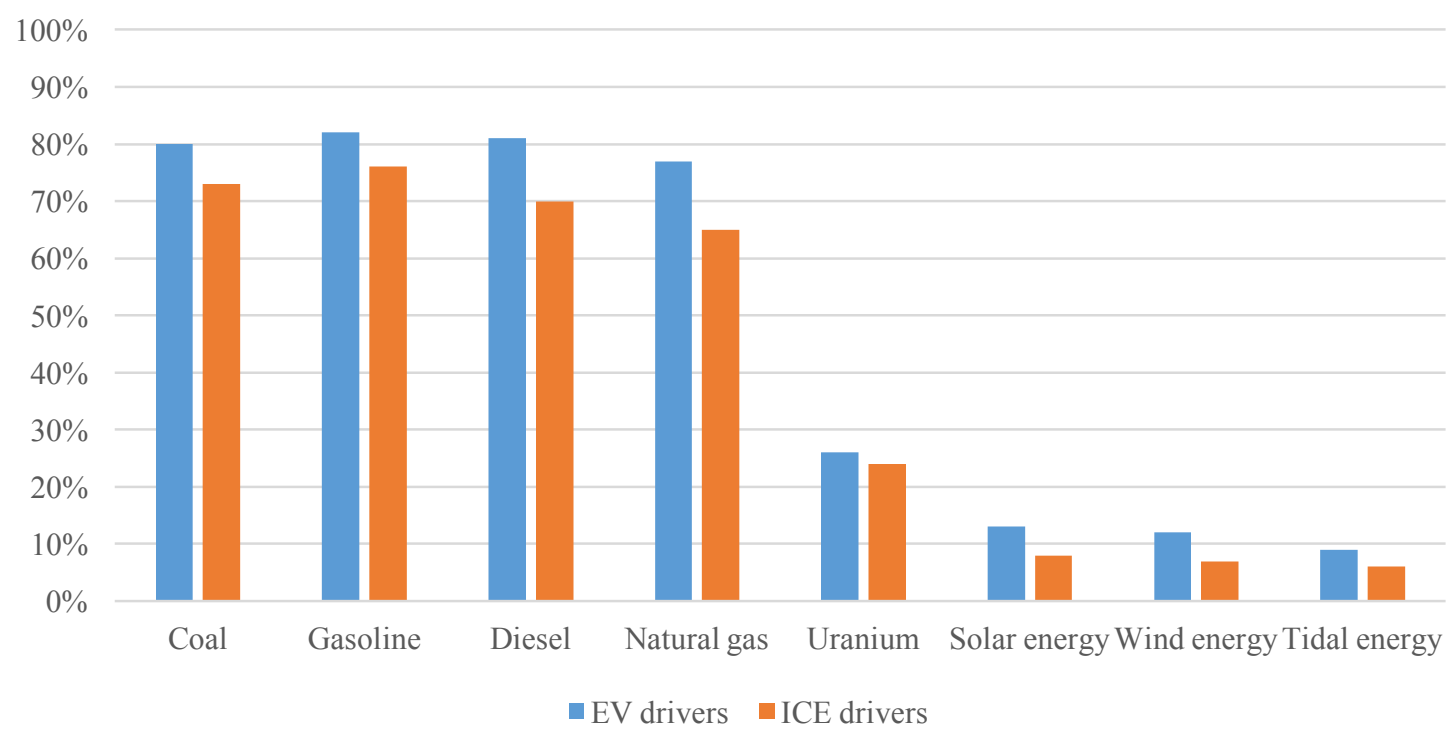

Gasoline is identified by the highest proportion of EV and ICE drivers as a 'fossil fuel,' followed by coal and diesel. Natural gas is seen by less respondents as a fossil fuel compared to gasoline. EV drivers in every category of supply mix options saw each fuel supply option as a fossil fuel, leading to the presumption that EV drivers are more critical of what supply fix sources produce fossil fuels (i.e. considering a more wide-encompassing life-cycle consideration in their individual analysis). Amongst the renewable supply mix options, ICE drivers were therefore more likely to view the options as a fossil fuel, and perhaps assume there are greater environmental benefits associated with those options. 


\subsubsection{Complexity (ease of use) as an indicator of purchase}

Complexity is addressed as the difficulty in understanding and using the innovation (Peters \& Dütschke, 2014). Their research indicates that respondents would be less likely to purchase and use an EV if they perceived the use of EVs as more complex, and less easy (ibid.). Driving is a fundamental practice for many individuals in North American societies, and therefore, formed habits such as re-fueling at a gasoline station can be difficult to break, and without clear incentive to adopt new behavioural patterns, there is little likelihood to suggest such amendments will occur.

Figure 28: Belief that respondents possess enough knowledge about "alternative vehicles" to make an informed choice for potential future purchase

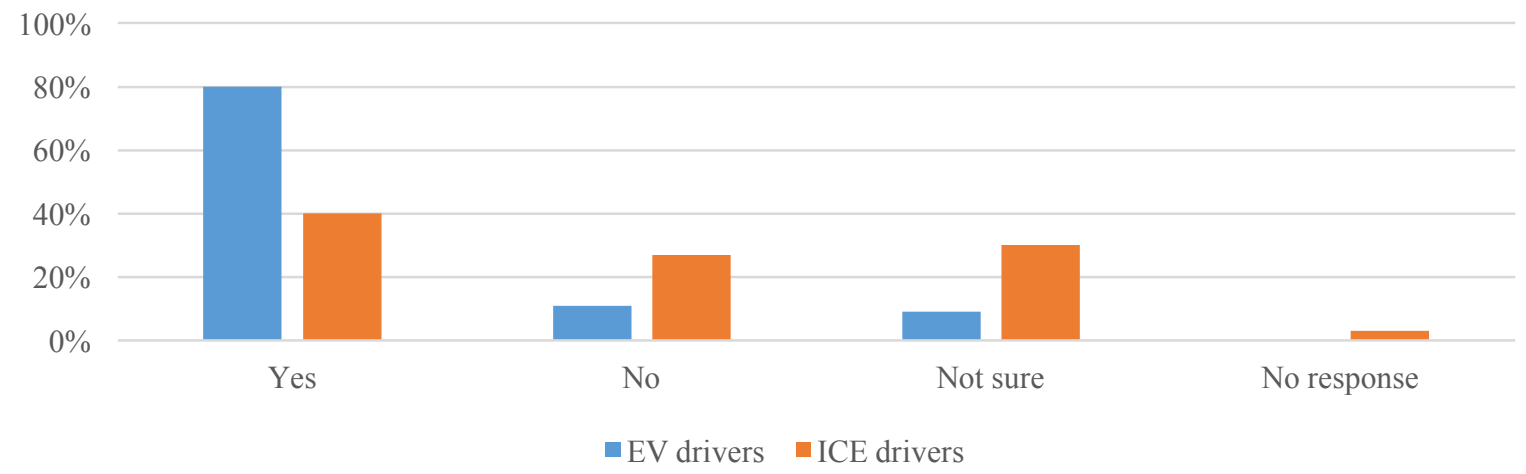

There are evident perceived knowledge gaps, particularly the number of individuals possessing enough knowledge to make an informed decision regarding EVs. Yet, perceived knowledge proved to not be a significant indicator in a non-EV owners' likelihood to purchase an EV. However, an ICE driver's perceived knowledge of the technology proved to have a significant relationship with gender, dwelling type, home ownership, and education amongst the socio-demographic variables and fuel costs, maintenance, environmental attitudes, likelihood to test drive, likelihood to visit a dealership, and social exposure amongst the decision-making variables. The only decision-making category in which perceived knowledge amongst ICE 
drivers proved to not have a significant relationship with was the correlation to the likelihood of purchase. Amongst EV drivers, the socio-demographic variables with significant correlations were gender, age, home ownership, and annual income, as well as environmental attitudes and likelihood to re-purchase amongst the decision-making variables.

\section{Perceived knowledge regarding electrified technology}

With any new innovative technology, misperceptions will become prevalent and may hinder immediate adoption of the product amongst the masses. Strategic management experts will often present timeline or clustered analyses to predict adoption rates given the characteristics of a society. However, if the opportunities and barriers are not understood at the individualistic level through accurate representation, the likelihood of predictive measures forecasting accurate uptake trends is highly questionable. EVs were long believed to obtain massive market uptake, and have still failed to capture the mainstream market in urban settings throughout North America.

Figure 29: Belief that sufficient information about EVs is available online among EV driving respondents

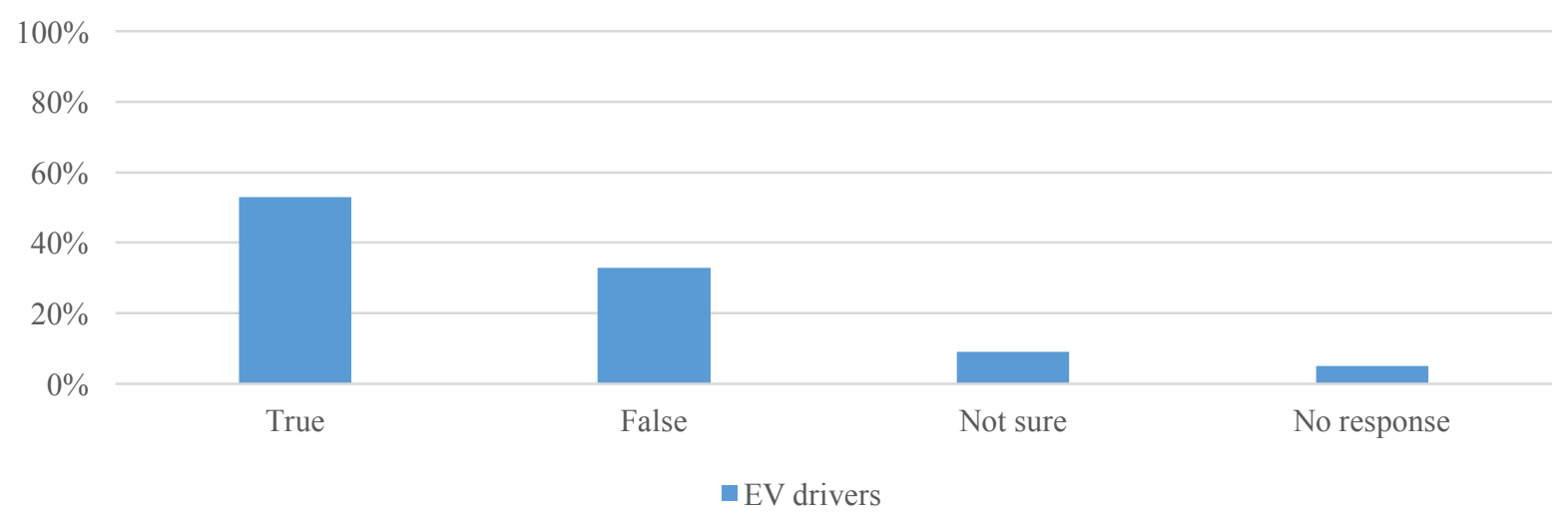

Amongst EV early adopters, there is clear interest from a technological perspective articulated by the participants. As a result, this study concerns itself with the way in which EV drivers acquired their knowledge of the vehicles and how that inevitably shaped their purchase 
decision. The majority of EV drivers found sufficient amounts of information through an online medium [Figure 29]. In supplement to the notion that consumer research is shifting to relying heavily on web-based content, 60 per cent of EV drivers perceived themselves to be more educated on EV technology than the dealers or salespeople who sold them their car [Figure 30].

Figure 30: Belief that they were more knowledgeable than the sales staff at dealerships amongst EV driving respondents who visited a dealership prior to making a purchase

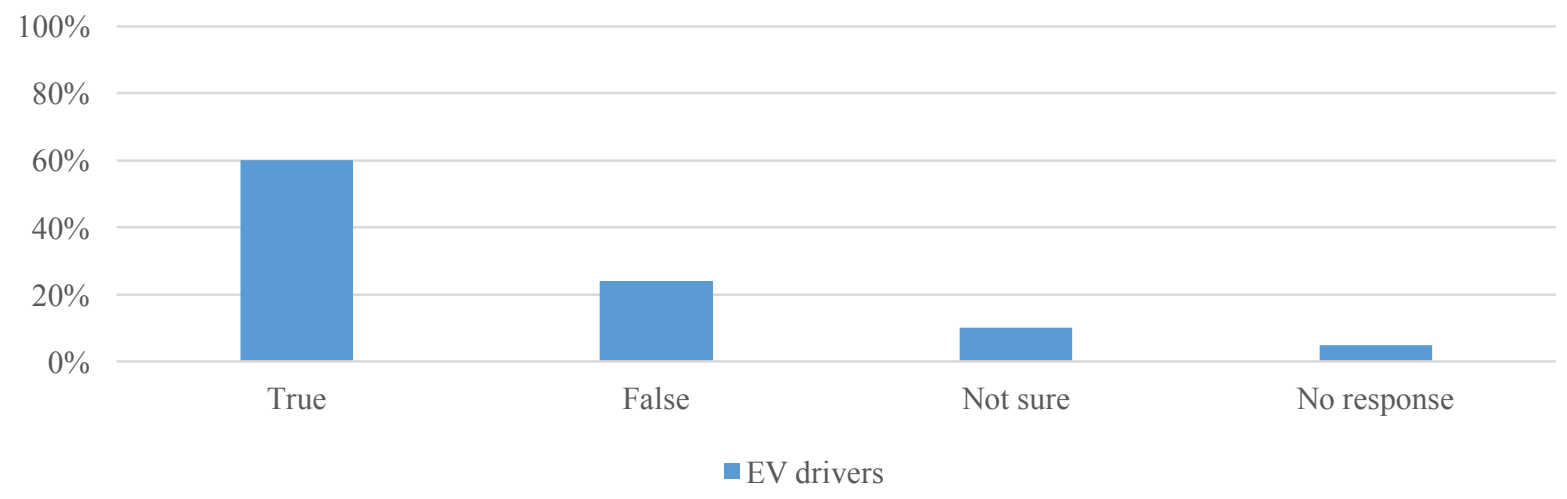

The lack of perceived expertise amongst dealership and sales staff is emphasized in the literature as problematic in prompting the further adoption amongst car-buyers who may not be dedicated to either an EV or ICE vehicles (Matthews et al., 2017).

\section{Perceived knowledge regarding incentive programs}

Incentive programs can often be utilized as a mechanism to address how the public sector selects and addresses priority areas. However, in the case of their EV related incentive programs, the Ontario government and the Ministry of Transportation Ontario have dedicated virtually no resources towards the public advertisement of such programs. As a result, five per cent of ICE drivers claim to be entirely aware of the existing EV incentive programs, while 62 per cent knew nothing about the available EV incentive programs. Perhaps of greater concern when measuring the effectiveness of such programs is that 54 per cent of EV owners knew a great deal about the programs in place to subsidize the costs of the vehicles they opted to purchase. 
Figure 31: Participants aware of Ontario's provincial incentives for PHEV and BEV purchases

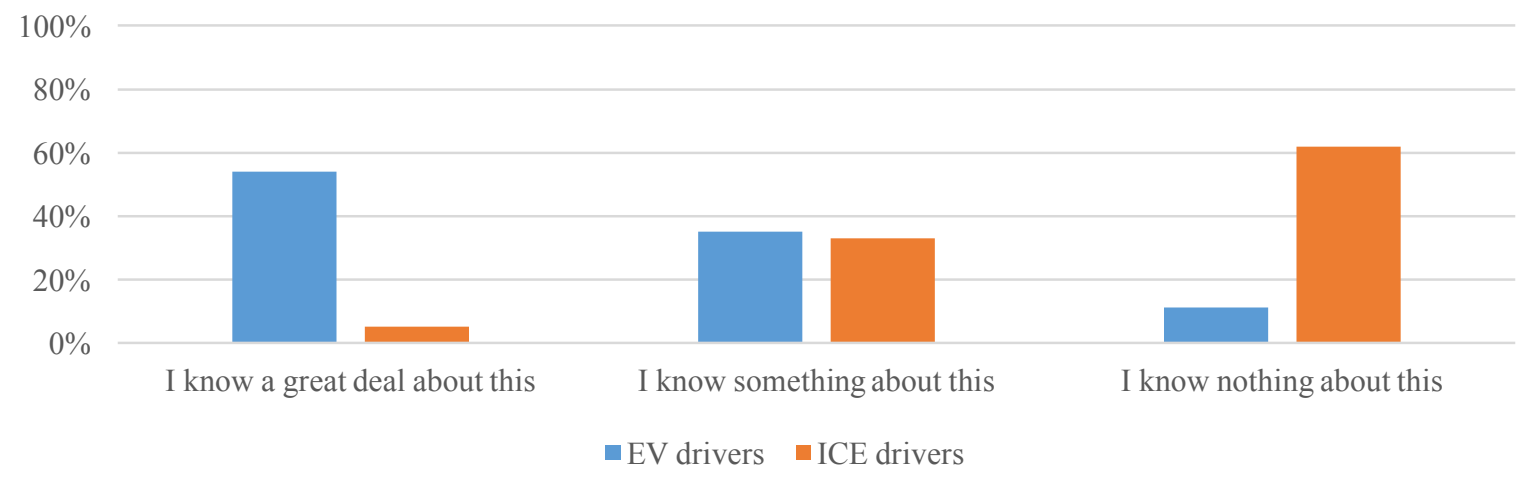

Less individuals than the number aware of the incentive programs amongst both cohorts were aware of Ontario's provincial incentives for the relevant home infrastructure purchase and installation to accompany the purchase of an EV. A mere four per cent of ICE drivers expressed their complete awareness of the EVSE purchase incentive program available, while 68 per cent had no idea such a program existed. Similarly, four per cent of ICE drivers expressed their awareness of the EVSE installation incentives available, while 69 per cent did not know this was available. In both queries, less than 50 per cent of EV drivers perhaps eligible for such programs were aware of the program details in full. This lack of knowledge perhaps creates additional barriers that prevent prospective EV drivers from engaging with the technology.

Figure 32: Participants aware of Ontario's provincial incentives for electric vehicles supply equipment (EVSE) purchases

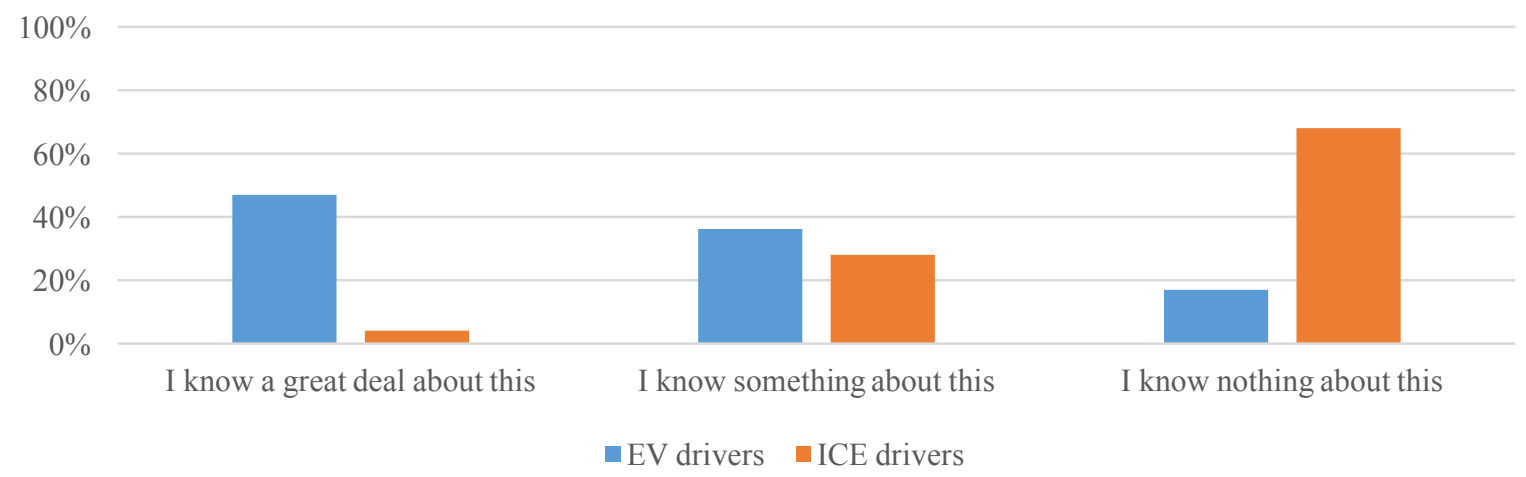




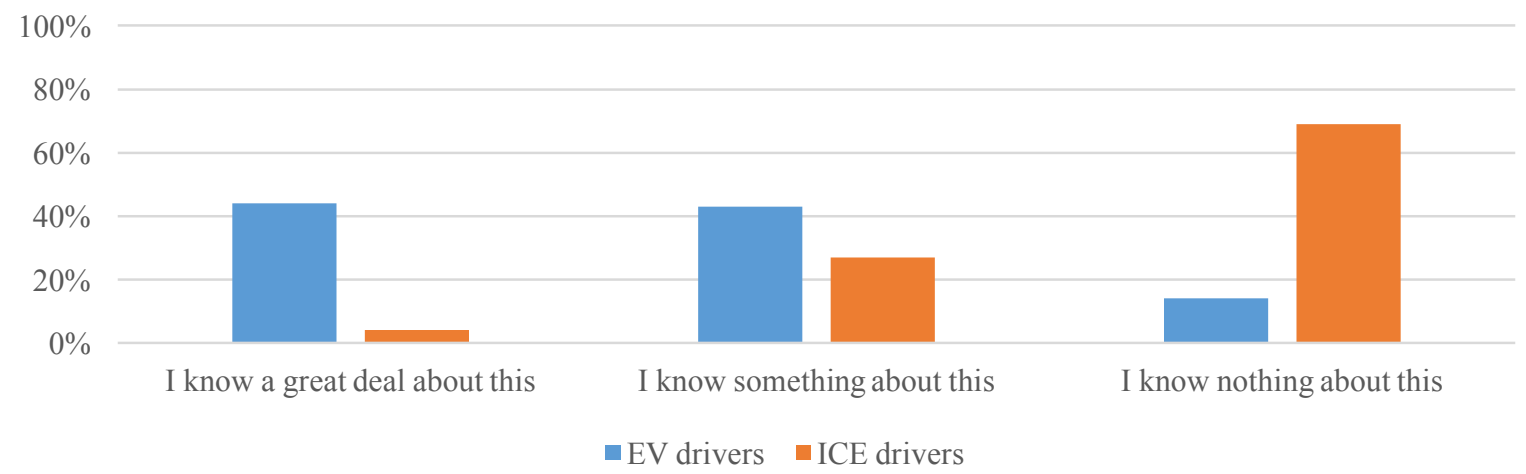

Such trends of low consumer awareness of incentive programs have been evident in the literature (Krause et al., 2013; Pinkse et al., 2014; Matthews et al., 2017). Public sector initiatives to subsidize the cost of EVs are not widely recognized by the mainstream car buying audience, which can defeat of the purpose of such initiatives.

\subsubsection{Trialability as an indicator of purchase}

Trialability is defined as the possibility to test the innovation before the decision to adopt (Peters \& Dütschke, 2014). The availability of EVs in North American dealerships can be limited as automakers identify their limited uptake to date. However, the Government of Ontario addressed such concerns in initiating the funding of the world's first Electric Vehicle Discovery Centre in Toronto, created by Plug'n Drive (Plug'n Drive, 2017). The Centre is designed as an experiential learning environment where individuals can engage with the vehicles and learn about their environmental and economic benefits (ibid.). Given this impartial mandate, the Centre is a compelling education and outreach model to address and combat the gaps faced by consumers unable to acquire the desired information and engage with the technology at their local dealerships.

For ICE drivers, the main co-variates with significant relationships to the likelihood of test drive is one's income levels, the perceived cost of fuel, and the perceived cost of 
maintenance. Yet, amongst EV drivers, the only significant relationship is the perceived cost of maintenance. Trialability was not a statistically significant predictive factor to influence non-EV owners to purchase an EV as their next vehicle, but yet an overwhelming amount of EV drivers do partake in a test drive. Nonetheless, the majority of early EV adopters and ICE drivers did in fact complete a test drive. The test drive perhaps acts as a reinforcement in one's decision to purchase a new vehicle that may not have a deep influence on one's likelihood to purchase an EV as their next vehicle.

Figure 34: Participants that completed test drives amongst potential makes and models considered for purchase

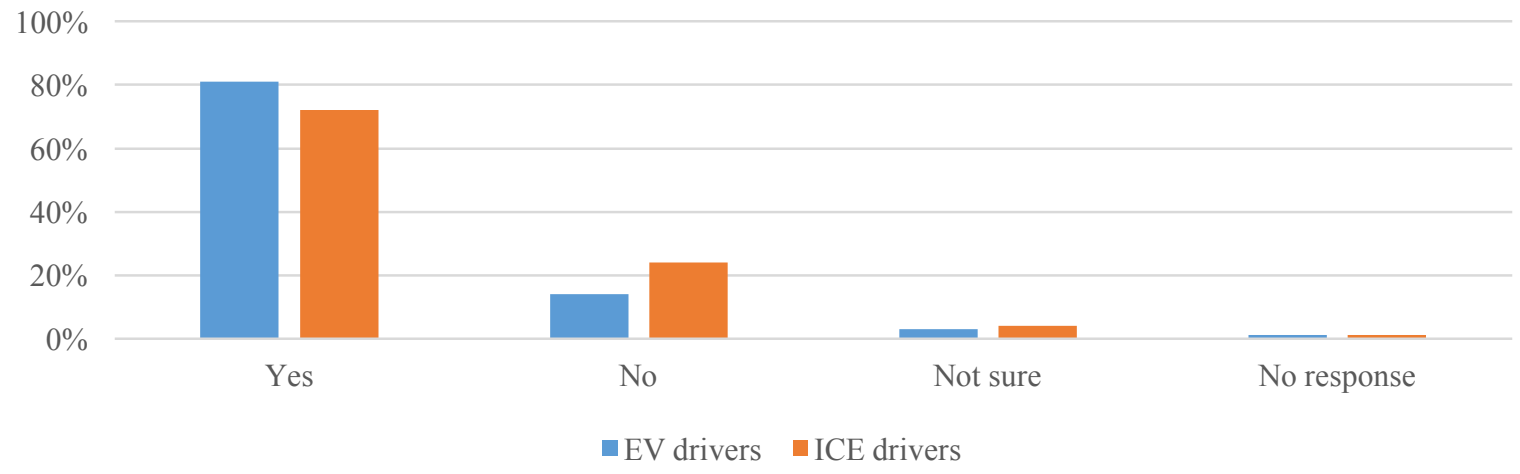

While there is no surprise EV drivers are more likely to have test driven an EV compared to ICE drivers, the proportion of ICE drivers who opted to test drive an EV is minimal, ranging between four to ten per cent. This begs for further inquiry as to whether consumers are uninterested in exploring these alternative vehicle options, or if the lack of exposure in dealerships serves as a barrier to prevent adoption. 
Figure 35: Type of electric vehicles test driven by participants

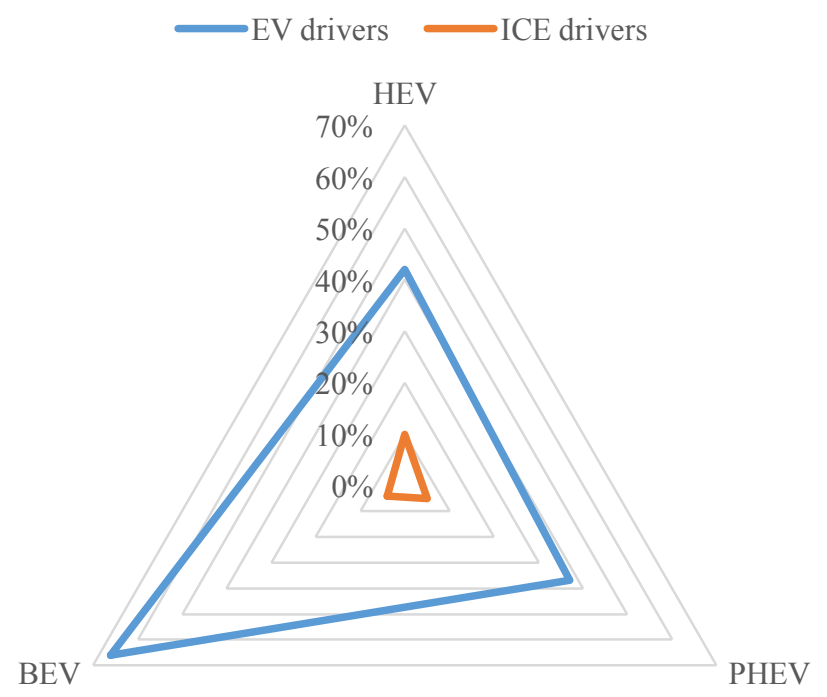

Non-EV owners are two times more likely to test drive an HEV instead of a BEV and PHEV, which reinforces other findings in the literature implying that hybrids may in fact act as an easier transition to electrified technologies for a more mainstream audience (Axsen et al., 2015; Axsen et al., 2016).

\subsubsection{Observability as an indicator of purchase}

Observability is defined as the visibility of an innovation (Peters \& Dütschke, 2014). In the case of this research, the term is understood as the type of interaction an individual has had with the EV in order to influence purchase. Since the model requires the selection of one query, the visitation to a dealership was selected as it best embodies the traditional pathway of purchasing a new vehicle. Pure observation did not influence the model as a statistically significant predictive factor when related to the likelihood of purchase of an EV. This invokes an 
assumption that interactions with the vehicle may be for purposes more related to confirmation as opposed to research.

When evaluating the relationship between the variates to the likelihood of visiting a car dealership, there were several significant patterns. Amongst ICE drivers, one's age, ownership of their dwelling, income, perceived cost of maintenance, and likelihood of test drive can impact the likelihood of visiting a dealership. Yet, Figure 30 remains an interesting case demonstrating that the majority of EV drivers feel as though dealers are in large part unknowledgeable about the vehicles. The only co-variate with a significant relationship amongst EV drivers is the test drive, which makes sense as both EV and ICE drivers who wanted to test drive a vehicle would traditionally go to the dealership to do so.

\section{Type of inquiry performed prior to purchase}

In order to get a better sense of market trends, there is great significance in understanding how an individual makes a decision based on the resources available to them. Figure 36 underscores that EV drivers are more likely to engage in all types of processes for further review. The trend suggests that EV drivers do more research prior to purchase. The greatest disparity is in online searching, which shows that 80 per cent of EV drivers to prior online research compared to 63 per cent of ICE drivers. The literature to date does not adequately address the means in which people seek out information to inform their purchase of an EV. The influence of online research as opposed to the dealership may be attributed to the younger population on average of the EV cohort. Perhaps when adopting new technology, the internet is a useful tool to read reviews and commentary provided by others to help decide whether an EV suits your existing or aspired lifestyle. 
Figure 36: Participant processes for reviewing potential makes and models of vehicles for purchase or lease

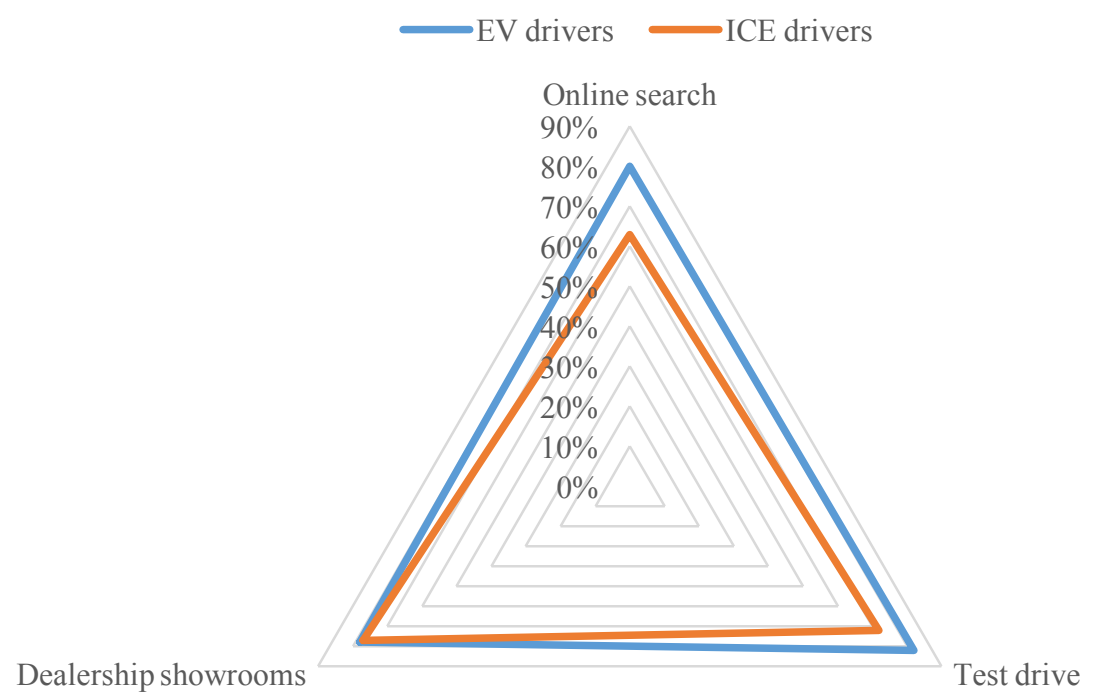

\subsubsection{Social norm}

Perceived social norm is defined as an individual's expectation that a certain kind of behaviour is expected by others (Peters \& Dütschke, 2014). The theory of the researchers references the TAM model later extension to include social norms, in an attempt to better account for inter-individual factors (Taylor \& Todd, 1995; Peters \& Dütschke, 2014). Social networks in prior research has been found to be somewhat influential over the likelihood of an individual purchasing an HEV where population densities are greater (Skerlos \& Winebrake, 2010). For the purposes of this study, social norms refer to networks and query as to whether participants were exposed to EVs by the people they surround themselves with.

Social influence was a significant predictive factor that may influence non-EV drivers to purchase an EV as their next vehicle. When analyzing the variables that had relationships with social exposure, ICE drivers demonstrated a relationship for the co-variates of gender, education, 
fuel costs, maintenance, and the likelihood of test driving the vehicle. EV drivers articulated no significant relationships with their social networks to determine whether they would re-purchase an EV as their next vehicle, which appears likely because they have already made the decision to do and may no longer seek the validation of others.

Over three-quarters of ICE drivers were never introduced to an EV as a result of their social networks, which suggests that people in their immediate networks may not drive EVs or participants may not be aware the vehicle is electrified. However, the significant correlation between the small proportion of ICE driving participants who stated they had been previously exposed to an EV and their likelihood to purchase showed promise. With less than half of current EV drivers expressing that they were initially exposed to the vehicle through their networks, this suggests that the early adopting community did not seek the satisfaction of the EV drivers before them in order to form a purchase decision.

Figure 37: Introduction of PHEV or BEV by anyone in one's social networks

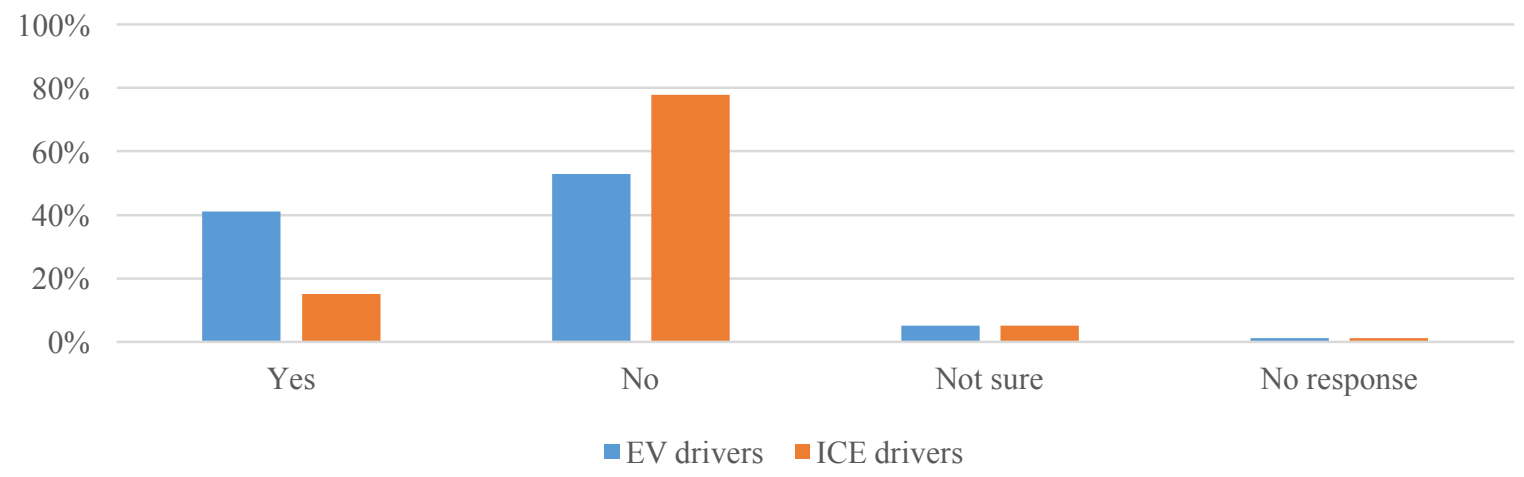

Of the vehicles participants were introduced to within their social networks, EV drivers were primarily introduced to BEVs (37 per cent) while ICE drivers were overwhelmingly introduced to PHEVs (46 per cent). Less than 20 per cent of ICE drivers are unsure as to which type of EV they drove, which perhaps perpetuates the misunderstanding towards hybrid powertrain technologies. 
Over half of EV drivers sought out the advice of others prior to their purchase, while onethird did not consult anyone in their social network [Figure 38]. One-third of EV drivers actually took their initial conversation one step further and tried driving an EV purchased by contacts in their network [Figure 39].

Figure 38: Participants who spoke with colleagues, family members, or friends about car options prior to purchase

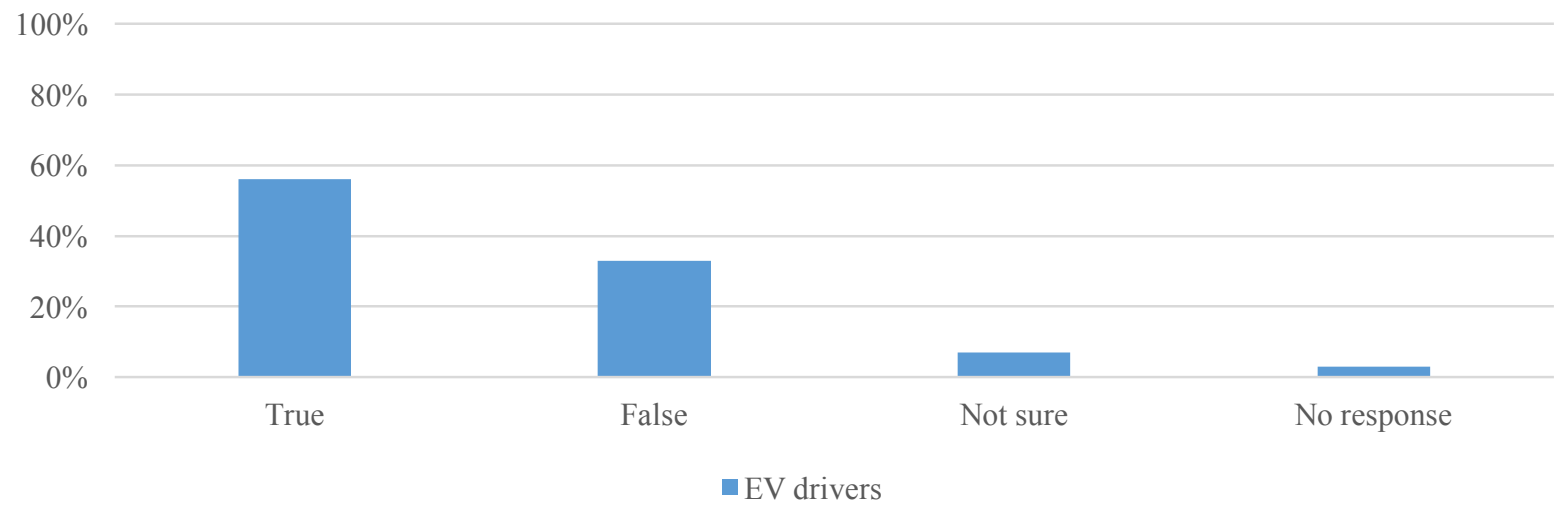

Figure 39: Participants who tried driving a PHEV or BEV owned by a friend or colleague

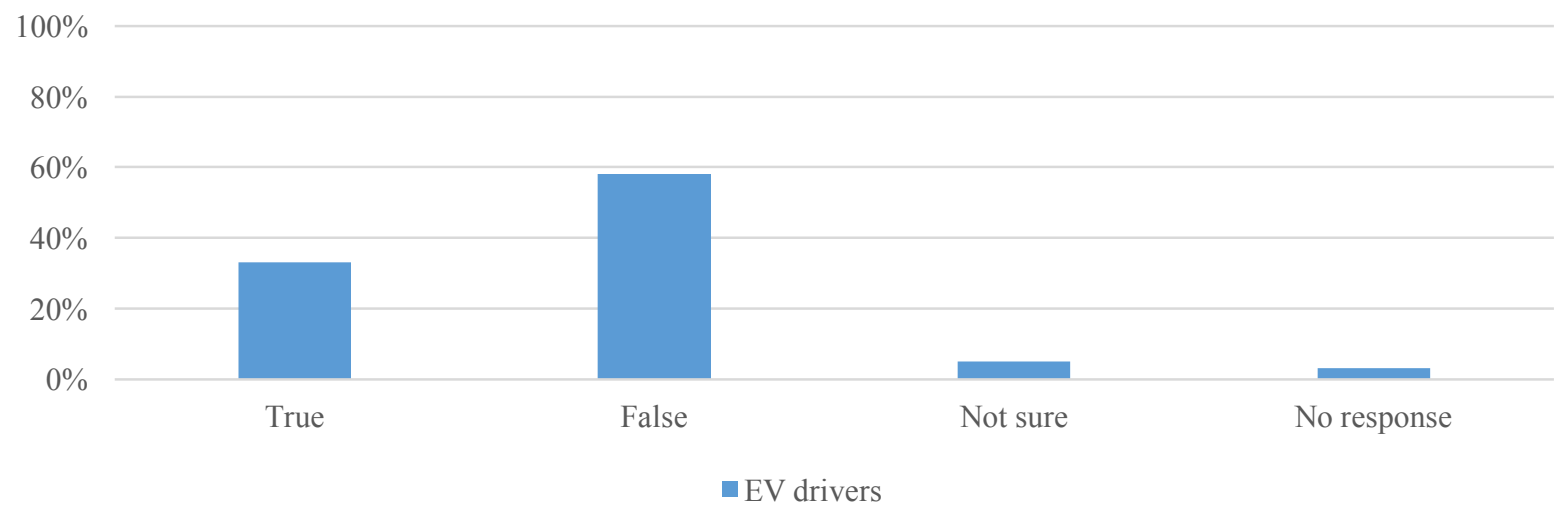




\section{Chapter 5 Conclusions}

This chapter provides a holistic impression of the research findings to guide future policy. As previously stated, this was Ontario's first known EV owners survey study, and therefore, aims to better inform the decision-making process based on the experiences and interests of prospective and existing EV drivers.

The typical EV driver proves to be younger, more educated consumers often looking for a second vehicle to acquire. Many work in the STEM fields and live in urban environments within the GTHA. The commitment to EVs amongst the entire survey participant population is not very strong, and there are clear gaps in the knowledge of EV technology that if addressed could stimulate far greater rates of uptake. Those who own an EV demonstrate high levels of satisfaction with their purchase, and believe they can drive further distances and use their car more than ICE drivers. Current EV drivers are therefore very likely to repurchase an EV as their next vehicle, while 21 per cent of ICE drivers were either very likely or likely to purchase an EV as their next vehicle. EV drivers, do however, have a higher upfront price range flexibility for purchasing a car, likely as a result of their higher income. The high initial upfront cost proves to not be sufficient enough to stimulate commitment from the majority of non-EV drivers, although there is a decent amount of interest present.

Low consumer awareness of the technology and related infrastructure, and thereby the implications on one's lifestyle, remains a persisting barrier to widespread adoption. This invites the question that if research is conducted in which the technology is thoroughly explained to participants, perhaps that could stimulate greater interest in electrified transportation options. EVs are not recognized amongst the non-owners' population for the cost-saving potential that the current EV drivers advocate for. As well, the EV has been presented as a more feasible option 
for inter-city driving, but as the network of public charging stations is established and expanded on relevant highways, it will be interesting to see the impacts that has on demand for EVs. Range anxiety remains a persistent problem and because of the rapid acceleration in EV battery technology, consumer perception largely persists that the car may not be able to travel the distance desired by the user, whether or not this is factually evident. This study also validates that amongst potential EV drivers who are passively considering adoption, hybrid models can act as an experimental buffer to engage with EVs without entirely committed to a BEV.

The market itself is experiencing large-scale reform as a result of fast-paced innovation, and as a result the EV is receiving greater representation in the automotive space as the race to commercialize occurs. Despite the newfound spotlight of EVs in the media, PEV sales seem to be hindered by the lack of available models. Both EV and ICE drivers are committed to Toyota in large part, but the highest level of commitment was demonstrated by EV drivers to Tesla, a product intensely disturbing the status-quo in an already dynamic sector. Both EV and ICE drivers are committed to Sedans and SUVs, and as new EV makes and models enter the Canadian market this interest will likely intensify. From a more holistic impression of the impacts of the technology, non-EV drivers generally believe that their cars contribute to global warming, but not enough to commit to purchase an EV. This alludes to a lower WTP likely attributed to the perceived costs of EV ownership.

Based on the model proposed, this research is predominately concerned with the interest levels of non-EV owners who may be likely to purchase an EV as their next vehicle, and which co-variates that information relates to. For ICE drivers, age, the number of individuals in their household, and their level of education were statistically significant co-variates to influence the model. As well, compatibility (concern for the environment) and social norms (social network 
influences) were statistically significant predictive factors in the non-EV owner's likelihood to purchase an EV as their next vehicle. Environmental concern was notably prevalent as the findings indicate that one's belief in possessing personal responsibility in confronting climate change may be an initial motivator in the purchase of an EV. However, this finding did not deviate from previous research and assumptions in the marketing of such vehicles. Arguably the most original component of this research stems from the importance of one's social network in their likelihood to purchase an EV. When drivers were introduced to an EV by someone in their personal network, they were the cohort increasingly likely to adopt the vehicle. The key aspects of such a finding indicate that scenarios in which prospective drivers interact with existing owners to discover their perception of the vehicle may be a strategy useful way of encouraging uptake. Remarkably, an overwhelming number of GTHA residents are also not aware of EV incentives, and this draws concerns that public policy is not being utilized as effectively as possible.

As previously mentioned, this research provides the opportunity for practical outputs beyond the scope of academia. The academic community and future researchers may benefit from this research acting as a case study for exploring the opportunities and implications of emerging and future alternative mobility options, especially with more sustainable transportation options such as electric transit and hydrogen fuel cell gaining traction. Both automakers and dealerships may find the gaps of knowledge striking and perhaps this can initiate a dialogue on how dealers should be better trained to address public inquiries and find solutions to the lack of makes and models often available on-site. The results clearly indicate that the current dealership model is not efficient and not serving the interested EV drivers much use. Public stakeholders and government policy-makers may find such results promising in terms of the expressed 
growing interest but also may consider the re-structuring of existing policies that are proving to be less effective in generating mass consumer interest. In addition, as Canada's largest city, there is an opportunity to utilize these findings to better plan for the uptake of EVs in smaller communities and towns in Ontario and elsewhere. There is a great deal of opportunities to improve EV metrics using these findings, notably as this is the first survey of its kind specific to the GTHA.

Further research into the topic is highly recommended and it is hoped this study inspires future curiosity in the topic. A qualitative interview study with owners and prospective buyers to better understand the intentions that speak to the data captured in this study would be particularly useful for further insight. In terms of the possible replication or repetition of a study of this nature, it is strongly recommended that the scale is expanded to include other jurisdictions with differing policies to better measure the actual effectiveness of Ontario's work to date. In addition, worthwhile research could include testing price-demand elasticity and consumer response to gasoline price variances as an indicator of EV interest. Lastly, the role of social networks in stimulating EV interests may be an entirely separate study given the weak but significant results 


\section{Appendix}

Table 19: Full relationship modelling amongst socio-demographic variables amongst ICE drivers (from Table 6)

\begin{tabular}{|c|c|c|c|c|c|c|c|}
\hline & Gender & Age & $\begin{array}{l}\text { Household } \\
\text { number }\end{array}$ & Dwelling & Own/rent & Income & Education \\
\hline \multicolumn{8}{|l|}{ Gender } \\
\hline $\begin{array}{l}\text { Correlation } \\
\text { coefficient }\end{array}$ & & $0.172 * *$ & -0.021 & -0.059 & $-0.091 * *$ & 0.018 & -0.029 \\
\hline Sig. (2-tailed) & & 0.000 & 0.503 & 0.061 & 0.004 & 0.568 & 0.366 \\
\hline$n$ value & & 1000 & 1000 & 1000 & 1000 & 1000 & 1000 \\
\hline \multicolumn{8}{|l|}{ Age } \\
\hline $\begin{array}{l}\text { Correlation } \\
\text { coefficient }\end{array}$ & & & $-0.225 * *$ & -0.028 & $-0.214^{* *}$ & 0.035 & $-0.072 *$ \\
\hline Sig. (2-tailed) & & & 0.000 & 0.380 & 0.000 & 0.268 & 0.022 \\
\hline$n$ value & & & 1000 & 1000 & 1000 & 1000 & 1000 \\
\hline \multicolumn{8}{|l|}{$\begin{array}{l}\text { Household } \\
\text { number }\end{array}$} \\
\hline $\begin{array}{l}\text { Correlation } \\
\text { coefficient }\end{array}$ & & & & $-0.315^{* *}$ & $-0.075^{*}$ & $0.255^{* *}$ & 0.001 \\
\hline Sig. (2-tailed) & & & & 0.000 & 0.017 & 0.000 & 0.985 \\
\hline$n$ value & & & & 1000 & 1000 & 1000 & 1000 \\
\hline \multicolumn{8}{|l|}{ Dwelling } \\
\hline $\begin{array}{l}\text { Correlation } \\
\text { coefficient }\end{array}$ & & & & & $0.454 * *$ & $-0.255^{*}$ & -0.022 \\
\hline Sig. (2-tailed) & & & & & 0.000 & 0.000 & 0.486 \\
\hline$n$ value & & & & & 1000 & 1000 & 1000 \\
\hline \multicolumn{8}{|l|}{ Own/rent } \\
\hline $\begin{array}{l}\text { Correlation } \\
\text { coefficient }\end{array}$ & & & & & & $-0.241 * *$ & -0.048 \\
\hline Sig. (2-tailed) & & & & & & 0.000 & 0.129 \\
\hline$n$ value & & & & & & 1000 & 1000 \\
\hline \multicolumn{8}{|l|}{ Income } \\
\hline $\begin{array}{l}\text { Correlation } \\
\text { coefficient } \\
\text { Sig. (2-tailed) }\end{array}$ & & & & & & & $\begin{array}{l}-0.186^{* *} \\
0.000\end{array}$ \\
\hline$n$ value & & & & & & & 1000 \\
\hline $\begin{array}{l}\text { Education } \\
\text { Correlation } \\
\text { coefficient } \\
\text { Sig. (2-tailed) } \\
n \text { value }\end{array}$ & & & & & & & \\
\hline
\end{tabular}

Table 20: Full relationship modelling amongst socio-demographic variables amongst EV drivers (from Table 7)

\begin{tabular}{|c|c|c|c|c|c|c|c|}
\hline & Gender & Age & $\begin{array}{l}\text { Household } \\
\text { number }\end{array}$ & Dwelling & Own/rent & Income & Education \\
\hline \multicolumn{8}{|l|}{ Gender } \\
\hline $\begin{array}{l}\text { Correlation } \\
\text { coefficient }\end{array}$ & & $0.271 * *$ & -0.015 & -0.136 & -0.117 & $0.231 * *$ & -0.018 \\
\hline Sig. (2-tailed) & & 0.000 & 0.841 & 0.059 & 0.105 & 0.001 & 0.801 \\
\hline$n$ value & & 192 & 192 & 192 & 192 & 192 & 192 \\
\hline \multicolumn{8}{|l|}{ Age } \\
\hline $\begin{array}{l}\text { Correlation } \\
\text { coefficient }\end{array}$ & & & 0.021 & $-0.263 * *$ & $-0.263 * *$ & $0.381 * *$ & -0.080 \\
\hline Sig. (2-tailed) & & & 0.777 & 0.000 & 0.000 & 0.000 & 0.270 \\
\hline$n$ value & & & 192 & 192 & 192 & 192 & 192 \\
\hline
\end{tabular}




\begin{tabular}{|c|c|c|c|c|}
\hline $\begin{array}{l}\text { Correlation } \\
\text { coefficient }\end{array}$ & -0.134 & 0.006 & 0.132 & -0.047 \\
\hline Sig. (2-tailed) & 0.063 & 0.937 & 0.067 & 0.517 \\
\hline$n$ value & 192 & 192 & 192 & 192 \\
\hline \multicolumn{5}{|l|}{ Dwelling } \\
\hline $\begin{array}{l}\text { Correlation } \\
\text { coefficient }\end{array}$ & & $0.427 * *$ & $-0.240 * *$ & -0.058 \\
\hline Sig. (2-tailed) & & 0.000 & 0.001 & 0.428 \\
\hline$n$ value & & 192 & 192 & 192 \\
\hline \multicolumn{5}{|l|}{ Own/rent } \\
\hline $\begin{array}{l}\text { Correlation } \\
\text { coefficient }\end{array}$ & & & $-0.318 * *$ & 0.038 \\
\hline Sig. (2-tailed) & & & 0.000 & 0.600 \\
\hline$n$ value & & & 192 & 192 \\
\hline \multicolumn{5}{|l|}{ Income } \\
\hline $\begin{array}{l}\text { Correlation } \\
\text { coefficient }\end{array}$ & & & & 0.058 \\
\hline Sig. (2-tailed) & & & & 0.425 \\
\hline$n$ value & & & & 192 \\
\hline $\begin{array}{l}\text { Education } \\
\text { Correlation } \\
\text { coefficient } \\
\text { Sig. (2-tailed) } \\
n \text { value }\end{array}$ & & & & \\
\hline
\end{tabular}

Table 21: Full relationship modelling amongst purchase decision-making factors based on socio-demographic factors amongst ICE drivers (from Table 12)

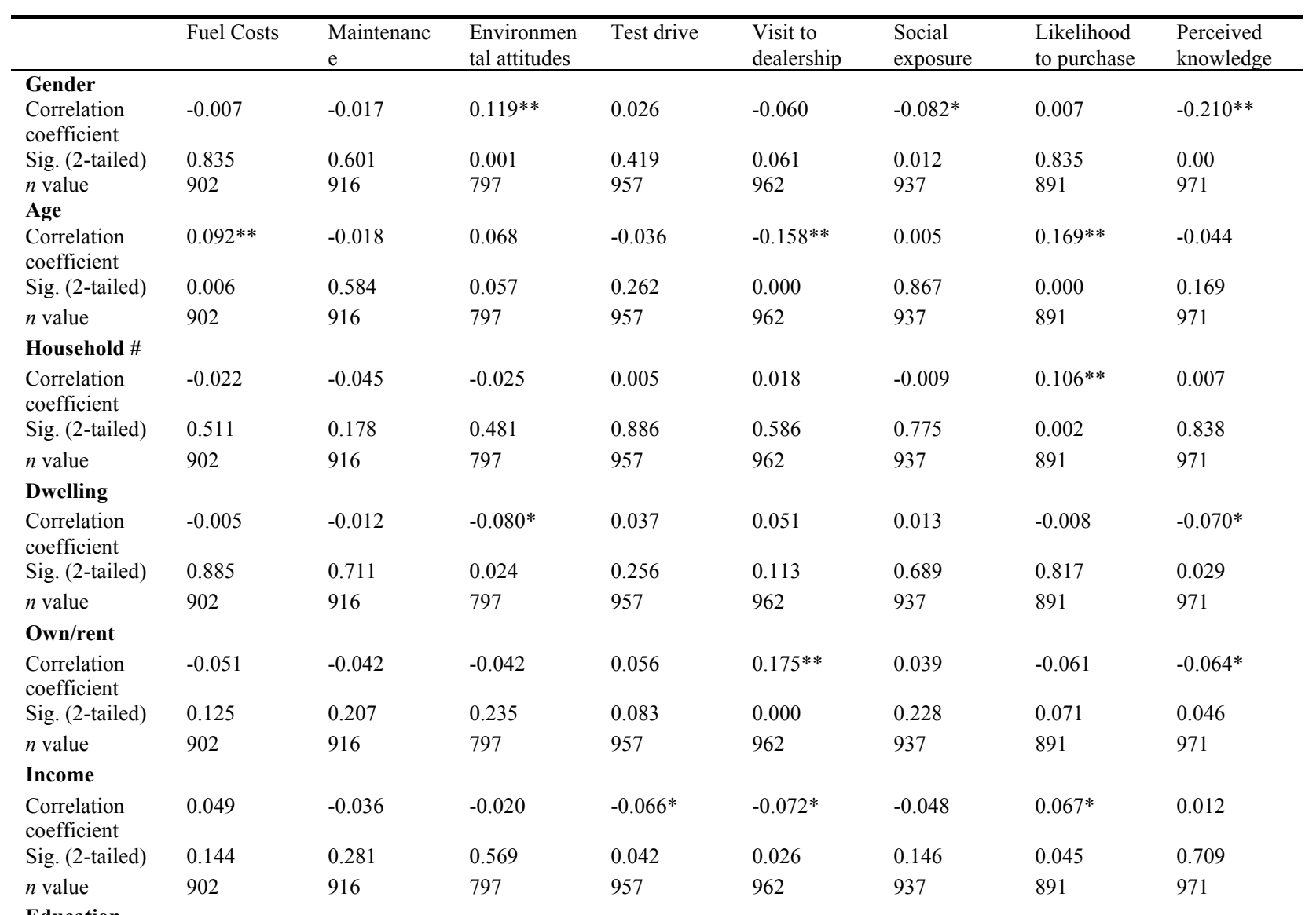




\begin{tabular}{lllllllll}
$\begin{array}{l}\text { Correlation } \\
\text { coefficient }\end{array}$ & -0.053 & $-0.072 *$ & 0.026 & -0.044 & -0.034 & $-0.089 * *$ & $-0.103 * *$ & $-0.098^{* *}$ \\
$\begin{array}{l}\text { Sig. (2-tailed) } \\
n \text { value }\end{array}$ & 0.115 & 0.029 & 0.466 & 0.177 & 0.297 & 0.006 & 0.002 & 0.002 \\
\hline & 902 & 916 & 797 & 957 & 962 & 937 & 891 & 971 \\
\hline
\end{tabular}

Table 22: Full relationship modelling amongst purchase decision-making factors based on socio-demographic factors amongst EV drivers (from Table 13)

\begin{tabular}{|c|c|c|c|c|c|c|c|c|}
\hline & Fuel Costs & $\begin{array}{l}\text { Maintenanc } \\
\mathrm{e}\end{array}$ & $\begin{array}{l}\text { Environmen } \\
\text { tal attitudes }\end{array}$ & Test drive & $\begin{array}{l}\text { Visit to } \\
\text { dealership }\end{array}$ & $\begin{array}{l}\text { Social } \\
\text { exposure }\end{array}$ & $\begin{array}{l}\text { Likelihood } \\
\text { to purchase }\end{array}$ & $\begin{array}{l}\text { Perceived } \\
\text { knowledge }\end{array}$ \\
\hline \multicolumn{9}{|l|}{ Gender } \\
\hline $\begin{array}{l}\text { Correlation } \\
\text { coefficient }\end{array}$ & 0.054 & -0.107 & $-0.222 * *$ & 0.031 & -0.008 & 0.081 & $-0.166^{*}$ & $-0.214 * *$ \\
\hline Sig. (2-tailed) & 0.473 & 0.150 & 0.003 & 0.675 & 0.913 & 0.276 & 0.023 & 0.003 \\
\hline$n$ value & 177 & 181 & 173 & 184 & 183 & 181 & 188 & 192 \\
\hline \multicolumn{9}{|l|}{ Age } \\
\hline $\begin{array}{l}\text { Correlation } \\
\text { coefficient }\end{array}$ & 0.102 & -0.100 & $-0.246^{* *}$ & -0.043 & -0.023 & 0.120 & $-0.373 * *$ & $-0.361 * *$ \\
\hline Sig. (2-tailed) & 0.175 & 0.182 & 0.001 & 0.559 & 0.753 & 0.107 & 0.000 & 0.000 \\
\hline$n$ value & 177 & 181 & 173 & 184 & 183 & 181 & 188 & 192 \\
\hline \multicolumn{9}{|l|}{ Household \# } \\
\hline $\begin{array}{l}\text { Correlation } \\
\text { coefficient }\end{array}$ & -0.147 & -0.024 & -0.034 & -0.054 & -0.116 & -0.070 & 0.015 & -0.079 \\
\hline Sig. (2-tailed) & 0.051 & 0.749 & 0.656 & 0.463 & 0.116 & 0.346 & 0.834 & 0.276 \\
\hline$n$ value & 177 & 181 & 173 & 184 & 183 & 181 & 188 & 192 \\
\hline \multicolumn{9}{|l|}{ Dwelling } \\
\hline $\begin{array}{l}\text { Correlation } \\
\text { coefficient }\end{array}$ & -0.045 & -0.085 & 0.033 & 0.020 & -0.051 & 0.053 & 0.114 & 0.111 \\
\hline Sig. (2-tailed) & 0.553 & 0.256 & 0.669 & 0.792 & 0.497 & 0.474 & 0.120 & 0.125 \\
\hline$n$ value & 177 & 181 & 173 & 184 & 183 & 181 & 188 & 192 \\
\hline \multicolumn{9}{|l|}{ Own/rent } \\
\hline $\begin{array}{l}\text { Correlation } \\
\text { coefficient }\end{array}$ & -0.018 & 0.117 & -0.052 & 0.041 & 0.055 & 0.012 & 0.050 & $-0.159^{*}$ \\
\hline Sig. (2-tailed) & 0.810 & 0.115 & 0.494 & 0.576 & 0.457 & 0.872 & 0.494 & 0.027 \\
\hline$n$ value & 177 & 181 & 173 & 184 & 183 & 181 & 188 & 192 \\
\hline \multicolumn{9}{|l|}{ Income } \\
\hline $\begin{array}{l}\text { Correlation } \\
\text { coefficient }\end{array}$ & 0.118 & -0.066 & -0.141 & -0.041 & -0.029 & -0.116 & $-0.383 *$ & $-0.224 * *$ \\
\hline Sig. (2-tailed) & 0.118 & 0.380 & 0.064 & 0.576 & 0.700 & 0.121 & 0.000 & 0.002 \\
\hline$n$ value & 177 & 181 & 173 & 184 & 183 & 181 & 188 & 192 \\
\hline \multicolumn{9}{|l|}{ Education } \\
\hline $\begin{array}{l}\text { Correlation } \\
\text { coefficient }\end{array}$ & -0.081 & 0.089 & 0.011 & -0.087 & 0.035 & -0.140 & 0.109 & 0.060 \\
\hline Sig. (2-tailed) & 0.282 & 0.236 & 0.887 & 0.243 & 0.635 & 0.060 & 0.136 & 0.405 \\
\hline$n$ value & 177 & 181 & 173 & 184 & 183 & 181 & 188 & 192 \\
\hline
\end{tabular}

Table 23: Full relationship modelling amongst factors to influence purchase amongst ICE drivers (from Table 14)

\begin{tabular}{|c|c|c|c|c|c|c|c|c|}
\hline & Fuel Costs & $\begin{array}{l}\text { Maintenanc } \\
\mathrm{e}\end{array}$ & $\begin{array}{l}\text { Environmen } \\
\text { tal attitudes }\end{array}$ & Test drive & $\begin{array}{l}\text { Visit to } \\
\text { dealership }\end{array}$ & $\begin{array}{l}\text { Social } \\
\text { exposure }\end{array}$ & $\begin{array}{l}\text { Likelihood } \\
\text { to purchase }\end{array}$ & $\begin{array}{l}\text { Perceived } \\
\text { knowledge }\end{array}$ \\
\hline \multicolumn{9}{|l|}{ Fuel Costs } \\
\hline $\begin{array}{l}\text { Correlation } \\
\text { coefficient }\end{array}$ & & $0.378 * *$ & -0.007 & $0.084 *$ & 0.039 & $0.091 * *$ & $0.108^{* *}$ & $0.105^{* *}$ \\
\hline Sig. (2-tailed) & & 0.000 & 0.856 & 0.012 & 0.250 & 0.007 & 0.002 & 0.002 \\
\hline$n$ value & & 861 & 738 & 878 & 885 & 865 & 808 & 880 \\
\hline
\end{tabular}




\begin{tabular}{|c|c|c|c|c|c|c|}
\hline $\begin{array}{l}\text { Correlation } \\
\text { coefficient }\end{array}$ & -0.013 & $0.175^{* *}$ & $0.114^{* *}$ & $0.179^{* *}$ & 0.043 & $0.176^{* *}$ \\
\hline Sig. (2-tailed) & 0.720 & 0.000 & 0.001 & 0.000 & 0.220 & 0.000 \\
\hline$n$ value & 754 & 893 & 899 & 882 & 821 & 893 \\
\hline \multicolumn{7}{|l|}{ Env attitudes } \\
\hline $\begin{array}{l}\text { Correlation } \\
\text { coefficient }\end{array}$ & & -0.015 & 0.042 & -0.028 & $0.166^{* *}$ & $-0.084 *$ \\
\hline Sig. (2-tailed) & & 0.674 & 0.239 & 0.445 & 0.000 & 0.19 \\
\hline$n$ value & & 781 & 780 & 768 & 719 & 787 \\
\hline \multicolumn{7}{|l|}{ Test drive } \\
\hline $\begin{array}{l}\text { Correlation } \\
\text { coefficient }\end{array}$ & & & $0.375^{* *}$ & $0.126^{* *}$ & -0.020 & $0.074 *$ \\
\hline Sig. (2-tailed) & & & 0.000 & 0.000 & 0.554 & 0.025 \\
\hline$n$ value & & & 939 & 918 & 859 & 931 \\
\hline \multicolumn{7}{|l|}{$\begin{array}{l}\text { Visit to } \\
\text { dealership }\end{array}$} \\
\hline $\begin{array}{l}\text { Correlation } \\
\text { coefficient }\end{array}$ & & & & 0.042 & 0.040 & $0.077^{*}$ \\
\hline Sig. (2-tailed) & & & & 0.201 & 0.237 & 0.019 \\
\hline$n$ value & & & & 921 & 861 & 938 \\
\hline \multicolumn{7}{|l|}{$\begin{array}{l}\text { Social } \\
\text { exposure }\end{array}$} \\
\hline $\begin{array}{l}\text { Correlation } \\
\text { coefficient }\end{array}$ & & & & & $0.113^{* *}$ & $0.171^{* *}$ \\
\hline Sig. (2-tailed) & & & & & 0.001 & 0.000 \\
\hline$n$ value & & & & & 842 & 915 \\
\hline \multicolumn{7}{|l|}{$\begin{array}{l}\text { Likelihood to } \\
\text { purchase }\end{array}$} \\
\hline $\begin{array}{l}\text { Correlation } \\
\text { coefficient }\end{array}$ & & & & & & $0.070^{*}$ \\
\hline $\begin{array}{l}\text { Sig. (2-tailed) } \\
n \text { value }\end{array}$ & & & & & & $\begin{array}{l}0.40 \\
870\end{array}$ \\
\hline $\begin{array}{l}\text { Perceived } \\
\text { knowledge } \\
\text { Correlation } \\
\text { coefficient } \\
\text { Sig. (2-tailed) } \\
n \text { value }\end{array}$ & & & & & & \\
\hline
\end{tabular}

Table 24: Full relationship modelling amongst factors to influence purchase amongst EV drivers (from Table 15)

\begin{tabular}{|c|c|c|c|c|c|c|c|c|}
\hline & Fuel Costs & $\begin{array}{l}\text { Maintenanc } \\
\mathrm{e}\end{array}$ & $\begin{array}{l}\text { Environmen } \\
\text { tal attitudes }\end{array}$ & Test drive & $\begin{array}{l}\text { Visit to } \\
\text { dealership }\end{array}$ & $\begin{array}{l}\text { Social } \\
\text { exposure }\end{array}$ & $\begin{array}{l}\text { Likelihood } \\
\text { to purchase }\end{array}$ & $\begin{array}{l}\text { Perceived } \\
\text { knowledge }\end{array}$ \\
\hline \multicolumn{9}{|l|}{ Fuel Costs } \\
\hline $\begin{array}{l}\text { Correlation } \\
\text { coefficient }\end{array}$ & & $0.368 * *$ & -0.068 & 0.049 & 0.092 & 0.146 & -0.053 & 0.016 \\
\hline Sig. (2-tailed) & & 0.000 & 0.384 & 0.230 & 0.230 & 0.057 & 0.489 & 0.829 \\
\hline$n$ value & & 172 & 164 & 171 & 171 & 170 & 176 & 177 \\
\hline \multicolumn{9}{|l|}{ Maintenance } \\
\hline $\begin{array}{l}\text { Correlation } \\
\text { coefficient }\end{array}$ & & & 0.034 & $0.218 * *$ & 0.109 & 0.054 & $0.329 * *$ & 0.051 \\
\hline Sig. (2-tailed) & & & 0.662 & 0.003 & 0.150 & 0.477 & 0.000 & 0.499 \\
\hline$n$ value & & & 164 & 178 & 175 & 175 & 179 & 181 \\
\hline \multicolumn{9}{|l|}{ Env attitudes } \\
\hline $\begin{array}{l}\text { Correlation } \\
\text { coefficient }\end{array}$ & & & & 0.001 & -0.010 & $-0,082$ & $0.352 * *$ & $0.182 *$ \\
\hline Sig. (2-tailed) & & & & 0.993 & 0.898 & 0.293 & 0.000 & 0.017 \\
\hline$n$ value & & & & 169 & 168 & 167 & 171 & 173 \\
\hline \multicolumn{9}{|l|}{ Test drive } \\
\hline $\begin{array}{l}\text { Correlation } \\
\text { coefficient }\end{array}$ & & & & & $0.263^{* *}$ & -0.053 & $0.160^{*}$ & 0.006 \\
\hline Sig. (2-tailed) & & & & & 0.000 & 0.478 & 0.031 & 0.932 \\
\hline
\end{tabular}




\begin{tabular}{|c|c|c|c|c|}
\hline$n$ value & 179 & 179 & 182 & 184 \\
\hline $\begin{array}{l}\text { Visit to } \\
\text { dealership }\end{array}$ & & & & \\
\hline $\begin{array}{l}\text { Correlation } \\
\text { coefficient }\end{array}$ & & -0.015 & 0.076 & 0.016 \\
\hline Sig. (2-tailed) & & 0.846 & 0.308 & 0.835 \\
\hline$n$ value & & 179 & 181 & 183 \\
\hline $\begin{array}{l}\text { Social } \\
\text { exposure }\end{array}$ & & & & \\
\hline $\begin{array}{l}\text { Correlation } \\
\text { coefficient }\end{array}$ & & & 0.026 & -0.057 \\
\hline Sig. (2-tailed) & & & 0.733 & 0.445 \\
\hline$n$ value & & & 179 & 181 \\
\hline $\begin{array}{l}\text { Likelihood to } \\
\text { purchase }\end{array}$ & & & & \\
\hline $\begin{array}{l}\text { Correlation } \\
\text { coefficient }\end{array}$ & & & & \\
\hline Sig. (2-tailed) & & & & 0.000 \\
\hline$n$ value & & & & 188 \\
\hline $\begin{array}{l}\text { Perceived } \\
\text { knowledge } \\
\text { Correlation } \\
\text { coefficient } \\
\text { Sig. (2-tailed) } \\
n \text { value }\end{array}$ & & & & \\
\hline
\end{tabular}

**. Correlation is significant at the 0.01 level (2-tailed).

*. Correlation is significant at the 0.05 level (2-tailed). 


\section{Bibliography}

Abelsohn, A., Stieb, D., Sanborn, M. D., \& Weir, E. (2002). Identifying and managing adverse environmental health effects: 2. Outdoor air pollution. Canadian Medical Association Journal, 166(9), 1161-1167.

Adepetu, A., \& Keshav, S. (2017). The relative importance of price and driving range on electric vehicle adoption: Los Angeles case study. Transportation, 44(2), 353-373.

Ahern, N. R. (2005). Using the Internet to conduct research. Nurse Researcher, 13(2), 55-70.

Ahmadi, L., Yip, A., Fowler, M., Young, S. B., \& Fraser, R. A. (2014). Environmental feasibility of re-use of electric vehicle batteries. Sustainable Energy Technologies and Assessments, 6, 64-74.

Ahn, J. K., Jung, K. H., Kim, D. H., Jin, H. B., Kim, H. S., \& Hwang, S. H. (2009). Analysis of a regenerative braking system for hybrid electric vehicles using an electro-mechanical brake. International Journal of Automotive Technology, 10(2), 229-234.

Ajzen, I. (1985). From intentions to actions: A theory of planned behavior. Action control. Springer Berlin Heidelberg.

Ajzen, I., \& Fishbein, M. (1975). Belief, attitude, intention and behavior: An introduction to theory and research. (Reading, MA: Addison-Wesley).

Ajzen, I., \& Fishbein, M. (1980). A theory of reasoned action. Understanding attitudes and predicting social behaviour.

Al-Alawi, B. M., \& Bradley, T. H. (2013). Review of hybrid, plug-in hybrid, and electric vehicle market modeling studies. Renewable and Sustainable Energy Reviews, 21, 190-203.

Alberini, A., \& Segerson, K. (2002). Assessing voluntary programs to improve environmental quality. Environmental and Resource Economics, 22(1-2), 157-184.

Amjad, S., Neelakrishnan, S., \& Rudramoorthy, R. (2010). Review of design considerations and technological challenges for successful development and deployment of plug-in hybrid electric vehicles. Renewable and Sustainable Energy Reviews, 14(3), 1104-1110.

Axsen, J., Bailey, J., \& Castro, M. A. (2015). Preference and lifestyle heterogeneity among potential plug-in electric vehicle buyers. Energy Economics, 50, 190-201.

Axsen, J., Goldberg, S., \& Bailey, J. (2016). How might potential future plug-in electric vehicle buyers differ from current "Pioneer" owners?. Transportation Research Part D: Transport and Environment, 47, 357-370. 
Axsen, J., Goldberg, S., Bailey, J., Kamiya, G., Langman, B., Cairns, J., Wolinetz, M., \& Miele, A. (2015). Electrifying Vehicles: Insights from the Canadian Plug-in Electric Vehicle Study. Simon Fraser University, Vancouver, Canada.

Axsen, J., \& Kurani, K. S. (2012). Interpersonal influence within car buyers' social networks: applying five perspectives to plug-in hybrid vehicle drivers. Environment and Planning $A, 44(5), 1047-1065$.

Axsen, J., \& Kurani, K. S. (2013). Hybrid, plug-in hybrid, or electric-What do car buyers want?. Energy Policy, 61, 532-543.

Axsen, J., Langman, B., \& Goldberg, S. (2017). Confusion of innovations: Mainstream consumer perceptions and misperceptions of electric-drive vehicles and charging programs in Canada. Energy Research \& Social Science, 27, 163-173.

Axsen, J., Orlebar, C., \& Skippon, S. (2013). Social influence and consumer preference formation for pro-environmental technology: The case of a UK workplace electricvehicle study. Ecological Economics, 95, 96-107.

Azzone, G., \& Bertelè, U. (1994). Exploiting green strategies for competitive advantage. Long Range Planning, 27(6), 69-81.

Bahn, O., Marcy, M., Vaillancourt, K., \& Waaub, J. P. (2013). Electrification of the Canadian road transportation sector: A 2050 outlook with TIMES-Canada. Energy Policy, 62, 593606.

Bailey, J., Miele, A., \& Axsen, J. (2015). Is awareness of public charging associated with consumer interest in plug-in electric vehicles?. Transportation Research Part D: Transport and Environment, 36, 1-9.

Bang, G. (2010). Energy security and climate change concerns: Triggers for energy policy change in the United States?. Energy Policy, 38(4), 1645-1653.

Barkenbus, J. N. (2010). Eco-driving: An overlooked climate change initiative. Energy Policy, 38(2), 762-769.

Barney, J. B. (1991). Firm resources and sustained competitive advantage. Journal of Management, 17(1), 99-120.

Barney, J. B. (2001). Resource-based theories of competitive advantage: A ten-year retrospective on the resource-based view. Journal of Management, 27(6), 643-650.

Bendell, J., \& Thomas, L. (2013). The appearance of elegant disruption: theorising sustainable luxury entrepreneurship. The Journal of Corporate Citizenship, (52), 9-24. 
Berrens, R. P., Bohara, A. K., Jenkins-Smith, H. C., Silva, C. L., \& Weimer, D. L. (2004). Information and effort in contingent valuation surveys: application to global climate change using national internet samples. Journal of Environmental Economics and Management, 47(2), 331-363.

Bilgin, B., Magne, P., Malysz, P., Yang, Y., Pantelic, V., Preindl, M., Korobkine, A., Jiang, W., Lawford, M. \& Emadi, A. (2015). Making the case for electrified transportation. IEEE Transactions on Transportation Electrification, 1(1), 4-17.

Burgess, M., King, N., Harris, M., \& Lewis, E. (2013). Electric vehicle drivers' reported interactions with the public: Driving stereotype change?. Transportation research part $F$ : traffic psychology and behaviour, 17, 33-44.

Bohnsack, R., Pinkse, J., \& Kolk, A. (2014). Business models for sustainable technologies: Exploring business model evolution in the case of electric vehicles. Research Policy, 43(2), 284-300.

Bradley, T. H., \& Frank, A. A. (2009). Design, demonstrations and sustainability impact assessments for plug-in hybrid electric vehicles. Renewable and Sustainable Energy Reviews, 13(1), 115-128.

Brown, D. M. (2012). Comparative climate change policy and federalism: an overview. Review of Policy Research, 29(3), 322-333.

Brown, M. (2013). Catching the PHEVer: simulating electric vehicle diffusion with an agentbased mixed logit model of vehicle choice. Journal of Artificial Societies and Social Simulation, 16(2), 5.

Brundtland, G. H. (1987). Report of the World Commission on Environment and Development: Our Common Future. United Nations.

Bubeck, S., Tomaschek, J., \& Fahl, U. (2016). Perspectives of electric mobility: Total cost of ownership of electric vehicles in Germany. Transport Policy, 50, 63-77.

Burch, S. (2010). Transforming barriers into enablers of action on climate change: insights from three municipal case studies in British Columbia, Canada. Global Environmental Change, 20(2), 287-297.

Burke, A. F. (2007). Batteries and ultracapacitors for electric, hybrid, and fuel cell vehicles. Proceedings of the IEEE, 95(4), 806-820.

Campbell, A. R., Ryley, T., \& Thring, R. (2012). Identifying the early adopters of alternative fuel vehicles: A case study of Birmingham, United Kingdom. Transportation Research Part A: Policy and Practice, 46(8), 1318-1327. 
Capstick, S., Whitmarsh, L., Poortinga, W., Pidgeon, N., \& Upham, P. (2015). International trends in public perceptions of climate change over the past quarter century. Wiley Interdisciplinary Reviews: Climate Change, 6(1), 35-61.

Cardoso, G., Stadler, M., Bozchalui, M. C., Sharma, R., Marnay, C., Barbosa-Póvoa, A., \& Ferrão, P. (2014). Optimal investment and scheduling of distributed energy resources with uncertainty in electric vehicle driving schedules. Energy, 64, 17-30.

Carley, S., Krause, R. M., Lane, B. W., \& Graham, J. D. (2013). Intent to purchase a plug-in electric vehicle: A survey of early impressions in large US cites. Transportation Research Part D: Transport and Environment, 18, 39-45.

Cavoukian, A., Polonetsky, J., \& Wolf, C. (2010). Smartprivacy for the smart grid: embedding privacy into the design of electricity conservation. Identity in the Information Society, 3(2), 275-294.

Chan, C. C. (2002). The state of the art of electric and hybrid vehicles. Proceedings of the IEEE, 90(2), 247-275.

Chau, K. T., Wong, Y. S., \& Chan, C. C. (1999). An overview of energy sources for electric vehicles. Energy Conversion and Management, 40(10), 1021-1039.

Chéron, E., \& Zins, M. (1997). Electric vehicle purchasing intentions: The concern over battery charge duration. Transportation Research Part A: Policy and Practice, 31(3), 235-243.

Chen, B., \& Midler, C. (2016). Designing strategy for the globalisation of innovation: perspectives for foreign electric vehicle manufacturers in China. International Journal of Automotive Technology and Management, 16(4), 436-463.

City of Toronto. (2007). Greenhouse Gases and Air Pollutants in the City of Toronto: Towards a Harmonized Strategy for Reducing Emissions. [Available online]. https://www1.toronto.ca/city_of_toronto/environment_and_energy/key_priorities/files/pd f/ghg-aq-inventory-june2007.pdf.

City of Toronto. (2014). Deputy Mayor's Roundtable on Gridlock \& Traffic Congestion. [Available online]. http://www.toronto.ca/legdocs/mmis/2014/ex/bgrd/backgroundfile72899.pdf.

City of Toronto. (2015). Toronto's 2013 Greenhouse Gas Inventory. [Available online]. http://www.toronto.ca/legdocs/mmis/2016/pe/bgrd/backgroundfile-87697.pdf.

Clean Tech Canada. (2016). Feds investing \$62.5M in electric charging stations, alternative fuel infrastructure. [Available online]. http://www.canadianmanufacturing.com/sustainability/feds-investing-62-5m-electriccharging-stations-alternative-fuel-167885/. 
Clement-Nyns, K., Haesen, E., \& Driesen, J. (2010). The impact of charging plug-in hybrid electric vehicles on a residential distribution grid. IEEE Transactions on Power Systems, 25(1), 371-380.

Cockburn, C. (1983). Brothers: male dominance and technological change (Pluto, London).

Conrad, S. A., Rutherford, M. B., \& Haider, W. (2017). Profiling Farmers' Preferences about Drought Response Policies Using a Choice Experiment in the Okanagan Basin, Canada. Water Resources Management, 31(9), 2837-2851.

Coutts, E., \& Jann, B. (2011). Sensitive questions in online surveys: Experimental results for the randomized response technique (RRT) and the unmatched count technique (UCT). Sociological Methods \& Research, 40(1), 169-193.

Cowan, R., \& Hultén, S. (1996). Escaping lock-in: the case of the electric vehicle. Technological Forecasting and Social Change, 53(1), 61-79.

Craft, J., Howlett, M., Crawford, M., \& McNutt, K. (2013). Assessing policy capacity for climate change adaptation: Governance arrangements, resource deployments, and analytical skills in Canadian infrastructure policy making. Review of Policy Research, 30(1), 42-65.

CTV News. (2016). Liberal budget promises \$7B to 'champion' green initiatives. [Available online]. http://www.ctvnews.ca/politics/liberal-budget-promises-7b-to-champion-greeninitiatives-1.2828685.

Daniels, E. A. (2009). Sex objects, athletes, and sexy athletes: How media representations of women athletes can impact adolescent girls and college women. Journal of Adolescent Research, 24(4), 399-422.

Darcovich, K., Recoskie, S., Ribberink, H., Pincet, F., \& Foissac, A. (2017). Effect on battery life of vehicle-to-home electric power provision under Canadian residential electrical demand. Applied Thermal Engineering, 114, 1515-1522.

Davis, F. D. (1993). User acceptance of information technology: system characteristics, user perceptions and behavioral impacts. International Journal of Man-Machine Studies, $38(3), 475-487$.

De Haan, P., Mueller, M. G., \& Peters, A. (2006). Does the hybrid Toyota Prius lead to rebound effects? Analysis of size and number of cars previously owned by Swiss Prius buyers. Ecological Economics, 58(3), 592-605.

Dean, T. J., \& McMullen, J. S. (2007). Toward a theory of sustainable entrepreneurship: Reducing environmental degradation through entrepreneurial action. Journal of Business Venturing, 22(1), 50-76. 
Degirmenci, K., \& Breitner, M. H. (2017). Consumer purchase intentions for electric vehicles: Is green more important than price and range?. Transportation Research Part D: Transport and Environment, 51, 250-260.

Delmas, M. A., \& Montes-Sancho, M. J. (2011). US state policies for renewable energy: Context and effectiveness. Energy Policy, 39(5), 2273-2288.

DeWaters, J., Qaqish, B., Graham, M., \& Powers, S. (2013). Designing an energy literacy questionnaire for middle and high school youth. The Journal of Environmental Education, 44(1), 56-78.

Dong, J., Liu, C., \& Lin, Z. (2014). Charging infrastructure planning for promoting battery electric vehicles: An activity-based approach using multiday travel data. Transportation Research Part C: Emerging Technologies, 38, 44-55.

Drews, S., \& Van den Bergh, J. C. (2016). What explains public support for climate policies? A review of empirical and experimental studies. Climate Policy, 16(7), 855-876.

Duarte, G., Rolim, C., \& Baptista, P. (2016). How battery electric vehicles can contribute to sustainable urban logistics: a real-world application in Lisbon, Portugal. Sustainable Energy Technologies and Assessments, 15, 71-78.

Dumortier, J., Siddiki, S., Carley, S., Cisney, J., Krause, R. M., Lane, B. W., Rupp, J. A., \& Graham, J. D. (2015). Effects of providing total cost of ownership information on consumers' intent to purchase a hybrid or plug-in electric vehicle. Transportation Research Part A: Policy and Practice, 72, 71-86.

Dyerson, R., \& Pilkington, A. (2005). Gales of creative destruction and the opportunistic incumbent: The case of electric vehicles in California. Technology Analysis \& Strategic Management, 17(4), 391-408.

Eaves, S., \& Eaves, J. (2004). A cost comparison of fuel-cell and battery electric vehicles. Journal of Power Sources, 130(1), 208-212.

Eberle, U., \& Von Helmolt, R. (2010). Sustainable transportation based on electric vehicle concepts: a brief overview. Energy \& Environmental Science, 3(6), 689-699.

Eckerberg, K., \& Forsberg, B. (1998). Implementing Agenda 21 in local government: the Swedish experience. Local Environment, 3(3), 333-347.

Egbue, O., \& Long, S. (2012). Barriers to widespread adoption of electric vehicles: An analysis of consumer attitudes and perceptions. Energy Policy, 48, 717-729.

Eisler, D. (2016). Energy Literacy in Canada: A Summary. 
Environment and Climate Change Canada. (2015). Canada's Second Biennial Report on Climate Change. [Available online]. https://www.ec.gc.ca/GES-GHG/02D095CB-BAB0-40D6B7F0828145249AF5/3001\%20UNFCCC\%202nd\%20Biennial\%20Report_e_v7_lowRes.pdf.

Environment and Climate Change Canada. (2016). Canadian Environmental Sustainability Indicators: Greenhouse Gas Emissions. [Available online]. https://www.ec.gc.ca/indicateurs-indicators/18F3BB9C-43A1-491E-983576C8DB9DDFA3/GHGEmissions_EN.pdf.

Evans, J. R., \& Mathur, A. (2005). The value of online surveys. Internet Research, 15(2), 195 219.

Flamm, B. J., \& Agrawal, A. W. (2012). Constraints to green vehicle ownership: A focus group study. Transportation Research Part D: Transport and Environment, 17(2), 108-115.

Franke, T., \& Krems, J. F. (2013). What drives range preferences in electric vehicle users?. Transport Policy, 30, 56-62.

Franke, T., Neumann, I., Bühler, F., Cocron, P., \& Krems, J. F. (2012). Experiencing range in an electric vehicle: Understanding psychological barriers. Applied Psychology, 61(3), 368391.

Freund, P., \& Martin, G. (2007). Hyperautomobility, the social organization of space, and health. Mobilities, 2(1), 37-49.

Gong, M., Simpson, A., Koh, L., \& Tan, K. H. (2016). Inside out: The interrelationships of sustainable performance metrics and its effect on business decision making: Theory and practice. Resources, Conservation and Recycling.

Gore, C. D. (2010). The limits and opportunities of networks: Municipalities and Canadian climate change policy. Review of Policy Research, 27(1), 27-46.

Government of Ontario. (2007). Go Green: Ontario’s Action Plan on Climate Change. [Available online].

http://www.climateontario.ca/doc/workshop/2011LakeSimcoe/Ontarios\%20Go\%20Green \%20Action\%20Plan\%20on\%20Climate\%20Change.pdf.

Government of Ontario. (2009). Green Energy Act, 2009, S.O. 2009, c. 12, Sched. A. [Available online]. https://www.ontario.ca/laws/statute/09g12.

Government of Ontario. (2015). Ontario permanently bans coal-fired electricity generation. [Available online]. https://news.ontario.ca/ene/en/2015/11/ontario-permanently-banscoal-fired-electricity-generation.html. 
Government of Ontario. (2016). Ontario's Five Year Climate Change Action Plan: 2016-2020. [Available online]. http://www.applications.ene.gov.on.ca/ccap/products/CCAP_ENGLISH.pdf.

Graham, J. D., Cisney, J., Carley, S., \& Rupp, J. (2014). No time for pessimism about electric cars. Issues in Science and Technology, 31(1), 33.

Green, E. H., Skerlos, S. J., \& Winebrake, J. J. (2014). Increasing electric vehicle policy efficiency and effectiveness by reducing mainstream market bias. Energy Policy, 65, 562566.

Grint, K., \& Gill, R. (Eds.). (1995). The Gender-Technology Relation: Contemporary Theory and Research. Taylor \& Francis.

Haddadian, G., Khodayar, M., \& Shahidehpour, M. (2015). Accelerating the global adoption of electric vehicles: barriers and drivers. The Electricity Journal, 28(10), 53-68.

Hagman, J., Ritzén, S., Stier, J. J., \& Susilo, Y. (2016). Total cost of ownership and its potential implications for battery electric vehicle diffusion. Research in Transportation Business \& Management, 18, 11-17.

Hajimiragha, A., Canizares, C. A., Fowler, M. W., \& Elkamel, A. (2010). Optimal transition to plug-in hybrid electric vehicles in Ontario, Canada, considering the electricity-grid limitations. IEEE Transactions on Industrial Electronics, 57(2), 690-701.

Hall, C. M. (2011). A typology of governance and its implications for tourism policy analysis. Journal of Sustainable Tourism, 19(4-5), 437-457.

Hassan, J. A., \& Duncan, A. (1994). Integrating Energy: the Problems of Developing an Energy Policy in the European Communities, 1945-1980. Journal of European Economic History, 23(1), 159.

Hatzopoulou, M., Miller, E., \& Santos, B. (2007). Integrating vehicle emission modeling with activity-based travel demand modeling: case study of the Greater Toronto, Canada, Area. Transportation Research Record: Journal of the Transportation Research Board, (2011), 29-39.

Henderson, A. E., Reed, M., \& Davis, S. K. (2014). Voluntary stewardship and the Canadian Species at Risk Act: exploring rancher willingness to support species at risk in the Canadian prairies. Human Dimensions of Wildlife, 19(1), 17-32.

Hensher, D. A., Rose, J. M., \& Greene, W. H. (2005). Applied Choice Analysis: A Primer. Cambridge University Press.

Hidrue, M. K., Parsons, G. R., Kempton, W., \& Gardner, M. P. (2011). Willingness to pay for electric vehicles and their attributes. Resource and Energy Economics, 33(3), 686-705. 
Higgins, C. D., Mohamed, M., \& Ferguson, M. R. (2017). Size matters: How vehicle body type affects consumer preferences for electric vehicles. Transportation Research Part A: Policy and Practice, 100, 182-201.

Horak, M. (2013). State rescaling in practice: urban governance reform in Toronto. Urban Research \& Practice, 6(3), 311-328.

Harrison, K. (2013). Federalism and climate policy innovation: A critical reassessment. Canadian Public Policy, 39(2), S95-S108.

Houle, D., Lachapelle, E., \& Purdon, M. (2015). Comparative politics of sub-federal cap-andtrade: Implementing the western climate initiative. Global Environmental Politics.

Independent Electricity System Operator. (2017). Ontario’s Supply Mix. [Available online]. http://www.ieso.ca/learn/ontario-supply-mix/ontario-energy-capacity.

Intergovernmental Panel on Climate Change. Working Group 3. (2007). Climate Change 2007: Mitigation: Contribution of Working Group III to the Fourth Assessment Report of the Intergovernmental Panel on Climate Change: Summary for Policymakers and Technical Summary. B. Metz, O. Davidson, P. Bosch, R. Dave, \& L. Meyer (Eds.). Cambridge University Press.

Jabareen, Y. R. (2006). Sustainable urban forms their typologies, models, and concepts. Journal of Planning Education and Research, 26(1), 38-52.

Jaguemont, J., Boulon, L., Dubé, Y., \& Martel, F. (2016). Thermal Management of a Hybrid Electric Vehicle in Cold Weather. IEEE Transactions on Energy Conversion, 31(3), $1110-1120$.

Jarrett, A., \& Kim, I. Y. (2011). Design optimization of electric vehicle battery cooling plates for thermal performance. Journal of Power Sources, 196(23), 10359-10368.

Jiang, S. (2016). Purchase intention for electric vehicles in China from a customer-value perspective. Social Behavior and Personality: An International Journal, 44(4), 641-655.

Kamruzzaman, M., Shatu, F. M., Hine, J., \& Turrell, G. (2015). Commuting mode choice in transit oriented development: Disentangling the effects of competitive neighbourhoods, travel attitudes, and self-selection. Transport Policy, 42, 187-196.

Kawgan-Kagan, I. (2015). Early adopters of carsharing with and without BEVs with respect to gender preferences. European Transport Research Review, 7(4), 33.

Keil, R., \& Young, D. (2008). Transportation: the bottleneck of regional competitiveness in Toronto. Environment and Planning C: Government and Policy, 26(4), 728-751. 
Kemp, R. (1994). Technology and the transition to environmental sustainability: the problem of technological regime shifts. Futures, 26(10), 1023-1046.

Kempton, W., \& Tomić, J. (2005). Vehicle-to-grid power fundamentals: Calculating capacity and net revenue. Journal of Power Sources, 144(1), 268-279.

Kessler, J., Schillo, B., Shelby, M., \& Haspel, A. (1994). Is natural gas really the answer?: Targeting natural gas in US climate change mitigation policy. Energy Policy, 22(7), 623628.

Kley, F., Lerch, C., \& Dallinger, D. (2011). New business models for electric cars-A holistic approach. Energy Policy, 39(6), 3392-3403.

Klitkou, A., Bolwig, S., Hansen, T., \& Wessberg, N. (2015). The role of lock-in mechanisms in transition processes: the case of energy for road transport. Environmental Innovation and Societal Transitions, 16, 22-37.

Knox-Hayes, J., Brown, M. A., Sovacool, B. K., \& Wang, Y. (2013). Understanding attitudes toward energy security: results of a cross-national survey. Global Environmental Change, 23(3), 609-622.

Koropeski, A., Loane, G., \& Gough, J. (1998). Toronto-making room for all modes. Institute of Transportation Engineers. ITE Journal, 68(6), 42.

Krause, R. M., Carley, S. R., Lane, B. W., \& Graham, J. D. (2013). Perception and reality: Public knowledge of plug-in electric vehicles in 21 US cities. Energy Policy, 63, 433440.

Krause, R. M., Lane, B. W., Carley, S., \& Graham, J. D. (2016). Assessing demand by urban consumers for plug-in electric vehicles under future cost and technological scenarios. International Journal of Sustainable Transportation, 10(8), 742-751.

Kurani, K. S., Turrentine, T., \& Sperling, D. (1994). Demand for electric vehicles in hybrid households: an exploratory analysis. Transport Policy, 1(4), 244-256.

Kyläheiko, K., Jantunen, A., Puumalainen, K., Saarenketo, S., \& Tuppura, A. (2011). Innovation and internationalization as growth strategies: The role of technological capabilities and appropriability. International Business Review, 20(5), 508-520.

Lachapelle, E., Borick, C. P., \& Rabe, B. (2012). Public attitudes toward climate science and climate policy in federal systems: Canada and the United States compared. Review of Policy Research, 29(3), 334-357.

Larson, P. D., Viáfara, J., Parsons, R. V., \& Elias, A. (2014). Consumer attitudes about electric cars: Pricing analysis and policy implications. Transportation Research Part A: Policy and Practice, 69, 299-314. 
Lave, L. B., \& MacLean, H. L. (2002). An environmental-economic evaluation of hybrid electric vehicles: Toyota's Prius vs. its conventional internal combustion engine Corolla. Transportation Research Part D: Transport and Environment, 7(2), 155-162.

Lee, D. H., Park, S. Y., Hong, J. C., Choi, S. J., \& Kim, J. W. (2013). Analysis of the energy and environmental effects of green car deployment by an integrating energy system model with a forecasting model. Applied Energy, 103, 306-316.

Levinson, D. M., Gillen, D., \& Kanafani, A. (1998). The social costs of intercity transportation: a review and comparison of air and highway. Transport Reviews, 18(3), 215-240.

Li, S. G., Sharkh, S. M., Walsh, F. C., \& Zhang, C. N. (2011). Energy and battery management of a plug-in series hybrid electric vehicle using fuzzy logic. IEEE Transactions on Vehicular Technology, 60(8), 3571-3585.

Liu, Z., Wen, F., \& Ledwich, G. (2013). Optimal planning of electric-vehicle charging stations in distribution systems. IEEE Transactions on Power Delivery, 28(1), 102-110.

Loiselle-Lapointe, A., Conde, A. J., \& Ribberink, H. (2017). Chevrolet Volt on-road test programs in Canada part 1: Effects of drive cycle, ambient temperature and accessory usage on energy consumption and all-electric range. International Journal of Automotive Technology, 18(1), 103-115.

Lyon, T. P., \& Maxwell, J. W. (2007). Environmental public voluntary programs reconsidered. Policy Studies Journal, 35(4), 723-750.

Mackendrick, N. A. (2005). The role of the state in voluntary environmental reform: A case study of public land. Policy Sciences, 38(1), 21-44.

Magliocca, N. R. (2012). The use of agent-based models as virtual laboratories for exploring human-environment interactions in land-use systems. University of Maryland, Baltimore County.

Mahlia, T. M. I., Tohno, S., \& Tezuka, T. (2013). International experience on incentive program in support of fuel economy standards and labelling for motor vehicle: a comprehensive review. Renewable and Sustainable Energy Reviews, 25, 18-33.

Mahoney, J. T., \& Pandian, J. R. (1992). The resource-based view within the conversation of strategic management. Strategic Management Journal, 13(5), 363-380.

Mallia, E., \& Lewis, G. (2013). Life cycle greenhouse gas emissions of electricity generation in the province of Ontario, Canada. The International Journal of Life Cycle Assessment, 18(2), 377-391. 
Matisoff, D. C. (2012). Privatizing Climate Change Policy: is there a public benefit?. Environmental and Resource Economics, 53(3), 409-433.

Matthews, L., Lynes, J., Riemer, M., Del Matto, T., \& Cloet, N. (2017). Do we have a car for you? Encouraging the uptake of electric vehicles at point of sale. Energy Policy, 100, 7988.

McKitrick, R. (2006). The politics of pollution: party regimes and air quality in Canada. Canadian Journal of Economics, 39(2), 604-620.

Mega, V. P. (2016). Sustainable Energy and Transport Systems. In Conscious Coastal Cities (pp. 107-146). Springer International Publishing.

Melton, N., Axsen, J., \& Goldberg, S. (2017). Evaluating plug-in electric vehicle policies in the context of long-term greenhouse gas reduction goals: Comparing 10 Canadian provinces using the "PEV policy report card". Energy Policy, 107, 381-393.

Metrolinx. (2008). The Big Move: Transforming Transportation in the Greater Toronto and Hamilton Area. [Available online]. http://www.metrolinx.com/en/regionalplanning/bigmove/The_Big_Move_Approved_Cha nges_EN.pdf.

Metrolinx. (2016). The Transit Project Assessment Process (TPAP). [Available online]. https://www.metrolinxengage.com/en/content/transit-project-assessment-process-tpap.

Mills, S., \& Gore, C. (2016). Public and Local Government Leader Opinions on Environmental Federalism: Comparing Issues and National Contexts. State and Local Government Review, 48(3), 165-174.

Ministry of Energy - Ontario. (2017). Smart Grid Fund. [Available online]. http://www.energy.gov.on.ca/en/smart-grid-fund/.

Ministry of the Environment and Climate Change. (2015). Ontario first province in Canada to set 2030 greenhouse gas pollution reduction target. [Available online]. https://news.ontario.ca/ene/en/2015/05/ontario-first-province-in-canada-to-set-2030greenhouse-gas-pollution-reduction-target.html.

Ministry of Transportation Ontario. (2016). Electric Vehicle Charger Ontario (EVCO). [Available online]. http://www.mto.gov.on.ca/english/vehicles/electric/electric-vehiclechargers-ontario.shtml.

Ministry of Transportation Ontario. (2017). Electric Vehicle Incentive Program (EVIP). [Available online]. http://www.mto.gov.on.ca/english/vehicles/electric/electric-vehicleincentive-program.shtml. 
Mohamed, M., Higgins, C., Ferguson, M., \& Kanaroglou, P. (2016). Identifying and characterizing potential electric vehicle adopters in Canada: A two-stage modelling approach. Transport Policy, 52, 100-112.

Momirlan, M., \& Veziroglu, T. N. (2005). The properties of hydrogen as fuel tomorrow in sustainable energy system for a cleaner planet. International Journal of Hydrogen Energy, 30(7), 795-802.

Moussa, S. G., Leithead, A., Li, S. M., Chan, T. W., Wentzell, J. J., Stroud, C., Zhang, J., Lee, P., Lu, G., Brook, J. R., Hayden, K., Narayan, J., \& Liggio, J. (2016). Emissions of hydrogen cyanide from on-road gasoline and diesel vehicles. Atmospheric Environment, 131, 185-195.

Musavi, F., Eberle, W., \& Dunford, W. G. (2011). A high-performance single-phase bridgeless interleaved PFC converter for plug-in hybrid electric vehicle battery chargers. IEEE Transactions on Industry Applications, 47(4), 1833-1843.

Nagorsky, B., Sabag, K., Emerson, D., \& Hewitt, S. (2016). Moving Beyond Evaluation to Transit Project Prioritization: Lessons from the Toronto, Ontario, Canada, Context. Transportation Research Record: Journal of the Transportation Research Board. 64-71.

Naor, M., Bernardes, E. S., Druehl, C. T., \& Shiftan, Y. (2015). Overcoming barriers to adoption of environmentally-friendly innovations through design and strategy: learning from the failure of an electric vehicle infrastructure firm. International Journal of Operations \& Production Management, 35(1), 26-59.

Nathwani, J., \& Chen, Z. (2013). Canada's Low Carbon Electricity Advantage: The Case for an Inter-Regional Trade Strategy.

Nolan, A. (2010). A dynamic analysis of household car ownership. Transportation Research Part A: Policy and Practice, 44(6), 446-455.

Nonaka, I., \& Peltokorpi, V. (2006). Knowledge-based view of radical innovation: Toyota Prius case. Innovation, Science, and Institutional Change: A Research Handbook, 88-104.

Noori, H., Munro, H., Deszca, G., \& McWilliams B. (1999). Developing the "right" breakthrough product/service: an application of the umbrella methodology to electric vehicles - Part B. International Journal of Technology Management, 17(5), 563-579.

Office of the Premier. (2015). Cap and trade system to limit greenhouse gas pollution in Ontario. [Available online]. https://news.ontario.ca/opo/en/2015/04/cap-and-trade-system-to-limitgreenhouse-gas-pollution-in-ontario.html.

Panday, A., \& Bansal, H. O. (2014). A review of optimal energy management strategies for hybrid electric vehicle. International Journal of Vehicular Technology, 2014. 
Perera, P., Hewage, K., \& Sadiq, R. (2017). Are we ready for alternative fuel transportation systems in Canada: A regional vignette. Journal of Cleaner Production, 166, 717-731.

Peteraf, M. A. (1993). The cornerstones of competitive advantage: a resource-based view. Strategic Management Journal, 14(3), 179-191.

Peters, A., \& Dütschke, E. (2014). How do consumers perceive electric vehicles? A comparison of German consumer groups. Journal of Environmental Policy \& Planning, 16(3), 359377.

Pettifor, H., Wilson, C., Axsen, J., Abrahamse, W., \& Anable, J. (2017). Social influence in the global diffusion of alternative fuel vehicles-A meta-analysis. Journal of Transport Geography, 62, 247-261.

Petrunic, J. G., Ontario EV Technology \& Innovation Roadmap: Where we've been and where we need to go in support of technology development and commercialization for electrified transportation technologies in Ontario. (In press). Automotive Partnership Research Council, McMaster University. Hamilton, ON.

Pierre, M., Jemelin, C., \& Louvet, N. (2011). Driving an electric vehicle. A sociological analysis on pioneer users. Energy Efficiency, 4(4), 511.

Pinkse, J., Bohnsack, R., \& Kolk, A. (2014). The Role of Public and Private Protection in Disruptive Innovation: The Automotive Industry and the Emergence of Low-Emission Vehicles. Journal of Product Innovation Management, 31(1), 43-60.

Pinkse, J., \& Kolk, A. (2010). Challenges and trade-offs in corporate innovation for climate change. Business Strategy and the Environment, 19(4), 261-272.

Plug'n Drive. (2017). Electric Vehicle Discovery Centre. [Available online]. https://plugndrive.ca/electric-vehicle-discovery-centre.

Rahman, K. M., \& Ehsani, M. (1996). Performance analysis of electric motor drives for electric and hybrid electric vehicle applications. In Power Electronics in Transportation, 1996., IEEE. 49-56.

Ranga, M., \& Etzkowitz, H. (2010). Athena in the world of techne: the gender dimension of technology, innovation and entrepreneurship. Journal of Technology Management \& Innovation, 5(1), 1-12.

Rasouli, S., \& Timmermans, H. (2016). Influence of social networks on latent choice of electric cars: a mixed logit specification using experimental design data. Networks and Spatial Economics, 16(1), 99-130.

Relph, E. (2013). Toronto: Transformations in a city and its region. University of Pennsylvania Press. 
Reyes, J. R. M. D., Parsons, R. V., \& Hoemsen, R. (2016). Winter happens: the effect of ambient temperature on the travel range of electric vehicles. IEEE Transactions on Vehicular Technology, 65(6), 4016-4022.

Rezvani, Z., Jansson, J., \& Bodin, J. (2015). Advances in consumer electric vehicle adoption research: A review and research agenda. Transportation research Part D: Transport and Environment, 34, 122-136.

Rhodes, E., Axsen, J., \& Jaccard, M. (2015). Gauging citizen support for a low carbon fuel standard. Energy Policy, 79, 104-114.

Richardson, D. B. (2013). Electric vehicles and the electric grid: A review of modeling approaches, Impacts, and renewable energy integration. Renewable and Sustainable Energy Reviews, 19, 247-254.

Robinson, J., \& Erickson, L. E. (2016). Infrastructure for Charging Electric Vehicles. Solar Powered Charging Infrastructure for Electric Vehicles: A Sustainable Development, 35.

Rogers, E. M. (2003). Diffusion of Innovations. (New York: Free Press).

Rowlands, I. H. (2007). The development of renewable electricity policy in the province of Ontario: the influence of ideas and timing. Review of Policy Research, 24(3), 185-207.

Rowlands, I. H., Reid, T., \& Parker, P. (2015). Research with disaggregated electricity end-use data in households: review and recommendations. Wiley Interdisciplinary Reviews: Energy and Environment, 4(5), 383-396.

Salisa, A. R., Walker, P. D., Zhang, N., \& Zhu, J. G. (2015). Comparative cost-based analysis of a novel plug-in hybrid electric vehicle with conventional and hybrid electric vehicles. International Journal of Automotive and Mechanical Engineering, 11, 2262.

Santini, D., Patterson, P., \& Vyas, A. (2000). Importance of vehicle costs, fuel prices, and fuel efficiency in hybrid electric vehicle market success. Transportation Research Record: Journal of the Transportation Research Board, 11-19.

Sattler, B. (2014). Evidence-based Choices: Conscious Caring for Mother Earth. International Journal for Human Caring, 18(2), 18-24.

Schwanen, T., Banister, D., \& Anable, J. (2011). Scientific research about climate change mitigation in transport: A critical review. Transportation Research Part A: Policy and Practice, 45(10), 993-1006.

Schmidt, E. (2017). Electric vehicles sales in Canada: Q1 2017. [Available online]. http://www.fleetcarma.com/electric-vehicle-sales-canada-q1-2017/. 
Schneider, U., Dütschke, E., \& Peters, A. (2014). How Does the Actual Usage of Electric Vehicles Influence Consumer Acceptance?. In Evolutionary Paths Towards the Mobility Patterns of the Future (pp. 49-66). Springer Berlin Heidelberg.

Schuitema, G., Anable, J., Skippon, S., \& Kinnear, N. (2013). The role of instrumental, hedonic and symbolic attributes in the intention to adopt electric vehicles. Transportation Research Part A: Policy and Practice, 48, 39-49.

Schumpeter, J. (1942). Creative destruction. Capitalism, Socialism and Democracy, 825.

Sexton, S. E., \& Sexton, A. L. (2014). Conspicuous conservation: The Prius halo and willingness to pay for environmental bona fides. Journal of Environmental Economics and Management, 67(3), 303-317.

Shokrzadeh, S., \& Bibeau, E. (2016). Sustainable integration of intermittent renewable energy and electrified light-duty transportation through repurposing batteries of plug-in electric vehicles. Energy, 106, 701-711.

Sierzchula, W., Bakker, S., Maat, K., \& van Wee, B. (2014). The influence of financial incentives and other socio-economic factors on electric vehicle adoption. Energy Policy, 68, 183-194.

Sims, R., Schaeffer, R., Creutzig, F., Cruz-Núñez, X., D’Agosto, M., Dimitriu, D., Figueroa Meza, M.J., Fulton, L., Kobayashi, S., Lah, O., McKinnon, A., Newman, P., Ouyang, M., Schauer, J.J., Sperling, D., \& Tiwari, G. (2014). 2014: Transport. In: Climate Change 2014: Mitigation of Climate Change. Contribution of Working Group III to the Fifth Assessment Report of the Intergovernmental Panel on Climate Change. Cambridge University Press, Cambridge, United Kingdom and New York, NY, USA.

Skerlos, S. J., \& Winebrake, J. J. (2010). Targeting plug-in hybrid electric vehicle policies to increase social benefits. Energy Policy, 38(2), 705-708.

Skippon, S., \& Garwood, M. (2011). Responses to battery electric vehicles: UK consumer attitudes and attributions of symbolic meaning following direct experience to reduce psychological distance. Transportation Research Part D: Transport and Environment, 16(7), 525-531.

Smart, K. (2000). Losing Ground: How SUVs Are Making the United States Less Fuel-Efficient and Options for Reversing the Downward Trend. Environmental Law, 7, 159.

Smith, T. W., Kim, J., \& Son, J. (2017). Public Attitudes toward Climate Change and Other Environmental Issues across Countries. International Journal of Sociology, 47(1), 62-80.

Smyth, J. D., Dillman, D. A., Christian, L. M., \& O'Neill, A. C. (2010). Using the Internet to survey small towns and communities: Limitations and possibilities in the early 21 st century. American Behavioral Scientist, 53(9), 1423-1448. 
Smyth, S. M. (2014). The greening of Canadian cyber laws: What environmental law can teach and cyber law can learn. International Journal of Cyber Criminology, 8(2), 111.

Srivastava, A. K., Annabathina, B., \& Kamalasadan, S. (2010). The challenges and policy options for integrating plug-in hybrid electric vehicle into the electric grid. The Electricity Journal, 23(3), 83-91.

Statistics Canada. (2016). Motor vehicle registrations, by province and territory. [Available online]. http://www.statcan.gc.ca/tables-tableaux/sum-som/101/cst01/trade14a-eng.htm.

Statistics Canada. (2017). Toronto, C [Census subdivision], Ontario and Ontario [Province] (table). Census Profile. 2016 Census. Statistics Canada Catalogue no. 98-316-X2016001. Ottawa. Released February 8, 2017. [Available online]. http://www12.statcan.gc.ca/census-recensement/2016/dp-pd/prof/index.cfm?Lang=E.

Stavins, R. N. (2003). Experience with market-based environmental policy instruments. Handbook of Environmental Economics, 1, 355-435.

Stokes, J. R., Hendrickson, T. P., \& Horvath, A. (2014). Save water to save carbon and money: Developing abatement costs for expanded greenhouse gas reduction portfolios. Environmental Science \& Technology, 48(23), 13583-13591.

Stoutenborough, J. W., \& Vedlitz, A. (2016). The role of scientific knowledge in the public's perceptions of energy technology risks. Energy Policy, 96, 206-216.

Struben, J., \& Sterman, J. D. (2008). Transition challenges for alternative fuel vehicle and transportation systems. Environment and Planning B: Planning and Design, 35(6), 10701097.

Stuart, J., Collins, P., Alger, M., \& Whitelaw, G. (2016). Embracing sustainability: the incorporation of sustainability principles in municipal planning and policy in four midsized municipalities in Ontario, Canada. Local Environment, 21(2), 219-240.

Sykes, M., \& Axsen, J. (2017). No free ride to zero-emissions: Simulating a region's need to implement its own zero-emissions vehicle (ZEV) mandate to achieve $2050 \mathrm{GHG}$ targets. Energy Policy, 110, 447-460.

Tamor, M. A., Gearhart, C., \& Soto, C. (2013). A statistical approach to estimating acceptance of electric vehicles and electrification of personal transportation. Transportation Research Part C: Emerging Technologies, 26, 125-134.

Taylor, S., \& Todd, P. A. (1995). Understanding information technology usage: A test of competing models. Information Systems Research, 6(2), 144-176. 
Tazerart, F., Mokrani, Z., Rekioua, D., \& Rekioua, T. (2015). Direct torque control implementation with losses minimization of induction motor for electric vehicle applications with high operating life of the battery. International Journal of Hydrogen Energy, 40(39), 13827-13838.

Teece, D. J. (1986). Profiting from technological innovation: Implications for integration, collaboration, licensing and public policy. Research Policy, 15(6), 285-305.

Transport Canada. (2011). Transportation in Canada 2011. [Available online]. http://www.tc.gc.ca/eng/policy/report-aca-anre2011-index-3010.htm.

Uiterkamp, A. J., \& Vlek, C. (2007). Practice and outcomes of multidisciplinary research for environmental sustainability. Journal of Social Issues, 63(1), 175-197.

Unruh, G. C. (2000). Understanding carbon lock-in. Energy Policy, 28(12), 817-830.

Unruh, G. C. (2002). Escaping carbon lock-in. Energy Policy, 30(4), 317-325.

Van Basshuysen, R., \& Schäfer, F. (2004). Internal combustion engine handbook-basics, components, systems and perspectives, 345 .

Vyn, R. J., \& McCullough, R. M. (2014). The effects of wind turbines on property values in Ontario: does public perception match empirical evidence?. Canadian Journal of Agricultural Economics/Revue canadienne d'agroeconomie, 62(3), 365-392.

Wagner, D. (2017). Sustaining Uber: Opportunities for Electric Vehicle Integration.

Wajcman, J. (1991). Patriarchy, technology, and conceptions of skill. Work and Occupations, 18(1), 29-45.

Walsh, P. R. (2012). Innovation nirvana or innovation wasteland? Identifying commercialization strategies for small and medium renewable energy enterprises. Technovation, 32(1), 3242.

Wang, R., Wang, Y., Feng, C., \& Zhang, X. (2015). Powertrain preheating system of tracked hybrid electric vehicle in cold weather. Applied Thermal Engineering, 91, 252-258.

Weiss, M., Patel, M. K., Junginger, M., Perujo, A., Bonnel, P., \& van Grootveld, G. (2012). On the electrification of road transport-Learning rates and price forecasts for hybrid-electric and battery-electric vehicles. Energy Policy, 48, 374-393.

Wells, P., \& Nieuwenhuis, P. (2012). Transition failure: Understanding continuity in the automotive industry. Technological Forecasting and Social Change, 79(9), 1681-1692.

Wenzel, T. P., \& Ross, M. (2005). The effects of vehicle model and driver behavior on risk. Accident Analysis \& Prevention, 37(3), 479-494. 
Wernerfelt, B. (1984). A resource-based view of the firm. Strategic Management Journal, 5(2), 171-180.

Wesseling, J. H., Niesten, E. M. M. I., Faber, J., \& Hekkert, M. P. (2015). Business strategies of incumbents in the market for electric vehicles: Opportunities and incentives for sustainable innovation. Business Strategy and the Environment, 24(6), 518-531.

Wolinetz, M., \& Axsen, J. (2017). How policy can build the plug-in electric vehicle market: Insights from the REspondent-based Preference and Constraints (REPAC) model. Technological Forecasting and Social Change, 117, 238-250.

World Bank. (n.d.). Land area (sq. km.). [Available online]. https://data.worldbank.org/indicator/AG.LND.TOTL.K2.

Woudsma, C., Jakubicek, P., \& Dablanc, L. (2016). Logistics sprawl in North America: methodological issues and a case study in Toronto. Transportation Research Procedia, 12, 474-488.

Yavuz, M., Oztaysi, B., Onar, S. C., \& Kahraman, C. (2015). Multi-criteria evaluation of alternative-fuel vehicles via a hierarchical hesitant fuzzy linguistic model. Expert Systems with Applications, 42(5), 2835-2848.

Yin, R. K. (2013). Case study research: Design and methods. Sage Publications.

Zhang, Y. (2000). Using the Internet for survey research: A case study. Journal of the Association for Information Science and Technology, 51(1), 57-68.

Zhang, X., Chan, S. H., Ho, H. K., Tan, S. C., Li, M., Li, G., Li J. \& Feng, Z. (2015). Towards a smart energy network: The roles of fuel/electrolysis cells and technological perspectives. International Journal of Hydrogen Energy, 40(21), 6866-6919.

Zito, P., \& Salvo, G. (2011). Toward an urban transport sustainability index: an European comparison. European Transport Research Review, 3(4), 179-195.

Zou, P. X., Morshed, A. L., Van Manh A. M., Phung, D. W., Stewart, R., Bertone, E., Sahin, O., $\&$ Buntine, C. (2017). Achieving energy efficiency in government buildings through mandatory policy and program enforcement. Frontiers of Engineering Management, 4(1), 92-103. 